\title{
Discovery of a Potent Thiazolidine Free Fatty Acid Receptor 2 Agonist with Favorable Pharmacokinetic Properties
}

Hansen, Anders Højgaard; Sergeev, Eugenia; Bolognini, Daniele; Sprenger, Richard R.;

Ekberg, Jeppe Hvidtfeldt; Ejsing, Christer S.; McKenzie, Christine J.; Rexen Ulven, Elisabeth; Milligan, Graeme; Ulven, Trond

Published in:

Journal of Medicinal Chemistry

DOI:

10.1021/acs.jmedchem.8b00855

Publication date:

2018

Document version

Publisher's PDF, also known as Version of record

Document license:

CC BY

Citation for published version (APA):

Hansen, A. H., Sergeev, E., Bolognini, D., Sprenger, R. R., Ekberg, J. H., Ejsing, C. S., McKenzie, C. J., Rexen Ulven, E., Milligan, G., \& Ulven, T. (2018). Discovery of a Potent Thiazolidine Free Fatty Acid Receptor 2 Agonist with Favorable Pharmacokinetic Properties. Journal of Medicinal Chemistry, 61(21), 9534-9550.

https://doi.org/10.1021/acs.jmedchem.8b00855 


\title{
Discovery of a Potent Thiazolidine Free Fatty Acid Receptor 2 Agonist with Favorable Pharmacokinetic Properties
}

\author{
Anders Højgaard Hansen, ${ }^{\dagger}$ Eugenia Sergeev, ${ }^{\ddagger}$ Daniele Bolognini, ${ }^{\ddagger}$ Richard R. Sprenger, ${ }^{\S}$

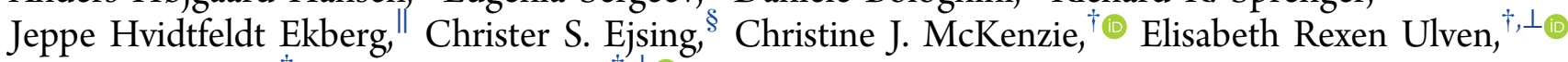 \\ Graeme Milligan, ${ }^{\ddagger}$ and Trond Ulven $*, \dagger, \perp{ }^{\circ}$
}

${ }^{\dagger}$ Department of Physics, Chemistry and Pharmacy, University of Southern Denmark, Campusvej 55, DK-5230 Odense M, Denmark

${ }^{\ddagger}$ Centre for Translational Pharmacology, Institute of Molecular, Cell and Systems Biology, College of Medical, Veterinary and Life Sciences, University of Glasgow, Glasgow G12 8QQ Scotland, United Kingdom

${ }^{\S}$ Department of Biochemistry and Molecular Biology, University of Southern Denmark, Campusvej 55, DK-5230 Odense M, Denmark

"Novo Nordisk Foundation Center for Basic Metabolic Research, Faculty of Health and Medical Sciences, University of Copenhagen, Blegdamsvej 3, 2200 Copenhagen, Denmark

${ }^{\perp}$ Department of Drug Design and Pharmacology, University of Copenhagen, Universitetsparken 2, DK-2100 Copenhagen, Denmark

\section{Supporting Information}

\begin{abstract}
Free fatty acid receptor 2 (FFA2/GPR43) is a receptor for short-chain fatty acids reported to be involved in regulation of metabolism, appetite, fat accumulation, and inflammatory responses and is a potential target for treatment of various inflammatory and metabolic diseases. By bioisosteric replacement of the central pyrrolidine core of a previously disclosed FFA2 agonist with a synthetically more tractable thiazolidine, we were able to rapidly synthesize and screen analogues modified at both the 2- and 3-positions on the thiazolidine core. Herein, we report SAR exploration of

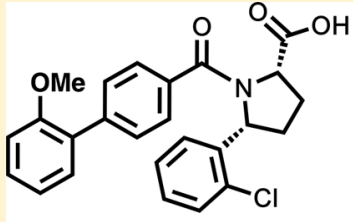

4

$\mathrm{pEC}_{50}=6.3$

$\operatorname{cog} P=5.1$

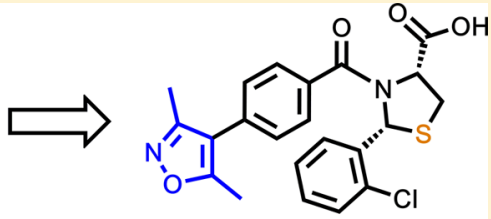

31 (TUG-1375)

$\mathrm{pEC}_{50}=7.1$

$\log D_{7.4}=0.94(\operatorname{cog} P=3.6)$

$32 \% F$ thiazolidine FFA2 agonists and the identification of 31 (TUG1375), a compound with significantly increased potency (7-fold in a cAMP assay) and reduced lipophilicity (50-fold reduced $\operatorname{cog} P$ ) relative to the pyrrolidine lead structure. The compound has high solubility, high chemical, microsomal, and hepatocyte stability, and favorable pharmacokinetic properties and was confirmed to induce human neutrophil mobilization and to inhibit lipolysis in murine adipocytes.
\end{abstract}

\section{INTRODUCTION}

The short-chain free fatty acid receptor FFA2 (formerly GPR43) is a G-protein-coupled receptor that is activated by physiological concentrations of short-chain fatty acids (SCFAs), primarily acetate and propionate. ${ }^{1-5}$ FFA2 is expressed in a variety of tissues including immune cells, ${ }^{3}$ adipocytes, ${ }^{6}$ pancreatic $\beta$-cells, ${ }^{2}$ and enteroendocrine L-cells. ${ }^{7}$ Colonic fermentation of dietary fiber produces large amounts of SCFAs, and results indicate that an interplay between FFA2 and dietary fiber via colonic fermentation to produce SCFAs is implicated in promoting a healthy composition of microorganisms in the gut. ${ }^{8}$ Fiber-rich diets and SCFAs can counteract colitis, ${ }^{9,10}$ and exacerbated inflammation in colitis models has been reported for FFA2-knockout mice. ${ }^{11}$ However, others have found that FFA2-knockout mice exhibited reduced inflammatory responses in colitis models, ${ }^{12}$ and it is currently unclear if antagonists or agonists are preferable for the treatment of intestinal inflammation. So far, the antagonist GLPG0974 (1, Chart 1) is the only FFA2 modulator that has undergone clinical trials but unfortunately failed to meet end points against ulcerative colitis. ${ }^{13}$

Dietary fiber is also known to exert positive effects in diabetic subjects. ${ }^{14}$ Acetate has been shown to potentiate glucose-stimulated insulin secretion from $\beta$-cells in an FFA2dependent manner, ${ }^{15}$ and SCFAs were able to promote secretion of the incretin glucagon-like peptide-1 (GLP-1) from colonic cultures through FFA2 ${ }^{16}$ and both GLP-1 and the appetite regulating peptide YY (PYY) in vivo, ${ }^{17}$ indicating that activation of FFA2 could have beneficial effects on type 2 diabetes (T2D). Interestingly and in contrast, loss of FFA2 and FFA3 was found to improve insulin secretion and glucose tolerance. ${ }^{18}$ Moreover, SCFA-mediated activation of FFA2 has been found to suppress adipose insulin signaling, leading to reduced fat accumulation in adipose tissue, and to promote GLP-1 secretion in the gut. ${ }^{19}$ Thus, both agonists and antagonists of FFA2 are considered to be potential therapeutics

Received: May 29, 2018

Published: September 24, 2018 
Chart 1. FFA2 Modulators ${ }^{a}$
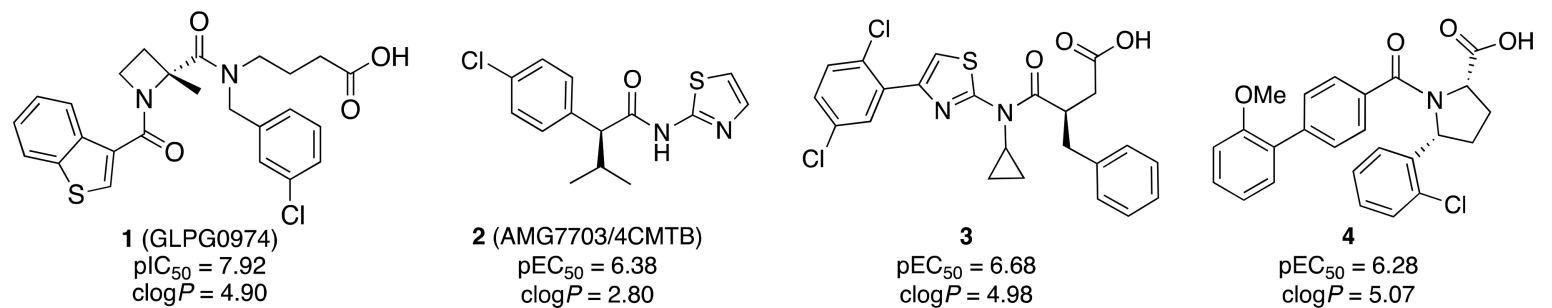

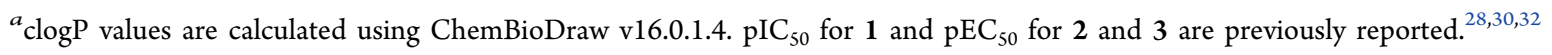

for treatment of T2D and obesity. ${ }^{5,19-25}$ Several FFA2 agonists have been disclosed, including an allosteric agonist series from Amgen represented by 2 (known as AMG7703 or 4-CMTB) and an orthosteric agonist series originating from Euroscreen represented by $3 .^{20,26-30}$ A recent study found that agonist 4, also originating from Euroscreen, ${ }^{31}$ caused only marginal GLP1 secretion but led to significant PYY mucosal responses, inhibited insulin-promoted fat accumulation and intestinal functions, and suppressed food intake, supporting FFA2 as a possible antiobesity target. ${ }^{21}$

The FFA2 agonists disclosed hitherto have relatively high lipophilicity, which is associated with several undesired properties, $^{33-35}$ and only moderate potency (e.g., see Chart 1). Furthermore, the allosteric agonist 2 has solubility issues and has been reported to give results that differ from orthosteric FFA2 agonists, ${ }^{15}$ and the orthosteric agonist 3 was found to have stability issues. ${ }^{36}$ We therefore wished to explore 4, an FFA2 agonist reported to have properties useful for in vivo studies. ${ }^{21}$ Initially, we sought to explore the SAR around the pyrrolidine scaffold of 4; however, the synthetic route to obtain this class of FFA2 agonists is rather lengthy and precludes efficient exploration of parts of the molecule. We therefore opted for replacing the central pyrrolidine by a thiazolidine. This replacement strategy has previously been employed for HIV protease inhibitors. ${ }^{37}$ Herein, we report SAR investigations of substituted thiazolidine FFA2 agonists and the discovery of an FFA2 agonist with improved potency, reduced lipophilicity, and favorable physicochemical and pharmacokinetic properties.

\section{RESULTS AND DISCUSSION}

Synthesis. Pyrrolidine ligands were synthesized in seven linear steps from L-pyroglutamic acid (5, Scheme 1) essentially as previously described by Euroscreen, ${ }^{31}$ with the modifications that the ring opening by aryllithium was allowed to reach room temperature and that the amide coupling with pyrrolidine 6 was performed with bis(tetramethylene)fluoroformamidinium hexafluorophosphate (BTFFH). ${ }^{36}$

Thiazolidine ligands were synthesized in three steps by condensation of $(R)$-Cys-OMe hydrochloride with benzaldehydes via $7 \mathbf{a}-\mathbf{j}$ (Scheme 2). In contrast to the pyrrolidine route, this strategy allowed rapid access also to variations on the 2-position of the thiazolidine scaffold in a single step from readily available starting materials ${ }^{38}$ and formation of the desired $(2 R, 4 R)$-thiazolidine amide as the major product in the next step. ${ }^{39}$

Condensation of $(R)$-Cys-OMe hydrochloride with aldehydes produced mixtures of $\mathrm{C}(2)$ epimeric methyl (4R)-2arylthiazolidine-4-carboxylates $(7 \mathbf{a}-\mathbf{j}) \cdot{ }^{38}$ To obtain the $(2 R, 4 R)$-configuration, $7 \mathbf{a}-\mathbf{j}$ were treated with $\mathrm{Et}_{3} \mathrm{~N}$ and subsequently reacted with the relevant acid chlorides to give
Scheme 1. Synthesis of Pyrrolidines 4 and 37 from LPyroglutamic Acid $^{a}$
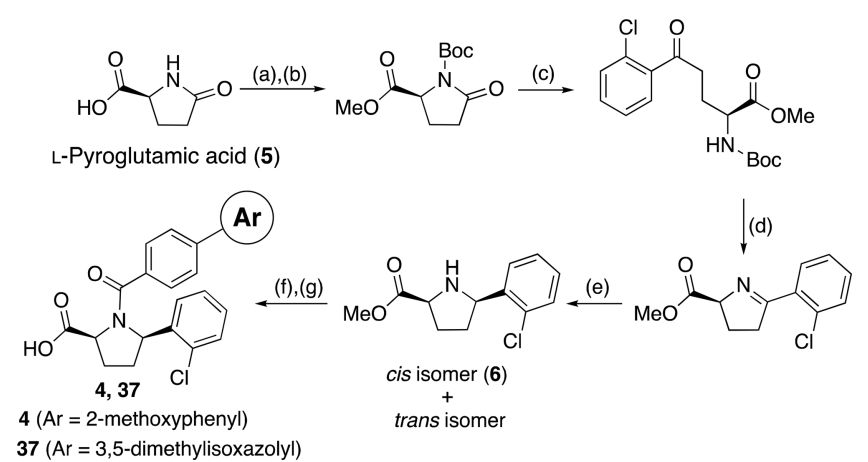

${ }^{a}$ Reagents and conditions: (a) $\mathrm{SOCl}_{2}, \mathrm{MeOH}, \mathrm{rt}, 70 \%$; (b) $\mathrm{Boc}_{2} \mathrm{O}$, DMAP, DCM, rt, 4 h, 98\%; (c) (i) 1-iodo-2-chlorobenzene, $n$-BuLi, THF, $20 \mathrm{~min}$ at $-78{ }^{\circ} \mathrm{C} \rightarrow \mathrm{rt}$; (ii) sat. aq $\mathrm{NH}_{4} \mathrm{Cl}, 67 \%$; (d) TFA, DCM, rt, 98\%; (e) $\mathrm{NaBH}_{3} \mathrm{CN}, \mathrm{AcOH}$ (cat.), $\mathrm{MeOH}, \mathrm{rt}, 71 \%$ (cis/ trans $2: 1,49 \% / 22 \%)$; (f) carboxylic acid, BTFFH, DIPEA, DCM, 80 ${ }^{\circ} \mathrm{C}, 8 \mathrm{~h}, 75 \%$; (g) LiOH (aq), THF, rt, 42-93\%.

Scheme 2. Synthesis of $(2 R, 4 R)-N$-Acylthiazolidine-4carboxylic Acids from (R)-Cys-OMe ${ }^{a}$

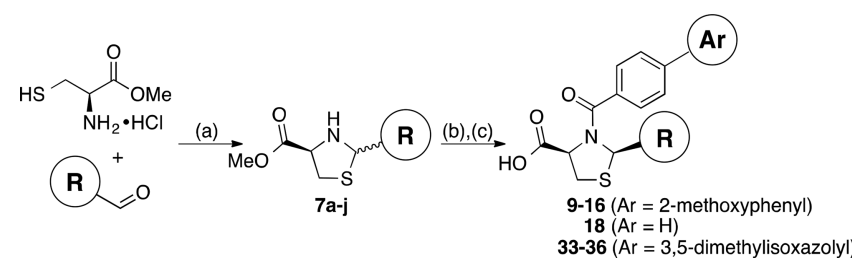

${ }^{a}$ Reagents and conditions: (a) $\mathrm{H}_{2} \mathrm{O} / \mathrm{EtOH} \mathrm{1:1,} \mathrm{KHCO}_{3}, \mathrm{rt}, 4-24 \mathrm{~h}$, 63-81\%; (b) benzoyl chlorides, $\mathrm{Et}_{3} \mathrm{~N},-10{ }^{\circ} \mathrm{C} \rightarrow \mathrm{rt}$, THF, $1-14 \mathrm{~h}$, 21-83\%; (c) LiI, EtOAc, $80{ }^{\circ} \mathrm{C}, 24-92 \%$.

the desired $(2 R, 4 R)$-products. ${ }^{39}$ Finally, demethylation using $\mathrm{LiI}$ in EtOAc afforded the corresponding $(2 R, 4 R)-N$ acylthiazolidine-4-carboxylic acids. ${ }^{39}$

A second set of analogues aimed at exploring the $N$-benzoyl part of the ligands was synthesized from central intermediates $\mathbf{8 a}, \mathbf{b}$ by Suzuki-Miyaura or Sonogashira cross-coupling followed by demethylation, affording the desired biarylic compounds in low to good yields (Scheme 3).

The crystal structure of $\mathbf{1 4}$ confirms unambiguously the $(2 R, 4 R)$-configuration of thiazolidine substituents (Figure 1). A relatively short intramolecular hydrogen bond of 2.598(2) $\AA$ is found between the carboxylic acid and pyridine group. The crystal packing (Supporting Information, Figure S1) shows no significant intermolecular interactions stronger than van de Waals forces. The intramolecular hydrogen bond is a likely reason for why crystals suitable for structural information were 
Scheme 3. Synthesis of Biaryl Analogues via Coupling Reactions $^{a}$

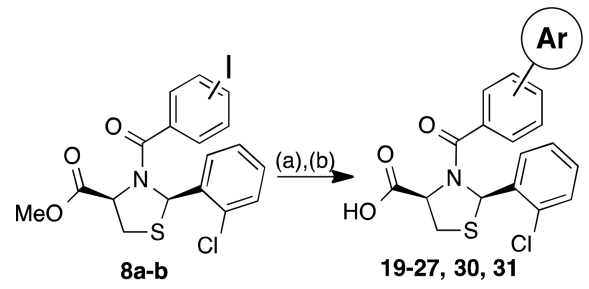

${ }^{a}$ Reagents and conditions: (a) $\mathrm{ArB}(\mathrm{OH})_{2}$ or ArBPin, $\mathrm{Pd}\left(\mathrm{PPh}_{3}\right)_{4}$, $\mathrm{MeOH}$, toluene, 6-27 h, 20-86\%; or $\mathrm{ArCCH}, \mathrm{Pd}\left(\mathrm{PPh}_{3}\right)_{2} \mathrm{Cl}_{2}, \mathrm{CuI}$, $\mathrm{Et}_{3} \mathrm{~N}, 4$ h, rt, 76\%; (b) LiI, EtOAc, $80{ }^{\circ} \mathrm{C}, 37-78 \%$.

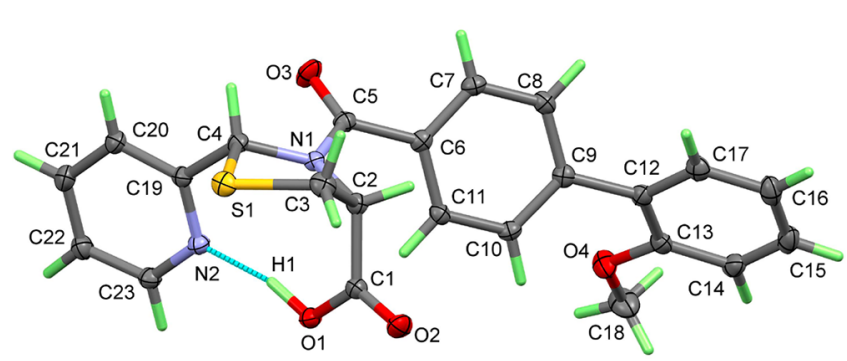

Figure 1. Perspective view of $\mathbf{1 4}$ drawn with $50 \%$ probability ellipsoids.

obtained for this compound but for none of the others. At physiological $\mathrm{pH}$ with the carboxylic acid ionized, the pyridyl hydrogen bond will be absent and the overall conformation is expected to be different. It is therefore not possible to draw conclusions regarding the configuration around the amide in the active conformation of 14 . In fact, rather than the $(Z)$ configuration apparent in the crystal structure of 14, computer minimizations indicate a general preference for the $(E)$ configuration around the amide in the compound series.

Biological Testing and SAR Analysis. Compounds were tested on the human (h)FFA2 receptor using both a bioluminescence resonance energy transfer (BRET)-based $\beta$ arrestin- 2 interaction assay and a cAMP inhibition assay. The former assay is an upstream signaling assay measuring BRET arising from agonist-mediated recruitment of $\beta$-arrestin- 2 to FFA2, and the latter assay evaluates inhibition of forskolininduced production of cAMP facilitated by coupling of FFA2 to $\mathrm{G} \alpha_{\mathrm{i} / \mathrm{o}}$ proteins. $^{40}$

The FFA2 agonist activity of $\mathbf{4}$ was confirmed in both assays. Compound 4 has previously been reported with an $\mathrm{EC}_{50}$ of 81 $\mathrm{nM}^{21}$ We obtained somewhat lower potencies of $1.2 \mu \mathrm{M}$ in the $\beta$-arrestin- 2 assay and $0.53 \mu \mathrm{M}$ in the cAMP assay. We were pleased to find that the thiazolidine analog 9 had only moderately decreased potency in both the BRET and the cAMP assay $\left(\Delta \mathrm{pEC}_{50}=-0.67\right.$ and -0.31 , respectively) relative to pyrrolidine 4 (Table 1 ). The easy access to substituted thiazolidines enabled a rapid screen of variations in the 2-position of the thiazolidine scaffold for 2-methoxy-1,1'biphenyl derivatives (Table 1).

Compared to 2-chlorophenyl (9), 3-chlorophenyl (10) or 4chlorophenyl (11) led to a decrease in potencies in the $\beta$ arrestin-2 assay, whereas 11 retained potency in the cAMP assay. Thus, the 3-position appeared to be disfavored and 4position substitution may be a route to G-protein-biased ligands. Substituting the 2-chloro by bromo (12) or hydrogen (13) retained potency in both assays.
Table 1. SAR Investigations at the Thiazolidine 2-Position

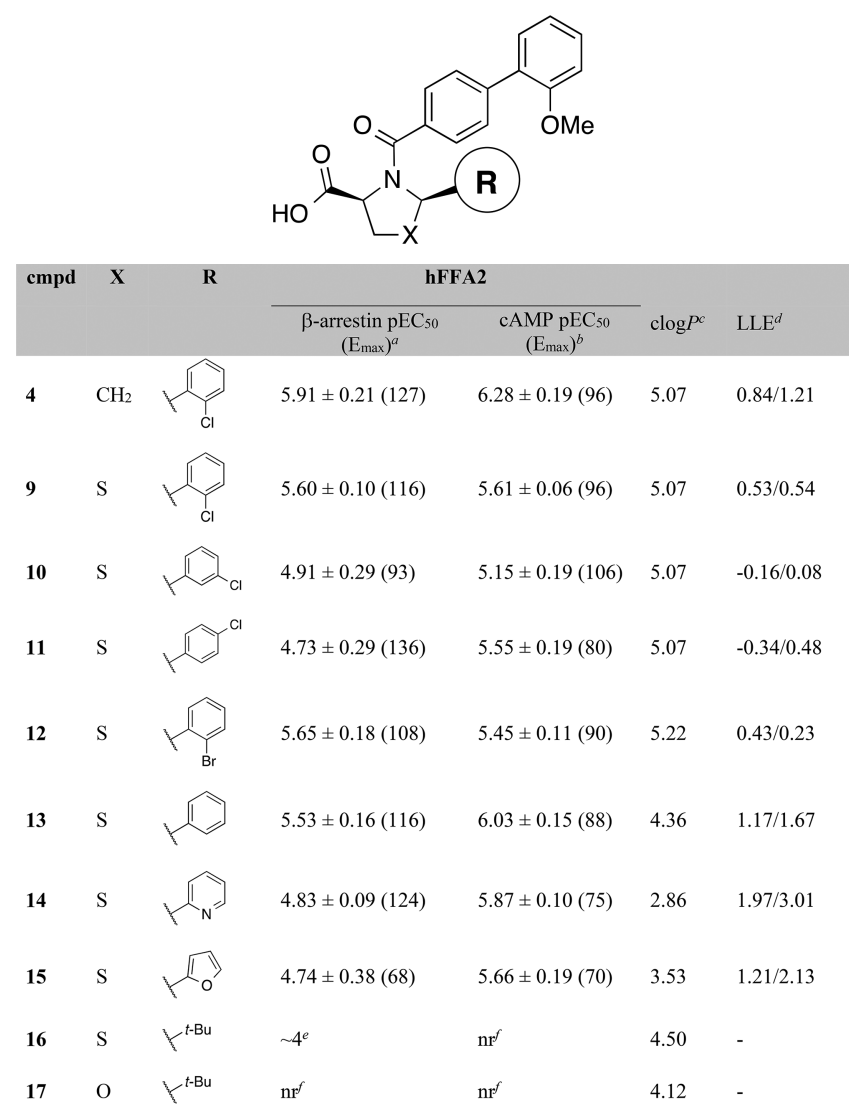

${ }^{a}$ BRET-based $\beta$-arrestin-2 recruitment assay. Efficacy $\left(E_{\max }\right)$ is relative to propionate. ${ }^{b}$ cAMP FFA2 assay. Efficacy $\left(E_{\max }\right)$ is relative to propionate. ${ }^{c} \operatorname{clog} \mathrm{P}$ values were calculated using ChemBioDraw v16.0.1.4. ${ }^{d}$ BRET/cAMP LLE values (LLE $=\mathrm{pEC}_{50}-\operatorname{clogP}$ ). ${ }^{e} 50 \%$ activation at $100 \mu \mathrm{M}$. ${ }^{f_{\mathrm{N}}}$ response up to $30 \mu \mathrm{M}$.

Installation of 2-pyridyl (14) or 2-furyl (15) onto the thiazolidine scaffold eroded potency in the $\beta$-arrestin- 2 assay compared to the phenyl derivatives but mostly preserved potency in the cAMP assay, again suggesting a route to Gprotein-biased agonists. Since the goal was both to increase potency and decrease lipophilicity, values for ligand-lipophilicity efficiency (LLE) ${ }^{33}$ based on calculated lipophilicity of the neutral compounds $(\operatorname{cog} \mathrm{P})$ were also used to guide the optimization. The hydrophilic pyridyl led to a marked improvement in LLE for $\mathbf{1 4}$ compared to all previous compounds including 4 but insufficient potency. The introduction of a tert-butyl group in the 2-position of the thiazolidine scaffold resulted in a compound (16) that only caused $50 \%$ receptor activation at $100 \mu \mathrm{M}$. Replacing sulfur with oxygen on 16 led to a completely inactive compound (17); hence, the oxazolidine scaffold was not explored further.

We next directed attention to the $N$-acyl substituent. As evident from 18 (Table 2), the biphenyl system is important for activity, as removing the terminal ring leads to complete loss of activity. Removing only the $2^{\prime}$-methoxy (19) also resulted in a pronounced loss of potency in both assays, as did moving the terminal phenyl to the 3-position (20). The $2^{\prime}$ fluoro-3'-methoxy (21) and the $4^{\prime}$-methoxy (22) analogues both led to decreased potency in both assays relative to the $2^{\prime}$ methoxy analogue 9. Compared to 19, installation of either acetyl (23) or nitrile (24) in the 4-position markedly boosted 
Table 2. SAR Investigation of the $N$-Acyl Substituent

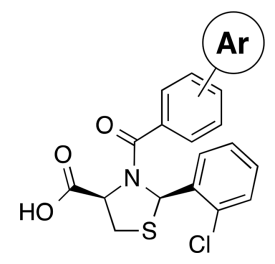

\begin{tabular}{|c|c|c|c|c|c|}
\hline \multirow[t]{2}{*}{ empd } & \multirow{2}{*}{$\underset{\text { (3/4-position) }}{\text { Ar }}$} & \multicolumn{2}{|c|}{ hFFA2 } & \multirow[b]{2}{*}{$\operatorname{clog} P^{c}$} & \multirow[b]{2}{*}{$\mathrm{LLE}^{d}$} \\
\hline & & $\begin{array}{c}\beta \text {-arrestin-2 } \\
\mathrm{pEC}_{50} \\
\left(\mathrm{E}_{\max }\right)^{a}\end{array}$ & $\begin{array}{l}\text { cAMP pEC } 50 \\
\left(\mathrm{E}_{\max }\right)^{b}\end{array}$ & & \\
\hline 18 & (4) & $\mathrm{nr}^{e}$ & $\mathrm{nr}^{e}$ & 3.82 & - \\
\hline 19 & (4) & $5.09 \pm 0.05(146)$ & $5.00 \pm 0.20(93)$ & 5.71 & $-0.62 /-0.71$ \\
\hline 20 & (3) & $4.59 \pm 0.13(141)$ & $5.40 \pm 0.04(91)$ & 5.71 & $-1.12 /-0.31$ \\
\hline 21 & (4) & $5.32 \pm 0.23(122)$ & $5.04 \pm 0.18(82)$ & 5.57 & $-0.25 /-0.53$ \\
\hline 22 & (4) & $4.66 \pm 0.16(174)$ & $5.35 \pm 0.15(87)$ & 5.63 & $-0.97 /-0.31$ \\
\hline 23 & (4) & $6.09 \pm 0.04(103)$ & $5.68 \pm 0.07(90)$ & 5.15 & $0.94 / 0.53$ \\
\hline 24 & (4) & $5.89 \pm 0.08(95)$ & $5.89 \pm 0.13(95)$ & 5.15 & $0.74 / 0.74$ \\
\hline 25 & (4) & $5.14 \pm 0.24(143)$ & $6.04 \pm 0.16(74)$ & 6.18 & $-1.04 /-0.14$ \\
\hline 26 & (4) & $5.36 \pm 0.12(146)$ & $5.40 \pm 0.19(82)$ & 5.91 & $-0.55 /-0.51$ \\
\hline 27 & (4) & $5.04 \pm 0.17\left(134^{f}\right)$ & $5.32 \pm 0.15(89)$ & 6.07 & $-1.03 /-0.75$ \\
\hline 28 & (4) & $5.22 \pm 0.12(130)$ & $5.68 \pm 0.09(83)$ & 6.46 & $-1.24 /-0.78$ \\
\hline 29 & (4) & $4.80 \pm 0.35(99)$ & $5.65 \pm 0.09(89)$ & 6.38 & $-1.58 /-0.73$ \\
\hline 30 & (4) & $6.01 \pm 0.04(103)$ & $6.67 \pm 0.12(77)$ & 4.04 & $1.97 / 2.63$ \\
\hline 31 & (4) & $6.10 \pm 0.07(99)$ & $7.11 \pm 0.08(86)$ & 3.63 & $2.47 / 3.48$ \\
\hline 32 & (4) & $4.68 \pm 0.11(108)$ & - & 5.60 & $-0.92 /-$ \\
\hline
\end{tabular}

${ }^{a}$ BRET-based $\beta$ arrestin-2 recruitment assay. Efficacy $\left(E_{\max }\right)$ is relative to propionate. ${ }^{b}$ cAMP FFA2 assay. Efficacy $\left(E_{\max }\right)$ is relative to propionate. ${ }^{c} \operatorname{clog} \mathrm{P}$ values were calculated using ChemBioDraw v16.0.1.4. ${ }^{d} \mathrm{LLE}=\mathrm{pEC}_{50}(\beta$-arrestin/cAMP $)-\operatorname{clogP} .{ }^{e}$ No response up to $30 \mu \mathrm{M}$. ${ }^{f}$ Average response at highest concentration relative to propionate.

potency in both $\beta$-arresin- 2 and cAMP assays, indicating that certain hydrogen bond accepting groups are favored in this region.

Replacing the $2^{\prime}$-methoxy (9) with $2^{\prime}$-chloro (25) or $2^{\prime}$ methyl (26) resulted in a marked potency boost in the cAMP assay for 25, whereas $2^{\prime}$-methoxyphenyl remained the preferred ring system in the $\beta$-arrestin- 2 assay $(9>25 \sim 26)$.

Extension of the biphenyl 19 by insertion of acetylene between the rings (28) caused a minor loss of potency in the cAMP assay but no changes in the $\beta$-arrestin- 2 assay. In a parallel manner, alkyne extension of 2-methoxyphenyl (9) into 29 reduced potency in the $\beta$-arrestin- 2 assay but preserved activity in the cAMP assay.

Overall, 4-biphenyl compounds with the terminal phenyl ring carrying lipophilic $(\mathbf{2 5}, \mathbf{2 6})$ or moderately hydrophilic (9) substituents in the ortho-position showed higher potencies than a nonsubstituted phenyl analogue such as 19 or 20, indicating that a nonplanar biphenyl conformation is favored for optimal binding of this compound class.

With this and the encouraging results from 23 and 24 in mind, we wished to explore biaryl systems with orthosubstituted polar heterocycles as the terminal ring. Satisfyingly, installation of 1-methyl-1H-pyrazolyl produced a significantly improved compound (30), whereas introduction of 3,5dimethylisoxazolyl (31) appeared as the most potent compound of the series with a $\mathrm{pEC}_{50}$ of 7.11 in the cAMP assay and an LLE increased by 2.3 relative to the initial pyrrolidine 4. Replacement of the methyl groups of 31 by phenyl and cyclopropyl (32) resulted in a 40-fold lower potency in the $\beta$-arrestin- 2 assay, indicating a limit to the acceptable steric bulk in this region.

Having identified 4-(3,5-dimethylisoxazolyl)benzoyl as a preferred N-substituent, we directed the attention back to the 2-substituent of the thiazolidine scaffold to screen for improved substituents in a second iteration (Table 3). This effort showed again that the 2-chloro (31) was clearly favored

Table 3. Variations in the 2-Position and Pyrrolidine Analogue with the Optimized Acyl Part

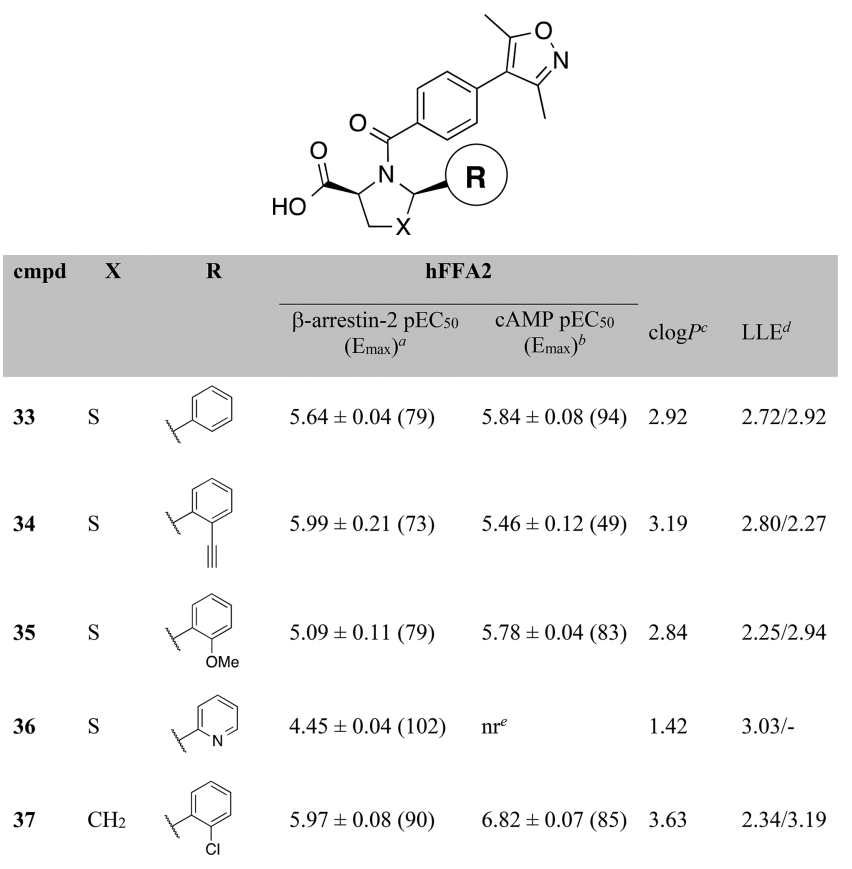

${ }^{a}$ BRET-based $\beta$ arrestin-2 recruitment assay. Efficacy $\left(E_{\max }\right)$ is relative to propionate. ${ }^{b}$ cAMP FFA2 assay. Efficacy $\left(E_{\max }\right)$ is relative to propionate. ${ }^{c} \operatorname{clog} \mathrm{P}$ values were calculated using ChemBioDraw v16.0.1.4. ${ }^{d} \mathrm{BRET} / \mathrm{cAMP}$ LLE values $\left(\mathrm{LLE}=\mathrm{pEC}_{50}-\operatorname{clogP}\right) .{ }^{e} \mathrm{No}$ response up to $30 \mu \mathrm{M}$. 
over a naked phenyl (33). The same was true for 2-ethynyl (34) and 2-methoxy (35). Furthermore, increasing the polarity by installation of 2-pyridyl (36) resulted in a weakly potent agonist in the $\beta$-arrestin- 2 assay, whereas 36 was devoid of any activity when evaluated in the cAMP assay. Since pyridyl analog 14 was a reasonably potent compound in both $\beta$ arrestin-2 and cAMP assays, the observation that 36 lost activity is likely explained by this compound being too polar to effectively reach the lipophilic binding site of FFA2.

As the initial idea was to use the thiazolidine as a bioisostere for pyrrolidine in the optimization of the compound series, the corresponding pyrrolidine 37 of thiazolidine 31 was synthesized and tested (Table 3). Although pyrrolidine 37 displayed appreciable FFA2 activity, its potency was lower than that of 31.

The occasionally diverging results in the cAMP and $\beta$ arrestin-2 assays illustrate that potencies in the functional assays do not directly reflect receptor affinity. To better understand the relationship between affinity and functional activity, we proceeded with further examination of 31 and selected analogs in an FFA2 competition binding assay using a radiolabeled version of antagonist $\mathbf{1}$ (Table 4). It has

Table 4. Binding Affinities of Compounds for FFA2

$\begin{array}{cc}\text { compd } & \mathrm{p} K_{\mathrm{i}}^{a} \\ 4 & 6.32 \pm 0.02 \\ 9 & 6.47 \pm 0.06 \\ 13 & 5.92 \pm 0.08 \\ 19 & 6.01 \pm 0.02 \\ 31 & 6.69 \pm 0.03 \\ 37 & 6.40 \pm 0.06\end{array}$

${ }^{a}$ Binding affinities of agonists determined using $\left[{ }^{3} \mathrm{H}\right]-\mathbf{1}$ in radioligand binding assays.

previously been confirmed that $\mathbf{1}$ and radiotracer $\left[{ }^{3} \mathrm{H}\right]-\mathbf{1}$ are orthosteric ligands and fully displaceable by propionate and the synthetic orthosteric agonist $3 .^{32,41}$ Pyrrolidines 4 and 37 and thiazolidines $9,13,19$, and 31 were also all confirmed to fully displace $\left[{ }^{3} \mathrm{H}\right]-1$. Parent pyrrolidine 4 exhibited a moderate binding affinity, and the corresponding thiazolidine (9) was found to be a slightly stronger binder, in contrast to the slightly lower potency observed in both functional assays. Upon comparing 9 with the analogue lacking the 2-chloro substituent of the 2-aryl (13) or lacking the 2 -methoxy (19) substituent at the biphenyl system, it becomes clear that both these features contribute significantly to the affinity $\left(\Delta \mathrm{p} K_{\mathrm{i}}=0.55\right.$ and 0.46 , respectively). The most potent thiazolidine (31) was indeed found to also exhibit the highest binding affinity within this selection. The corresponding pyrrolidine (37) displayed a significantly weaker binding affinity when compared to 31 $\left(\Delta \mathrm{p} K_{\mathrm{i}}=-0.29\right)$, which correlated well with the observed differences in functional potency between these two compounds. Hence, for isoxazoles 31 and 37, the thiazolidine central scaffold boosted both affinity and receptor activation compared to the pyrrolidine. Replacement of the 2methoxyphenyl (9) by the more polar 3,5-dimethylisoxazole (31) not only gave rise to the more potent thiazolidine-based agonist (31) but also reduced lipophilicity resulting in a marked improvement in LLE over $4(\Delta \operatorname{LLE}=2.27)$, and 31 indeed exhibits the highest LLE of all compounds in the study.

Molecular Modeling. To better understand the interaction of 31 with FFA2, the compound was docked in a previously established homology model of the receptor. ${ }^{32}$ The lowest energy pose of $\mathbf{3 1}$ is depicted in Figure 2. Compound 31 was found to effectively engage Arg180 and Arg255 via ionic and hydrogen bonding interactions, an observation that is in agreement with previous reports that both residues are known to be vital for receptor binding and activation. ${ }^{30,41}$ Simultaneously, the carboxylate carbonyl also interacted with the conserved Tyr238 through hydrogen bonding. The 2chlorophenyl moiety situated cis to the carboxylate was observed to interact with Phe 89 via displaced $\pi-\pi$ interactions, where the chloro substituent appears to orient the phenyl for
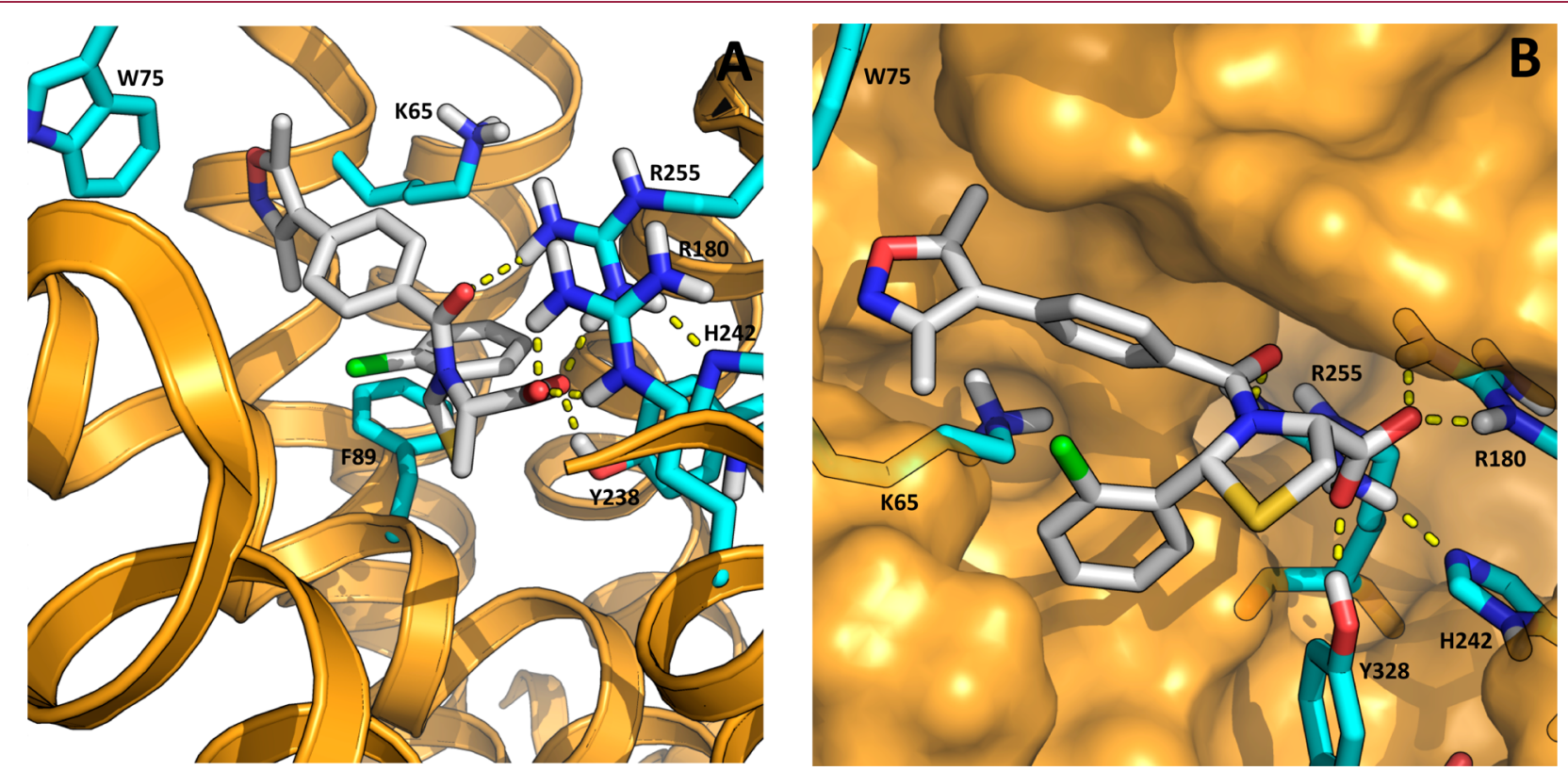

Figure 2. Lowest energy pose of 31 (gray) docked into hFFA2 (gold) with strongly interacting residues shown (cyan) and hydrogen bonds highlighted (yellow stipples). (A) Receptor as ribbon viewed from the angle of helix 4 and 5. (B) Same pose with receptor as surface viewed from the angle of helix 3 and 4 . 
optimal contact. Furthermore, the dimethylisoxazole ring formed $\pi$-cation interactions with Lys65 and edge-to-face $\pi-\pi$ interactions with Trp75 (Supporting Information, Figure S2). The shown pose also reflects higher energy poses. No alternative low-energy pose was identified.

Overall, groups of $\mathbf{3 1}$ found in the SAR analysis to be crucial for binding, such as 2-chlorophenyl and dimethylisoxazole, were confirmed by docking to contribute to the ligand receptor interaction, further supporting the proposed binding pose of 31 in hFFA2. Notably, both the carboxylate and the amide carbonyl of $\mathbf{3 1}$ were oriented toward the two arginine residues and Arg255 interacted directly with both groups through hydrogen bonds (Figure 2).

Characterization of 31 . Since 31 showed the highest potency and LLE based on calculated lipophilicity in both functional assays and the binding assay, it was decided to characterize its properties in further detail. Thus, $\mathbf{3 1}$ was tested and confirmed to be active on the murine FFA2 orthologue $\left(\mathrm{pEC}_{50}=6.44 \pm 0.13\right.$ in the cAMP assay). The compound was found to be inactive up to $100 \mu \mathrm{M}$ concentration at the closely related SCFA receptor FFA3 (formerly GPR41) and evoked no significant agonist or antagonist response in the long-chain fatty acid receptors FFA1 (GPR40) and FFA4 (GPR120) or in nuclear receptors $\operatorname{PPAR} \alpha, \operatorname{PPAR} \gamma, \operatorname{PPAR} \delta, \operatorname{LXR} \alpha$, and $\operatorname{LXR} \beta$ at $10 \mu \mathrm{M}$ (see the Supporting Information).

Previous FFA2 ligands are generally, apart from SCFAs, lipophilic compounds. In contrast, experimental lipophilicity of 31 (Table 5) was found to be in the lower part of the optimal

Table 5. Physicochemical Properties

\begin{tabular}{ll}
\multicolumn{1}{c}{ assay } & \multicolumn{1}{c}{$\mathbf{3 1}$} \\
$\log D(n$-octanol/PBS, $\mathrm{pH} 7.4)$ & 0.94 \\
$\begin{array}{l}\text { aqueous solubility (PBS, } \mathrm{pH} 7.4) \\
\text { chemical stability }\end{array}$ & $182 \mu \mathrm{M}$ \\
PBS, $37^{\circ} \mathrm{C}, 3$ weeks & $97.6 \%$ \\
FaSSIF, $2 \mathrm{~h}$ & $95 \%$ \\
FaSSGF, $2 \mathrm{~h}$ & $100 \%$ \\
metabolic stability (MLM, remaining, $1 \mathrm{~h})$ & $82 \%$ \\
\hline
\end{tabular}

range, ${ }^{34}$ giving an LLE of 6.2 based on the cAMP assay and measured lipophilicity. The compound also showed high aqueous solubility and chemical stability (Table 5). Recovery after incubation with $\mathrm{PBS}$ at $\mathrm{pH} 7.4$ or with fasted-state simulated gastric or intestinal fluid (FaSSGF/FaSSIF) was close to quantitative, indicating excellent chemical stability. Investigation of metabolic stability of $\mathbf{3 1}$ in mouse liver microsomes also resulted in a high recovery.

Hepatocyte stability is a better approximation to the in vivo properties than liver microsomes since mitochondrial metabolism and conjugation processes also take place. Incubation of 31 with primary mouse hepatocytes gave a recovery of $72 \%$ after $2 \mathrm{~h}$ and low intrinsic clearance $\left(<8(\mu \mathrm{L} / \mathrm{min}) / 10^{6}\right.$ cells $)$, indicating high metabolic stability in mouse hepatocytes (Supporting Information, Figure S3 and Table S6).

The pharmacokinetic profile of $\mathbf{3 1}$ was investigated in mice to establish its properties as a tool for in vivo studies, revealing a satisfactory half-life of $2 \mathrm{~h}$ and a moderate to low clearance of $20.3 \mathrm{~mL} \mathrm{~min}^{-1} \mathrm{~kg}^{-1}$ in mice (Table 6). Oral dosing of $10 \mathrm{mg} /$ $\mathrm{kg}$ resulted in a maximal plasma concentration of $6.5 \mu \mathrm{M}$ after $15 \mathrm{~min}$ and a bioavailability of $32 \%$. Furthermore, ip administration of 31 at $5 \mathrm{mg} / \mathrm{kg}$ in mice and analysis of plasma concentrations indicated an $\mathrm{AUC}_{0-\infty}$ of 60500 (ng/
Table 6. Pharmacokinetic Properties in Mice ${ }^{a}$

\begin{tabular}{lc} 
parameters & \multicolumn{1}{c}{31} \\
& Intravenous Administration \\
$t_{1 / 2}$ & $138 \mathrm{~min}$ \\
$\mathrm{AUC}_{0-\infty}$ & $246000 \mathrm{ng} \mathrm{min} \mathrm{mL}^{-1}$ \\
$V_{\mathrm{d}}$ & $4050 \mathrm{~mL} \mathrm{~kg}^{-1}$ \\
$\mathrm{CL}_{\text {total }}$ & $20.3 \mathrm{~mL} \mathrm{~min}^{-1} \mathrm{~kg}^{-1}$ \\
& Oral Administration \\
$t_{\max }$ & $15 \mathrm{~min}$ \\
$C_{\max }$ & $2880 \mathrm{ng} \mathrm{mL}^{-1}$ \\
$\mathrm{AUC}_{0-\infty}$ & $156000 \mathrm{ng} \mathrm{min} \mathrm{mL}^{-1}$ \\
$F$ & $32 \%$
\end{tabular}

${ }^{a}$ Administered at $10 \mathrm{mg} / \mathrm{kg}$ po and $5 \mathrm{mg} / \mathrm{kg}$ iv in Balb/c mice.

$\mathrm{mL}) \cdot \mathrm{min}$ a half-life of $82 \mathrm{~min}$ and thus a favorable profile relative to $4\left(\mathrm{AUC}_{0-\infty} \approx 25000(\mathrm{ng} / \mathrm{mL}) \cdot \mathrm{min}, t_{1 / 2} \approx 50\right.$ $\min )^{21}$

Agonist 3 has been shown to affect inflammatory responses in human neutrophils via FFA2 by induction of intracellular calcium and superoxide production. ${ }^{42}$ Propionate is known to exert beneficial anti-inflammatory effects, ${ }^{9}$ and the elimination of FFA2 from mice has previously been shown to cause increased inflammation in tissue models. ${ }^{11}$ Although the FFA2 antagonist $\mathbf{1}$ failed to meet the end point in clinical trials with ulcerative colitis patients, the compound was found to modulate neutrophil recruitment, ${ }^{43}$ and the therapeutic potential of FFA2 modulation in inflammatory disease is still not clear, especially since neutrophil recruitment may have both beneficial and detrimental effects. ${ }^{44}$ Hence, 31 and propionate were examined for their ability to promote human neutrophil migration, as it is already established that antagonists, such as 1, can inhibit chemotaxis in vitro and that acetate can induce chemotaxis in mouse neutrophils. ${ }^{45,46}$ Compound 31 at $1 \mu \mathrm{M}$ significantly induced migration of human neutrophils at a level comparable to propionate (C3) at a physiologically relevant concentration, ${ }^{47}$ an effect that was more than doubled at $10 \mu \mathrm{M}$ (Figure 3).

SCFAs have been shown to inhibit lipolysis in adipocytes mediated through FFA2 via the $\mathrm{G} \alpha_{\mathrm{i}}$ pathway. ${ }^{48}$ In this study we demonstrate that thiazolidine 31 , in particular when evaluated in cAMP assays, is a potent agonist of hFFA2 with

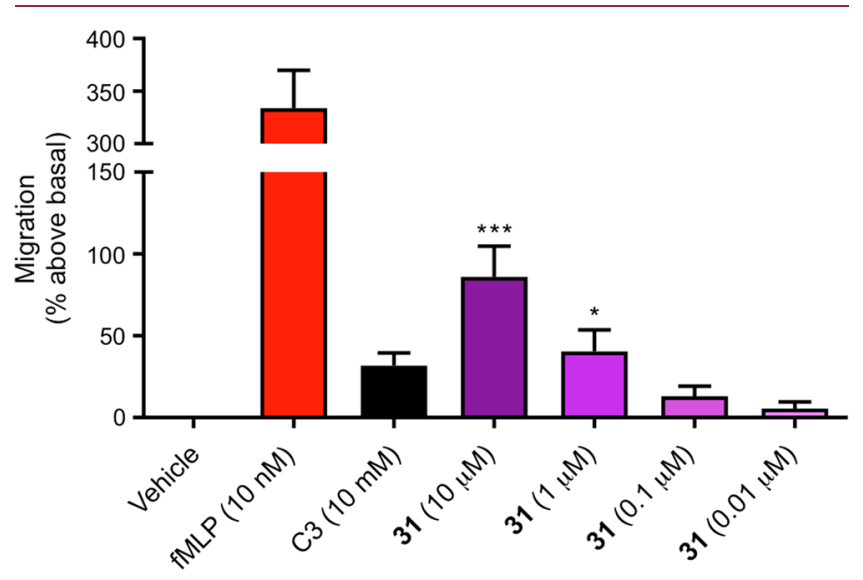

Figure 3. Ability of propionate (C3) and 31 to induce neutrophil migration relative to the highly potent chemotactic factor fMLP $(n=$ 4-6): $(*) p<0.05,(* * *) p<0.01$; one-way ANOVA followed by Dunnett post hoc test. 
retained activity at mFFA2. Therefore, 31 was evaluated for its ability to inhibit isoproterenol-induced lipolysis in murine adipocytes, a process known to be $\mathrm{G} \alpha_{\mathrm{i}}$ dependent. ${ }^{48}$ Even though 31 is slightly less potent on murine FFA2, 31 was, as predicted, 50-fold more potent than propionate in inhibiting lipolysis in isoproterenol-stimulated adipocytes (Figure 4).

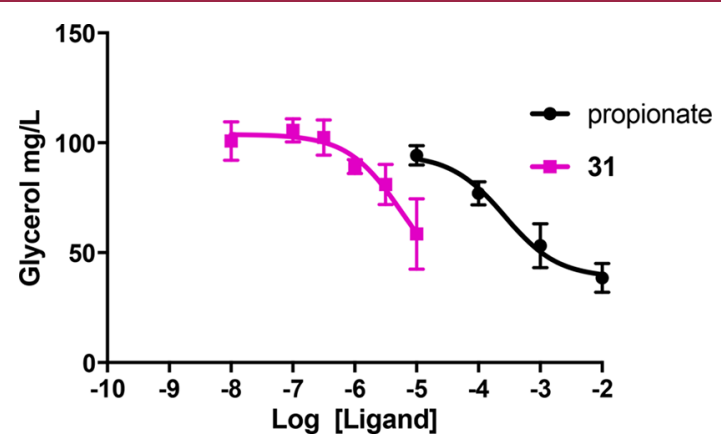

Figure 4. Inhibition of isoproterenol-induced lipolysis by propionate $\left(\mathrm{pEC}_{50}=3.6 \pm 0.4\right)$ and $31\left(\mathrm{pEC}_{50}=5.3 \pm 0.6\right)$ in murine adipocytes $(n=3-4)$.

\section{CONCLUSION}

Substitution of the central pyrrolidine of a published FFA2 agonist by a synthetically more tractable thiazolidine and rapid screening of substituents at this scaffold led to the discovery of the potent and selective FFA2 agonist 31, a compound with lipophilicity in the lower part of the optimal range and therefore also high LLE. The compound furthermore has excellent solubility, high chemical, microsomal, and hepatocyte stability, and favorable pharmacokinetic properties. Compound 31 was able to induce migration of human neutrophils and to inhibit lipolysis in murine adipocytes. Collectively, these properties render 31 an interesting tool compound for further exploration of FFA2 as a potential therapeutic target for treatment of inflammatory and metabolic diseases.

\section{EXPERIMENTAL SECTION}

Synthesis. All commercial starting materials and solvents were used without further purification unless otherwise stated. THF was freshly distilled from sodium/benzophenone. $\mathrm{MeOH}$ was freshly distilled from Mg. DCM was freshly distilled and stored over $4 \AA$ sieves. TLC was performed on TLC silica gel 60 F254 plates (Merck) and visualized at $254 \mathrm{~nm}$ or by staining with ninhydrin, $\mathrm{KMnO}_{4}$, or $\mathrm{FeCl}_{3}$ stains. Petroleum ether (PE) refers to alkanes with bp 60-80 ${ }^{\circ} \mathrm{C}$. Water used in reactions was demineralized, and water used for freeze-drying was filtered Milli-Q. Purification by flash chromatography was carried out using silica gel 60 (0.040-0.063 mm, Merck). Test compounds suspended in Milli- $\mathrm{Q}$ water $(1 \mathrm{~mL} / 10 \mathrm{mg}, 3$ drops $\mathrm{MeCN})$ were lyophilized on a Heto Drywinner freeze-dryer. ${ }^{1} \mathrm{H}$ and ${ }^{13} \mathrm{C}$ NMR spectra were recorded at 400 and $101 \mathrm{MHz}$, respectively, on a Bruker Avance III 400 at $300 \mathrm{~K}$. Spectra were calibrated relative to residual solvent peaks: ${ }^{1} \mathrm{H}$ NMR $\left(\mathrm{CDCl}_{3}\right), 7.26 \mathrm{ppm} ;{ }^{13} \mathrm{C} \mathrm{NMR}$ $\left(\mathrm{CDCl}_{3}\right), 77.16 \mathrm{ppm} ;{ }^{1} \mathrm{H}$ NMR (DMSO-d $\left.d_{6}\right), 2.50 \mathrm{ppm} ;{ }^{13} \mathrm{C}$ NMR (DMSO-d $), 39.52 \mathrm{ppm} ;{ }^{1} \mathrm{H}$ NMR $\left(\mathrm{CD}_{3} \mathrm{OD}\right), 3.31 \mathrm{ppm} ;{ }^{13} \mathrm{C}$ NMR $\left(\mathrm{CD}_{3} \mathrm{OD}\right), 49.00 \mathrm{ppm} ;{ }^{1} \mathrm{H}$ NMR $\left(\mathrm{CD}_{2} \mathrm{Cl}_{2}\right), 5.32 \mathrm{ppm} ;{ }^{13} \mathrm{C}$ NMR $\left(\mathrm{CD}_{2} \mathrm{Cl}_{2}\right), 53.84 \mathrm{ppm}$. Rotamer chemical shift values in ${ }^{1} \mathrm{H}$ NMR are marked by " $*$ " and have been assigned where possible. Rotamer peaks in ${ }^{1} \mathrm{H}$ NMR are labeled by an integral equal to that of its main partner. ${ }^{1} \mathrm{H}$ and ${ }^{13} \mathrm{C}$ spectra of 31 were obtained at 600 and $151 \mathrm{MHz}$, respectively, on an Agilent NMRS 600 at the indicated temperature (Supporting Information). High-resolution mass spectra (HRMS) were recorded on a Bruker micrOTOF-Q II (ESI). Specific optical rotation was recorded on Anton Paar MCP 100 polarimeter. Purity was determined by HPLC and confirmed by inspection of NMR spectra $\left({ }^{1} \mathrm{H}\right.$ and ${ }^{13} \mathrm{C}$ NMR). HPLC analysis was performed using a Dionex $120 \mathrm{C} 18$ column $(5 \mu \mathrm{m}, 4.6 \mathrm{~mm} \times 150 \mathrm{~mm})$; flow, $1 \mathrm{~mL} /$ $\mathrm{min} ; 10 \% \mathrm{MeCN}$ in water (0-1 min), $10-100 \% \mathrm{MeCN}$ in water (1$10 \mathrm{~min}$ ), $100 \% \mathrm{MeCN}$ (11-15 min), with both solvents containing $0.1 \%$ formic acid as modifier; UV detection at $254 \mathrm{~nm}$. All test compounds were of $\geq 95 \%$ purity. None of the test compounds contain substructures associated with pan-assay interfering activities (PAINS $)^{49}$ by inspection or by screening for PAINS or aggregators at http://zinc15.docking.org/patterns/home.

Methyl (4R)-2-(2-Chlorophenyl)thiazolidine-4-carboxylate (7a). L-Cysteine methyl ester hydrochloride $(1.51 \mathrm{~g}, 8.80 \mathrm{mmol})$ was dissolved in water $(6.6 \mathrm{~mL})$, and potassium bicarbonate $(879 \mathrm{mg}$, $8.78 \mathrm{mmol}$ ) was added followed by a solution of 2-chlorobenzaldehyde $(2.49 \mathrm{~g}, 18.1 \mathrm{mmol})$ in EtOH $(6.6 \mathrm{~mL})$. The reaction was stirred at $\mathrm{rt}$ for $12 \mathrm{~h}$, whereafter the reaction mixture was diluted with water and extracted with DCM $(\times 3)$. The combined organic phases were washed with brine, dried over $\mathrm{Na}_{2} \mathrm{SO}_{4}$, concentrated in vacuo, and purified by flash chromatography (EtOAc/PE, 1:5) to give $7 \mathbf{a}$ as a light yellow oil ( $1.68 \mathrm{~g}, 75 \%$ yield, $40 \%$ minor isomer and $60 \%$ major isomer): $R_{f}=0.22(\mathrm{EtOAc} / \mathrm{PE}, 1: 5) ;{ }^{1} \mathrm{H}$ NMR for minor isomer $(400$ $\left.\mathrm{MHz}, \mathrm{CDCl}_{3}\right) \delta 7.81(\mathrm{dd} J=7.6,1.8 \mathrm{~Hz}, 1 \mathrm{H}), 7.50-7.24(\mathrm{~m}, 6 \mathrm{H})$ [minor and major], $6.04(\mathrm{br} \mathrm{s}, 1 \mathrm{H}), 4.14-4.06(\mathrm{~m}, 1 \mathrm{H}), 3.90(\mathrm{~s}, 3 \mathrm{H})$, $3.56(\mathrm{dd}, J=10.3,6.9 \mathrm{~Hz}, 1 \mathrm{H}), 3.24-3.14(\mathrm{~m}, 2 \mathrm{H})$ [minor and major], 2.83 (br s, $1 \mathrm{H}) ;{ }^{1} \mathrm{H}$ NMR for major isomer $(400 \mathrm{MHz}$, $\left.\mathrm{CDCl}_{3}\right) \delta 7.66(\mathrm{dd}, J=7.7,1.7 \mathrm{~Hz}, 1 \mathrm{H}), 7.50-7.23(\mathrm{~m}, 6 \mathrm{H})[$ minor and major], $6.18(\mathrm{~s}, 1 \mathrm{H}), 4.34(\mathrm{app} \mathrm{t}, J=6.6 \mathrm{~Hz}, 1 \mathrm{H}), 3.91(\mathrm{~s}, 3 \mathrm{H})$, $3.43(\mathrm{dd}, J=10.6,6.5 \mathrm{~Hz}, 1 \mathrm{H}), 3.24-3.16(\mathrm{~m}, 2 \mathrm{H})$ [minor and major], 3.15 (br s, $1 \mathrm{H}) ;{ }^{13} \mathrm{C}$ NMR for mixture of diastereomers (101 $\left.\mathrm{MHz} \mathrm{CDCl}_{3}\right) \delta 172.2,171.7,140.2,136.0,133.9,133.1,130.0,129.9$, 129.8, 128.7, 128.3, 127.5, 127.0, 126.7, 68.5, 67.4, 65.6, 65.1, 52.8, 52.7, 39.1, 37.6; HRMS (ESI) calcd for $\mathrm{C}_{11} \mathrm{H}_{12} \mathrm{ClNNaO}_{2} \mathrm{~S}(\mathrm{M}+$ $\mathrm{Na}^{+}$), 280.0169; found, 280.0162 .

Methyl (4R)-2-(3-Chlorophenyl)thiazolidine-4-carboxylate (7b). The title compound was prepared as described for $7 \mathbf{a}$ using $\mathrm{L}-$ cysteine methyl ester hydrochloride $(119 \mathrm{mg}, 1.16 \mathrm{mmol})$ and 3 chlorobenzaldehyde $(328 \mathrm{mg}, 2.33 \mathrm{mmol})$ and obtained after flash chromatography (EtOAc/PE, 1:5) as a light yellow oil (214 mg, 71\% yield, $44 \%$ minor isomer and 56\% major isomer): $R_{f}=0.16$ (EtOAc/ $\mathrm{PE}, 1: 5) ;{ }^{1} \mathrm{H}$ NMR for minor isomer $\left(400 \mathrm{MHz}, \mathrm{CDCl}_{3}\right) \delta 7.50-7.48$ $(\mathrm{m}, 1 \mathrm{H}), 7.41-7.28(\mathrm{~m}, 4 \mathrm{H})$ [minor and major], 7.25-7.20 $(\mathrm{m}, 2 \mathrm{H})$ [minor and major], $5.78(\mathrm{~s}, 1 \mathrm{H}), 4.12(\mathrm{app} \mathrm{t}, J=6.6 \mathrm{~Hz}, 1 \mathrm{H}), 3.79(\mathrm{~s}$, $3 \mathrm{H}), 3.37(\mathrm{dd}, J=10.6,7.0 \mathrm{~Hz}, 1 \mathrm{H}), 3.18-3.06(\mathrm{~m}, 2 \mathrm{H})$ [minor and major], 2.92 (br s, $1 \mathrm{H}) ;{ }^{1} \mathrm{H}$ NMR for major isomer $(400 \mathrm{MHz}$, $\left.\mathrm{CDCl}_{3}\right) \delta 7.54-7.52(\mathrm{~m}, 1 \mathrm{H}), 7.41-7.28(\mathrm{~m}, 4 \mathrm{H})$ [minor and major], 7.25-7.20 (m, 2H) [minor and major], $5.50(\mathrm{br} \mathrm{s}, 1 \mathrm{H})$, 4.01-3.93 (m, 1H), $3.80(\mathrm{~s}, 3 \mathrm{H}), 3.45(\mathrm{dd}, J=10.3,7.1 \mathrm{~Hz}, 1 \mathrm{H})$, $3.18-3.06(\mathrm{~m}, 2 \mathrm{H})$ [minor and major], $2.62(\mathrm{br} \mathrm{s}, 1 \mathrm{H}) ;{ }^{13} \mathrm{C} \mathrm{NMR}$ for mixture of diastereomers $\left(101 \mathrm{MHz}, \mathrm{CDCl}_{3}\right) \delta 172.1,171.5,143.9$, $140.4,134.6,134.4,130.0,129.74,129.0,128.0,127.8,127.1,125.9$, 125.3, 71.8, 69.9, 65.6, 64.2, 52.7, 52.7, 39.2, 38.2; HRMS (ESI) calcd for $\mathrm{C}_{11} \mathrm{H}_{13} \mathrm{ClNO}_{2} \mathrm{~S}\left(\mathrm{M}+\mathrm{H}^{+}\right)$, 258.0350; found, 258.0356.

Methyl (4R)-2-(4-Chlorophenyl)thiazolidine-4-carboxylate (7c). The title compound was prepared as described for $7 \mathrm{a}$ using $\mathrm{L}-$ cysteine methyl ester hydrochloride $(200 \mathrm{mg}, 1.17 \mathrm{mmol})$ and 4chlorobenzaldehyde $(328 \mathrm{mg}, 2.33 \mathrm{mmol})$ and obtained after flash chromatography (EtOAc/PE, 1:5) as a light yellow oil (208 mg, 69\% yield, $42 \%$ minor isomer and 58\% major isomer): $R_{f}=0.19$ (EtOAc/ PE, 1:5); ${ }^{1} \mathrm{H}$ NMR for minor isomer $\left(400 \mathrm{MHz}, \mathrm{CDCl}_{3}\right) \delta 7.36-7.25$ $(\mathrm{m}, 4 \mathrm{H}), 5.77(\mathrm{~s}, 1 \mathrm{H}), 4.13(\mathrm{t}, J=6.5 \mathrm{~Hz}, 1 \mathrm{H}), 3.78(\mathrm{~s}, 3 \mathrm{H}), 3.36$ $(\mathrm{dd}, J=10.6,7.0 \mathrm{~Hz}, 1 \mathrm{H}), 3.16(\mathrm{dd}, J=10.6,6.1 \mathrm{~Hz}, 1 \mathrm{H}), 2.67(\mathrm{br} \mathrm{s}$, 2H) [minor and major]; ${ }^{1} \mathrm{H}$ NMR for major isomer $(400 \mathrm{MHz}$, $\left.\mathrm{CDCl}_{3}\right) \delta 7.48-7.39(\mathrm{~m}, 4 \mathrm{H}), 5.51(\mathrm{~s}, 1 \mathrm{H}), 3.97(\mathrm{dd}, J=8.8,7.2 \mathrm{~Hz}$, $1 \mathrm{H}), 3.45$ (dd, $J=10.3,7.1 \mathrm{~Hz}, 1 \mathrm{H}), 3.79(\mathrm{~s}, 3 \mathrm{H}), 3.10$ (dd, $J=10.3$, $9.0 \mathrm{~Hz}, 1 \mathrm{H}), 2.67$ (br s, $2 \mathrm{H})$ [minor and major]; ${ }^{13} \mathrm{C} \mathrm{NMR}$ for mixture of diastereomers $\left(101 \mathrm{MHz}, \mathrm{CDCl}_{3}\right) \delta 172.1,171.5,140.1$, $136.8,134.5,133.6,128.9,128.9,128.5,128.4,71.8,70.0,65.5,64.2$, $52.7,52.6,39.2$, 38.1; HRMS (ESI) calcd for $\mathrm{C}_{11} \mathrm{H}_{13} \mathrm{ClNO}_{2} \mathrm{~S}(\mathrm{M}+$ $\mathrm{H}^{+}$), 258.0350; found, 258.0361. 
Methyl (R)-2-(Pyridin-2-yl)thiazolidine-4-carboxylate (7e). The title compound was prepared as described for $7 \mathbf{a}$ using Lcysteine methyl ester hydrochloride $(200 \mathrm{mg}, 1.16 \mathrm{mmol})$ and picolinaldehyde (187 mg, $1.75 \mathrm{mmol}$ ) and obtained after flash chromatography (EtOAc/PE, 1:1) as a clear oil $(165 \mathrm{mg}, 63 \%$ yield, $45 \%$ minor isomer and 55\% major isomer): $R_{f}=0.18$ (EtOAc $/ \mathrm{PE}$, $1: 1) ;{ }^{1} \mathrm{H}$ NMR for minor isomer $\left(400 \mathrm{MHz}, \mathrm{CDCl}_{3}\right) \delta 8.57(\mathrm{~d}, J=4.8$ $\mathrm{Hz}, 1 \mathrm{H}), 7.72-7.61(\mathrm{~m}, 2 \mathrm{H})$ [minor and major], 7.35-7.27 $(\mathrm{m}, 2 \mathrm{H})$ [minor and major], 7.26-7.17 $(\mathrm{m}, 2 \mathrm{H})$ [minor and major], $5.85(\mathrm{~s}$, $1 \mathrm{H}), 4.56(\mathrm{dd}, J=6.4,4.6 \mathrm{~Hz}, 1 \mathrm{H}), 3.80(\mathrm{~s}, 3 \mathrm{H}), 3.63(\mathrm{br} \mathrm{s}, 2 \mathrm{H})$ [minor and major], 3.41-3.31 (m, 2H); ${ }^{1} \mathrm{H}$ NMR for major isomer $\left(400 \mathrm{MHz}, \mathrm{CDCl}_{3}\right) \delta 8.63(\mathrm{~d}, J=4.8 \mathrm{~Hz}, 1 \mathrm{H}), 7.72-7.61(\mathrm{~m}, 2 \mathrm{H})$ [minor and major], 7.35-7.27 $(\mathrm{m}, 2 \mathrm{H})$ [minor and major], 7.26$7.17(\mathrm{~m}, 2 \mathrm{H})$ [minor and major], $5.66(\mathrm{~s}, 1 \mathrm{H}), 4.04(\mathrm{dd}, J=9.7,6.7$ $\mathrm{Hz}, 1 \mathrm{H}), 3.83(\mathrm{~s}, 3 \mathrm{H}), 3.63$ (br s, $2 \mathrm{H}$ ) [minor and major], 3.45 (dd, $J$ $=10.1,6.7 \mathrm{~Hz}, 1 \mathrm{H}), 3.09(\mathrm{t}, J=9.9 \mathrm{~Hz}, 1 \mathrm{H}) ;{ }^{13} \mathrm{C}$ NMR for mixture of diastereomers $\left(101 \mathrm{MHz}, \mathrm{CDCl}_{3}\right) \delta 172.2,171.2,158.7,156.8,149.9$, 149.6, 136.8, 136.8, 123.4, 123.0, 122.1, 121.6, 71.6, 71.1, 66.3, 65.6, 52.6 [minor and major], 39.4, 38.7; HRMS (ESI) calcd for $\mathrm{C}_{10} \mathrm{H}_{12} \mathrm{~N}_{2} \mathrm{NaO}_{2} \mathrm{~S}\left(\mathrm{M}+\mathrm{Na}^{+}\right)$247.0512, found 247.0524.

Methyl (4R)-2-(2-Methoxyphenyl)thiazolidine-4-carboxylate (7f). The title compound was prepared as described for $7 \mathrm{a}$ using L-cysteine methyl ester hydrochloride $(254 \mathrm{mg}, 1.48 \mathrm{mmol})$ and 2-methoxybenzaldehyde (199 mg, $1.46 \mathrm{mmol}$ ) and obtained after flash chromatography (EtOAc/PE, 1:4) as a clear oil $(297 \mathrm{mg}, 81 \%$ yield, $40 \%$ minor isomer and 60\% major isomer): $R_{f}=0.21$ (EtOAc/ PE, 1:4); ${ }^{1} \mathrm{H}$ NMR for minor isomer $\left(400 \mathrm{MHz}, \mathrm{CDCl}_{3}\right) \delta 7.42(\mathrm{dd}, J$ $=7.6,1.5 \mathrm{~Hz}, 1 \mathrm{H}), 7.25-7.19(\mathrm{~m}, 1 \mathrm{H}), 7.00-6.92(\mathrm{~m}, 2 \mathrm{H}), 5.99(\mathrm{br}$ s, $1 \mathrm{H}), 4.25(\mathrm{app} \mathrm{t}, J=6.6 \mathrm{~Hz}, 1 \mathrm{H}), 3.85(\mathrm{~s}, 3 \mathrm{H}), 3.79(\mathrm{~s}, 6 \mathrm{H})$ [minor and major], $3.29(\mathrm{dd}, J=10.4,6.6 \mathrm{~Hz}, 1 \mathrm{H}), 3.06(\mathrm{br} \mathrm{s}, 2 \mathrm{H})$ [minor and major], $3.12-3.00(\mathrm{~m}, 2 \mathrm{H})$ [minor and major]; ${ }^{1} \mathrm{H}$ NMR for major isomer $\left(400 \mathrm{MHz}, \mathrm{CDCl}_{3}\right) \delta 7.49(\mathrm{dd}, J=7.6,1.6 \mathrm{~Hz}, 1 \mathrm{H})$, 7.32-7.26 (m, 1H), 6.92-6.83 (m, 2H), $5.83(\mathrm{~s}, 1 \mathrm{H}), 3.98-3.91(\mathrm{~m}$, $1 \mathrm{H}), 3.86(\mathrm{~s}, 3 \mathrm{H}), 3.79(\mathrm{~s}, 6 \mathrm{H})$ [minor and major], $3.42(\mathrm{dd}, J=10.1$, $6.8 \mathrm{~Hz}, 1 \mathrm{H}), 3.06(\mathrm{br} \mathrm{s}, 2 \mathrm{H})$ [minor and major], 3.12-3.00 (m, $2 \mathrm{H})$ [minor and major]; ${ }^{13} \mathrm{C}$ NMR for mixture of diastereomers (101 $\left.\mathrm{MHz}, \mathrm{CDCl}_{3}\right) \delta 172.3,171.8,157.4,156.8,130.1,129.7,128.7,127.8$, 126.2, 125.8, 120.9, 120.5, 111.2, 110.7, 67.7, 66.0, 65.8, 64.9, 55.7, 55.5, 52.51, 52.49, 39.0, 37.6; HRMS (ESI) calcd for $\mathrm{C}_{12} \mathrm{H}_{16} \mathrm{NO}_{3} \mathrm{~S}(\mathrm{M}$ $\left.+\mathrm{H}^{+}\right)$254.0845, found 254.0855.

Methyl (4R)-2-Phenylthiazolidine-4-carboxylate $(7 \mathrm{~g})$. The title compound was prepared as described for $7 \mathbf{a}$ using $\mathrm{L}$-cysteine methyl ester hydrochloride ( $327 \mathrm{mg}, 1.91 \mathrm{mmol}$ ) and benzaldehyde $(288 \mu \mathrm{L}, 2.83 \mathrm{mmol})$ and obtained after flash chromatography (EtOAc/PE, 1:4) as a clear oil (340 mg, $80 \%$ yield, $37 \%$ minor isomer and 63\% major isomer): $R_{f}=0.32(\mathrm{EtOAc} / \mathrm{PE}, 1: 4) ;{ }^{1} \mathrm{H}$ NMR for minor isomer $\left(400 \mathrm{MHz}, \mathrm{CDCl}_{3}\right) \delta 7.49-7.46(\mathrm{~m}, 2 \mathrm{H}), 7.39-7.22$ $(\mathrm{m}, 6 \mathrm{H})$ [minor and major], $5.81(\mathrm{~s}, 1 \mathrm{H}), 4.20($ app t, $J=6.1 \mathrm{~Hz}$, $1 \mathrm{H}), 3.77(\mathrm{~s}, 3 \mathrm{H}), 3.37(\mathrm{dd}, J=10.6,7.1 \mathrm{~Hz}, 1 \mathrm{H}), 3.19(\mathrm{dd}, J=10.6$, $5.8 \mathrm{~Hz}, 1 \mathrm{H}), 2.84(\mathrm{br} \mathrm{s}, 1 \mathrm{H})$; ${ }^{1} \mathrm{H}$ NMR for major isomer $(400 \mathrm{MHz}$, $\left.\mathrm{CDCl}_{3}\right) \delta 7.54-7.49(\mathrm{~m}, 2 \mathrm{H}), 7.39-7.22(\mathrm{~m}, 6 \mathrm{H})$ [minor and major], $5.55(\mathrm{~s}, 1 \mathrm{H}), 4.02-3.93(\mathrm{~m}, 1 \mathrm{H}), 3.78(\mathrm{~s}, 3 \mathrm{H}), 3.45(\mathrm{dd}, J=$ $10.3,7.1 \mathrm{~Hz}, 1 \mathrm{H}), 3.10(\mathrm{dd}, J=10.1,9.2 \mathrm{~Hz}, 1 \mathrm{H}), 2.66(\mathrm{br} \mathrm{s}, 1 \mathrm{H})$; ${ }^{13} \mathrm{C}$ NMR for mixture of diastereomers $\left(101 \mathrm{MHz}, \mathrm{CDCl}_{3}\right) \delta 172.2$, $171.6,141.2,138.3,128.73,128.72,128.5,127.9,127.5,127.0,72.7$, 70.9, 65.6, 64.4, 52.6, 52.5, 39.3, 38.2; HRMS (ESI) calcd for $\mathrm{C}_{11} \mathrm{H}_{13} \mathrm{NNaO}_{2} \mathrm{~S}\left(\mathrm{M}+\mathrm{Na}^{+}\right) 246.0559$, found 246.0565 .

Methyl (2R,4R)-2-(2-Chlorophenyl)-3-(4-iodobenzoyl)thiazolidine-4-carboxylate (8a). A predried vial with 7a (926 $\mathrm{mg}, 3.59 \mathrm{mmol})$ in THF $\left(7.4 \mathrm{~mL}\right.$, anhydrous) was cooled to $-10{ }^{\circ} \mathrm{C}$ and to it was added triethylamine $(1.25 \mathrm{~mL}, 8.97 \mathrm{mmol})$ dropwise. After stirring for $15 \mathrm{~min}$ at $\mathrm{rt}$ the solution was evaporated, the triethylammonium salt was redissolved in THF $(11 \mathrm{~mL})$, and the solution was cooled to $-10{ }^{\circ} \mathrm{C}$. 4-Iodobenzoyl chloride (1.05 g, 3.95 $\mathrm{mmol}$ ) dissolved in THF ( $15 \mathrm{~mL}$, anhydrous) was added dropwise, and the reaction mixture was allowed to reach rt. After stirring at $\mathrm{rt}$ for $4 \mathrm{~h}$ the solvent was evaporated off, to the crude residue was added water $(18 \mathrm{~mL})$, and the mixture was acidified with $1 \mathrm{M} \mathrm{HCl}(\mathrm{pH} 2-$ $3)$ and extracted with EtOAc $(\times 3)$. The organic phases were washed with brine, dried over $\mathrm{Na}_{2} \mathrm{SO}_{4}$, concentrated in vacuo, and purified by flash chromatography (EtOAc/PE, 1:3) to give central intermediate $8 \mathrm{a}$ as a white foam ( $1.43 \mathrm{~g}, 82 \%$ yield): $R_{f}=0.21$ (EtOAc/PE, 1:3); ${ }^{1} \mathrm{H}$ NMR $\left(400 \mathrm{MHz}, \mathrm{CDCl}_{3}\right) \delta 8.32(\mathrm{~d}, J=6.4 \mathrm{~Hz}, 1 \mathrm{H}), 7.64-7.47$ $(\mathrm{m}, 2 \mathrm{H}), 7.40-7.31(\mathrm{~m}, 2 \mathrm{H}), 7.30-7.22(\mathrm{~m}, 1 \mathrm{H}), 7.07-6.91(\mathrm{~m}$, 2H), 6.17 (br s, $1 \mathrm{H}), 5.07$ (app s, $1 \mathrm{H}), 3.86(\mathrm{~s}, 3 \mathrm{H}), 3.45-3.32(\mathrm{~m}$, $1 \mathrm{H}), 3.20(\mathrm{~m}, 1 \mathrm{H}) ;{ }^{13} \mathrm{C}$ NMR $\left(101 \mathrm{MHz}, \mathrm{CDCl}_{3}\right) \delta 170.3,169.9$, 138.9, 137.3, 134.1, 131.4, 129.8, 129.2, 128.5, 127.5, 127.3, 97.6, 65.8, 65.5, 52.8, 31.1; HRMS (ESI) calcd for $\mathrm{C}_{18} \mathrm{H}_{16} \mathrm{ClINO}_{3} \mathrm{~S}(\mathrm{M}+$ $\left.\mathrm{H}^{+}\right)$487.9579, found 487.9573. $[\alpha]^{20}{ }_{\mathrm{D}}+45^{\circ}$ (c 1.0, DCM).

Methyl (2R,4R)-2-(2-Chlorophenyl)-3-(3-iodobenzoyl)thiazolidine-4-carboxylate (8b). The title compound was prepared as described for $8 \mathbf{a}$ using $7 \mathbf{a}(300 \mathrm{mg}, 0.16 \mathrm{mmol})$ and 3-iodobenzoyl chloride $(347 \mathrm{mg}, 0.13 \mathrm{mmol})$ and obtained after flash chromatography $(\mathrm{EtOAc} / \mathrm{PE}, 1: 3)$ as a colorless oil $(237 \mathrm{mg}, 42 \%$ yield $): R_{f}=$ $0.26(\mathrm{EtOAc} / \mathrm{PE}, 1: 3) ;{ }^{1} \mathrm{H}$ NMR $\left(400 \mathrm{MHz}, \mathrm{CDCl}_{3}\right) \delta 8.30(\mathrm{~d}, J=$ $7.1 \mathrm{~Hz}, 1 \mathrm{H}), 7.68(\mathrm{~d}, J=7.3 \mathrm{~Hz}, 1 \mathrm{H}), 7.57-7.48(\mathrm{~m}, 1 \mathrm{H}), 7.40(\mathrm{t}, J=$ $7.2 \mathrm{~Hz}, 1 \mathrm{H}), 7.35(\mathrm{dd}, J=7.9,1.3 \mathrm{~Hz}, 1 \mathrm{H}), 7.29(\mathrm{~d}, J=7.3 \mathrm{~Hz}, 1 \mathrm{H})$, 7.24-7.17 (m, 1H), 7.01-6.91 (m, 1H), 6.15 (s, 1H), 5.13-4.96 (m, $1 \mathrm{H}), 3.89(\mathrm{~s}, 3 \mathrm{H}), 3.47-3.32(\mathrm{~m}, 1 \mathrm{H}), 3.32-3.15(\mathrm{~m}, 1 \mathrm{H}) ;{ }^{13} \mathrm{C}$ NMR $\left(101 \mathrm{MHz}, \mathrm{CDCl}_{3}\right) \delta 170.5,169.3,139.7,139.1,136.6,136.2$ 131.6, 130.0, 129.4, 127.8, 127.6, 126.1, 93.8, 65.8, 65.6, 53.0, 31.4; HRMS (ESI) calcd for $\mathrm{C}_{18} \mathrm{H}_{15} \mathrm{ClINNaO}_{3} \mathrm{~S}\left(\mathrm{M}+\mathrm{Na}^{+}\right)$509.9398, found 509.9393 .

(2R,4R)-2-(2-Chlorophenyl)-3-(2'-methoxybiphenyl-4carbonyl)thiazolidine-4-carboxylic Acid (9). Step 1: The methyl ester of the title compound 9a was prepared as described for 8a using $7 \mathbf{a}(100 \mathrm{mg}, 0.39 \mathrm{mmol})$ and 2 '-methoxybiphenyl-4-carbonyl chloride $(107 \mathrm{mg}, 0.44 \mathrm{mmol})$ and obtained after flash chromatography (EtOAc/PE, 1:3) as a clear viscous oil $\left(141 \mathrm{mg}, 77 \%\right.$ yield): $R_{f}=0.20$ (EtOAc/PE, 1:3); ${ }^{1} \mathrm{H}$ NMR $\left(400 \mathrm{MHz} \mathrm{CDCl}_{3}\right) \delta 8.38(\mathrm{~d}, J=7.0 \mathrm{~Hz}$, $1 \mathrm{H}), 7.49-7.19(\mathrm{~m}, 9 \mathrm{H}), 7.07-6.91(\mathrm{~m}, 2 \mathrm{H}), 6.32$ (br s, $1 \mathrm{H}), 5.18-$ $5.08(\mathrm{~m}, 1 \mathrm{H}), 3.89(\mathrm{br} \mathrm{s}, 3 \mathrm{H}), 3.76(\mathrm{~s}, 3 \mathrm{H}), 3.45-3.34(\mathrm{~m}, 1 \mathrm{H})$, 3.27-3.18 (m, 1H); ${ }^{13} \mathrm{C}$ NMR (101 MHz, $\left.\mathrm{CDCl}_{3}\right) \delta 171.0,170.8$, $156.5,141.4,139.5,133.0,131.7,130.7,129.9,129.6,129.4,129.3$, 129.1, 127.9, 127.4, 126.9, 121.0, 111.5, 66.1, 65.9, 55.6, 52.8, 31.3; HRMS (ESI) calcd for $\mathrm{C}_{25} \mathrm{H}_{23} \mathrm{ClNO}_{4} \mathrm{~S}\left(\mathrm{M}+\mathrm{H}^{+}\right)$468.1031, found 468.1028 .

Step 2: Methyl ester 9a (40 mg, $86 \mu \mathrm{mol}$ ) and LiI (46 mg, 0.34 $\mathrm{mmol})$ were dissolved in degassed EtOAc $(120 \mu \mathrm{L})$, the vial was capped, flushed with argon $(\times 3)$, and the reaction stirred at $80{ }^{\circ} \mathrm{C}$ in the dark. To the reaction mixture were added water and $1 \mathrm{M} \mathrm{HCl}$ $(1: 1)$, and extraction was with EtOAc $(\times 3)$. The combined organic phases were washed with $\mathrm{NaHSO}_{3}$, water, and brine. The organic layers were dried over $\mathrm{Na}_{2} \mathrm{SO}_{4}$, concentrated in vacuo, and purified by flash chromatography (EtOAc/PE, 2:1 $[1 \% \mathrm{AcOH}]$ ) to give the title compound 9 after freeze-drying as an amorphous solid $(20 \mathrm{mg}, 51 \%$ yield): $R_{f}=0.13(\mathrm{EtOAc} / \mathrm{PE}, 2: 1[1 \% \mathrm{AcOH}]) ;{ }^{1} \mathrm{H} \mathrm{NMR}(400 \mathrm{MHz}$, $\left.\mathrm{CDCl}_{3}\right) \delta 8.03(\mathrm{~d}, J=6.1 \mathrm{~Hz}, 1 \mathrm{H}), 7.45-7.40(\mathrm{~m}, 2 \mathrm{H}), 7.39-7.29$ (m, 5H), 7.29-7.21 (m, 2H), 7.05-6.93 (m, 2H), 6.37 (br s, $1 \mathrm{H})$, 5.28-5.16 (m, $1 \mathrm{H}), 3.77(\mathrm{~s}, 3 \mathrm{H}), 3.50-3.35(\mathrm{~m}, 2 \mathrm{H}) ;{ }^{13} \mathrm{C} \mathrm{NMR}$ $\left(101 \mathrm{MHz}, \mathrm{CDCl}_{3}\right) \delta 172.9,172.6,156.6,141.9,138.9,132.4,131.7$, $130.8,130.1,129.6,129.5,129.5,129.4,127.6,127.0,121.1,111.6$, 66.6, 66.1, 55.7, 31.0; HRMS (ESI) calcd for $\mathrm{C}_{24} \mathrm{H}_{20} \mathrm{ClNNaO}_{4} \mathrm{~S}(\mathrm{M}+$ $\mathrm{Na}^{+}$) 476.0694, found 476.0680. HPLC: $t_{\mathrm{R}}=12.28 \mathrm{~min}, 98.4 \%$. $[\alpha]^{20}{ }_{\mathrm{D}}+13^{\circ}(c 0.25, \mathrm{DCM})$.

(2R,4R)-2-(3-Chlorophenyl)-3-(2'-methoxybiphenyl-4carbonyl)thiazolidine-4-carboxylic Acid (10). Step 1: The methyl ester of the title compound 10a was prepared as described for 8 a using $7 \mathbf{b}(100 \mathrm{mg}, 0.39 \mathrm{mmol})$ and $2^{\prime}$-methoxybiphenyl-4-carbonyl chloride (105 mg, $0.43 \mathrm{mmol}$ ) and obtained after flash chromatography (EtOAc/PE, 1:3) as a clear viscous oil ( $152 \mathrm{mg}, 83 \%$ yield): $R_{f}$ $=0.18(\mathrm{EtOAc} / \mathrm{PE}, 1: 3) ;{ }^{1} \mathrm{H}$ NMR $\left(400 \mathrm{MHz}, \mathrm{CDCl}_{3}\right) \delta 7.71-7.64$ $(\mathrm{m}, 1 \mathrm{H}), 7.57(\mathrm{~d}, J=5.8 \mathrm{~Hz}, 1 \mathrm{H}), 7.48-7.41(\mathrm{~m}, 4 \mathrm{H}), 7.35-7.22(\mathrm{~m}$, $4 \mathrm{H}), 7.06-6.92(\mathrm{~m}, 2 \mathrm{H}), 6.15$ (br s, $1 \mathrm{H}), 5.17$ (app s, $1 \mathrm{H}), 3.85(\mathrm{~s}$, $3 \mathrm{H}), 3.79(\mathrm{~s}, 3 \mathrm{H}), 3.47-3.14(\mathrm{~m}, 2 \mathrm{H}) ;{ }^{13} \mathrm{C}$ NMR (400 MHz, $\left.\mathrm{CDCl}_{3}\right)$ $\delta$ 171.0, 170.5, 156.5, 143.5, 141.4, 134.4, 133.5, 130.8, 129.8, 129.6, $129.5,129.4,128.2,127.2,126.9,125.2,121.0,111.4,67.8,65.2,55.6$, 52.9, 32.0; HRMS (ESI) calcd for $\mathrm{C}_{25} \mathrm{H}_{22} \mathrm{ClNNaO}_{4} \mathrm{~S}\left(\mathrm{M}+\mathrm{Na}^{+}\right)$ 490.0850 , found 490.0830 . 
Step 2: The title compound $\mathbf{1 0}$ was prepared as described for $\mathbf{9}$ using methyl ester $10 \mathrm{a}(100 \mathrm{mg}, 0.21 \mathrm{mmol})$ and LiI (4 equiv) and obtained after flash chromatography (EtOAc/PE, 1:2 [2\% AcOH]) and subsequent freeze-drying as a white amorphous powder $(65 \mathrm{mg}$, $67 \%$ yield): $R_{f}=0.16(\mathrm{EtOAc} / \mathrm{PE}, 1: 2[2 \% \mathrm{AcOH}]) ;{ }^{1} \mathrm{H}$ NMR $(400$ $\left.\mathrm{MHz} \mathrm{CDCl}_{3}\right) \delta 7.61-7.39(\mathrm{~m}, 5 \mathrm{H}), 7.37-7.30(\mathrm{~m}, 2 \mathrm{H}), 7.29-7.22$ (m, 3H), 7.05-6.92 (m, 2H), $6.68($ br s, $1 \mathrm{H}), 6.16($ br s, $1 \mathrm{H}), 5.23$ (app s, 1H), $3.78(\mathrm{~s}, 3 \mathrm{H}), 3.49-3.35(\mathrm{~m}, 2 \mathrm{H}) ;{ }^{13} \mathrm{C}$ NMR $(101 \mathrm{MHz}$, $\left.\mathrm{CDCl}_{3}\right) \delta 172.5,172.1,156.5,142.8,141.9,134.7,132.7,130.9,130.0$, $129.8,129.5,129.4,128.5,127.0,124.9,121.1,111.5,68.3,65.0,55.7$, 31.6; HRMS (ESI) calcd for $\mathrm{C}_{24} \mathrm{H}_{20} \mathrm{ClNNaO}_{4} \mathrm{~S}\left(\mathrm{M}+\mathrm{Na}^{+}\right)$476.0694, found 476.0687. HPLC: $t_{\mathrm{R}}=12.10 \mathrm{~min}, 97.6 \%$. $[\alpha]_{\mathrm{D}}^{20}+23^{\circ}(c 1.0$, DCM).

$(2 R, 4 R)-2-(4-C h l o r o p h e n y l)-3-(2 '-m e t h o x y b i p h e n y l-4-$ carbonyl)thiazolidine-4-carboxylic Acid (11). Step 1: The methyl ester of the title compound 11a was prepared as described for 8a using $7 \mathrm{c}(99 \mathrm{mg}, 0.39 \mathrm{mmol})$ and 2'-methoxybiphenyl-4-carbonyl chloride $(107 \mathrm{mg}, 0.44 \mathrm{mmol})$ and obtained after flash chromatography (EtOAc/PE, 1:3) as a clear viscous oil (131 mg, 73\% yield): $R_{f}$ $=0.18($ EtOAc/PE, $1: 3) ;{ }^{1} \mathrm{H} \mathrm{NMR}\left(400 \mathrm{MHz}, \mathrm{CDCl}_{3}\right) \delta 7.63-7.57$ $(\mathrm{m}, 2 \mathrm{H}), 7.47-7.42(\mathrm{~m}, 4 \mathrm{H}), 7.36-7.20(\mathrm{~m}, 4 \mathrm{H}), 7.09-6.92(\mathrm{~m}$, $2 \mathrm{H}), 6.17$ (br s, $1 \mathrm{H}), 5.15$ (app s, $1 \mathrm{H}), 3.84$ (br s, $3 \mathrm{H}), 3.79(\mathrm{~s}, 3 \mathrm{H})$, 3.44-3.14 (m, 2H); ${ }^{13} \mathrm{C}$ NMR $\left(101 \mathrm{MHz}, \mathrm{CDCl}_{3}\right) \delta 171.0,170.6$, $156.5,141.3,140.1,133.8,133.6,130.8,129.6,129.5,129.4,128.7$, 128.5, 126.9, 121.0, 111.4, 67.7, 65.2, 55.6, 52.9, 32.0; HRMS (ESI) calcd for $\mathrm{C}_{25} \mathrm{H}_{23} \mathrm{ClNO}_{4} \mathrm{~S}\left(\mathrm{M}+\mathrm{H}^{+}\right)$468.1031, found 468.1009.

Step 2: The title compound $\mathbf{1 1}$ was prepared as described for 9 using methyl ester 11a (44 mg, $94 \mu \mathrm{mol}$ ) and LiI (4 equiv) and obtained after flash chromatography (EtOAc/PE, 1:2 [2\% AcOH]) and subsequent freeze-drying as a white amorphous powder $(56 \mathrm{mg}$, $24 \%$ yield): $R_{f}=0.17(\mathrm{EtOAc} / \mathrm{PE}, 1: 2[2 \% \mathrm{AcOH}]) ;{ }^{1} \mathrm{H}$ NMR $(400$ $\left.\mathrm{MHz}, \mathrm{CDCl}_{3}\right) \delta 7.52-7.18(\mathrm{~m}, 10 \mathrm{H}), 7.09-6.91(\mathrm{~m}, 2 \mathrm{H}), 6.18(\mathrm{br} \mathrm{s}$, $1 \mathrm{H}), 5.22($ app s, $1 \mathrm{H}), 3.79(\mathrm{~s}, 3 \mathrm{H}), 3.48-3.33(\mathrm{~m}, 2 \mathrm{H}) ;{ }^{13} \mathrm{C}$ NMR $\left(101 \mathrm{MHz}, \mathrm{CDCl}_{3}\right) \delta 172.7,172.0,156.5,141.9,139.2,134.2,132.7$, $130.8,129.8,129.5,129.4,128.9,128.2,127.0,121.1,111.5,68.4$, 65.2, 55.7, 31.5; HRMS (ESI) calcd for $\mathrm{C}_{24} \mathrm{H}_{20} \mathrm{ClNNaO}_{4} \mathrm{~S}\left(\mathrm{M}+\mathrm{Na}^{+}\right)$ 476.0694, found 476.0688. HPLC: $t_{\mathrm{R}}=12.17 \mathrm{~min}, 100 \%$. $[\alpha]^{20}{ }_{\mathrm{D}}+31^{\circ}$ (c 1.0, DCM).

$(2 R, 4 R)-2-(2-B r o m o p h e n y l)-3-(2 '-m e t h o x y b i p h e n y l-4-$ carbonyl)thiazolidine-4-carboxylic Acid (12). Step 1: Methyl (2R,4R)-2-(2-Bromophenyl)-3-(2'-methoxybiphenyl-4-carbonyl)thiazolidine-4-carboxylate (7i). The thiazolidine was prepared as described for 7a using L-cysteine methyl ester hydrochloride (201 $\mathrm{mg}, 1.17 \mathrm{mmol}$ ) and 2-bromobenzaldehyde (431 $\mathrm{mg}, 2.33 \mathrm{mmol})$. Crude methyl (4R)-2-(2-bromophenyl)thiazolidine-4-carboxylate (7i) was used without further purification in the next step.

Step 2: Methyl (2R,4R)-2-(2-Bromophenyl)-3-(2'-methoxybiphenyl-4carbonyl)thiazolidine-4-carboxylate (12a). Using the crude $7 \mathbf{i}(95 \mathrm{mg})$ and $2^{\prime}$-methoxybiphenyl-4-carbonyl chloride $(77 \mathrm{mg}, 0.31 \mathrm{mmol})$, the title compound was prepared as described for 8a and obtained after flash chromatography (EtOAc/PE, 1:3) as a clear viscous oil $(31 \mathrm{mg}$, $20 \%$ yield $): R_{f}=0.18(\mathrm{EtOAc} / \mathrm{PE}, 1: 3) ;{ }^{1} \mathrm{H} \mathrm{NMR}\left(400 \mathrm{MHz}, \mathrm{CDCl}_{3}\right)$ $\delta 8.39(\mathrm{~d}, J=7.4 \mathrm{~Hz}, 1 \mathrm{H}), 7.55(\mathrm{dd}, J=7.9,1.1 \mathrm{~Hz}, 1 \mathrm{H}), 7.47-7.36$ (m, 4H), 7.34-7.28 (m, 2H), 7.25-7.16 (m, 2H), 7.06-6.92 (m, $2 \mathrm{H}), 6.27$ (br s, $1 \mathrm{H}), 5.17-5.07(\mathrm{~m}, 1 \mathrm{H}), 3.90(\mathrm{br} \mathrm{s}, 3 \mathrm{H}), 3.76(\mathrm{~s}$, $3 \mathrm{H}), 3.41-3.33(\mathrm{~m}, 1 \mathrm{H}), 3.28-3.18(\mathrm{~m}, 1 \mathrm{H}) ;{ }^{13} \mathrm{C}$ NMR $(101 \mathrm{MHz}$, $\left.\mathrm{CDCl}_{3}\right) \delta 171.1,170.8,156.6,141.5,133.3,130.8,129.7,129.5$, $129.43,129.35,128.2,128.1,127.0,121.1,111.6,68.5,66.3,55.7$, 52.9, 31.2; HRMS (ESI) calcd for $\mathrm{C}_{25} \mathrm{H}_{23} \mathrm{BrNO}_{4} \mathrm{~S}\left(\mathrm{M}+\mathrm{H}^{+}\right)$ 512.0526, found 512.0520.

Step 3: The title compound $\mathbf{1 2}$ was prepared as described for $\mathbf{9}$ using methyl ester 12a (31 mg, $61 \mu \mathrm{mol})$ and LiI (4 equiv) and obtained after flash chromatography (EtOAc/PE, 1:1 [2\% AcOH]) and subsequent freeze-drying as a beige amorphous solid $(16 \mathrm{mg}, 54 \%$ yield): $R_{f}=0.23(\mathrm{EtOAc} / \mathrm{PE}, 1: 1[2 \% \mathrm{AcOH}]) ;{ }^{1} \mathrm{H} \mathrm{NMR}(400 \mathrm{MHz}$, $\left.\mathrm{CDCl}_{3}\right) \delta 8.14(\mathrm{~d}, J=4.4 \mathrm{~Hz}, 1 \mathrm{H}), 7.50(\mathrm{~d}, J=7.8 \mathrm{~Hz}, 1 \mathrm{H}), 7.41-$ $7.33(\mathrm{~m}, 3 \mathrm{H}), 7.33-7.27(\mathrm{~m}, 2 \mathrm{H}), 7.25-7.23(\mathrm{~m}, 1 \mathrm{H}), 7.20-7.09$ $(\mathrm{m}, 2 \mathrm{H}), 7.03-6.89(\mathrm{~m}, 2 \mathrm{H}), 6.25(\mathrm{br} \mathrm{s}, 1 \mathrm{H}), 5.20-5.13(\mathrm{~m}, 1 \mathrm{H})$, $3.72(\mathrm{~s}, 3 \mathrm{H}), 3.40-3.31(\mathrm{~m}, 2 \mathrm{H}) ;{ }^{13} \mathrm{C}$ NMR $\left(101 \mathrm{MHz}, \mathrm{CDCl}_{3}\right) \delta$ $173.0,172.6,156.6,141.7,140.6,133.3,132.6,130.8,129.6,129.5$,
$129.4,128.3,128.0,127.0,121.8,121.0,111.6,69.2,67.0,55.7,30.9$; HRMS (ESI) calcd for $\mathrm{C}_{24} \mathrm{H}_{21} \mathrm{BrNO}_{4} \mathrm{~S}\left(\mathrm{M}+\mathrm{H}^{+}\right)$498.0369, found 498.0345. HPLC: $t_{\mathrm{R}}=12.36 \mathrm{~min}, 99.8 \%$. $[\alpha]^{20}{ }_{\mathrm{D}}+17^{\circ}(c 0.3, \mathrm{DCM})$.

(2R,4R)-3-(2'-Methoxybiphenyl-4-carbonyl)-2-phenylthiazolidine-4-carboxylic Acid (13). Step 1: Methyl (2R,4R)-2Phenylthiazolidine-4-carboxylate $(7 \mathrm{~g})$. The thiazolidine was prepared as described for 7a using L-cysteine methyl ester hydrochloride $(201 \mathrm{mg}$, $1.17 \mathrm{mmol}$ ) and benzaldehyde $(247 \mathrm{mg}, 2.33 \mathrm{mmol})$. Crude methyl (4R)-2-phenylthiazolidine-4-carboxylate $(7 \mathrm{~g})$ was used without further purification in the next step.

Step 2: Methyl (2R,4R)-3-(2'-Methoxybiphenyl-4-carbonyl)-2-phenylthiazolidine-4-carboxylate (13a). Using crude $7 \mathrm{~g}(105 \mathrm{mg})$ and $2^{\prime}$ methoxybiphenyl-4-carbonyl chloride $(128 \mathrm{mg}, 0.52 \mathrm{mmol})$, the title compound was prepared as described for $\mathbf{8 a}$ and obtained after flash chromatography (EtOAc/PE, 1:3) as a white foam (146 mg, $72 \%$ yield): $R_{f}=0.18\left(\right.$ EtOAc/PE, 1:3); ${ }^{1} \mathrm{H}$ NMR $\left(400 \mathrm{MHz} \mathrm{CDCl}_{3}\right) \delta$ 7.71-7.56 (m, 2H), 7.47-7.18 (m, 9H), 7.04-6.91 (m, 2H), 6.19 (br s, $1 \mathrm{H}), 5.17$ (app s, $1 \mathrm{H}), 3.83$ (br s, 3H), $3.76(\mathrm{~s}, 3 \mathrm{H}), 3.44-3.16$ (m, $2 \mathrm{H}) ;{ }^{13} \mathrm{C} \mathrm{NMR}\left(101 \mathrm{MHz}, \mathrm{CDCl}_{3}\right) \delta 171.1,170.6,156.5,141.6$, $141.2,133.6,130.8,129.6,129.5,129.3,128.5,127.9,127.0,126.8$, 121.0, 111.4, 68.5, 65.2, 55.6, 52.8, 31.9; HRMS (ESI) calcd for $\mathrm{C}_{25} \mathrm{H}_{24} \mathrm{NO}_{4} \mathrm{~S}\left(\mathrm{M}+\mathrm{H}^{+}\right)$434.1421, found 434.1412.

Step 3: The title compound $\mathbf{1 3}$ was prepared as described for 9 using methyl ester 13a (100 mg, $0.23 \mathrm{mmol})$ and LiI (4 equiv) and obtained after flash chromatography (EtOAc/PE, 1:2 [1\% AcOH $]$ ) and subsequent freeze-drying as a white amorphous powder $(67 \mathrm{mg}$, $69 \%$ yield): $R_{f}=0.23($ EtOAc/PE, $1: 1[1 \% \mathrm{AcOH}]) ;{ }^{1} \mathrm{H}$ NMR $(400$ $\left.\mathrm{MHz}, \mathrm{CDCl}_{3}\right) \delta 8.79(\mathrm{br} \mathrm{s}, 1 \mathrm{H}), 7.46-7.39(\mathrm{~m}, 6 \mathrm{H}), 7.35-7.29(\mathrm{~m}$, $3 \mathrm{H}), 7.28-7.21(\mathrm{~m}, 2 \mathrm{H}), 7.02-6.90(\mathrm{~m}, 2 \mathrm{H}), 6.22(\mathrm{br} \mathrm{s}, 1 \mathrm{H}), 5.24$ (app s, $1 \mathrm{H}), 3.76(\mathrm{~s}, 3 \mathrm{H}), 3.47-3.34(\mathrm{~m}, 2 \mathrm{H}) ;{ }^{13} \mathrm{C}$ NMR $(101 \mathrm{MHz}$, $\left.\mathrm{CDCl}_{3}\right) \delta 172.7,172.3,156.5,141.7,140.7,132.8,130.8,129.6,129.4$, 128.7, 128.2, 127.0, 126.6, 121.0, 111.5, 69.1, 65.0, 55.6, 31.4; HRMS (ESI) calcd for $\mathrm{C}_{24} \mathrm{H}_{22} \mathrm{NO}_{4} \mathrm{~S}\left(\mathrm{M}+\mathrm{H}^{+}\right)$420.1264, found 420.1259 . HPLC: $t_{\mathrm{R}}=11.70 \mathrm{~min}, 97.6 \%$. $[\alpha]_{\mathrm{D}}^{20}+22^{\circ}(\mathrm{c} 1.0, \mathrm{DCM})$.

$(2 R, 4 R)-3-\left(2^{\prime}-M e t h o x y b i p h e n y l-4-c a r b o n y l\right)-2-(p y r i d i n-2-y l)-$ thiazolidine-4-carboxylic Acid (14). Step 1: The thiazolidine was prepared as described for 7a using L-cysteine methyl ester hydrochloride $(150 \mathrm{mg}, 0.87 \mathrm{mmol})$ and picolinaldehyde $(187 \mathrm{mg}, 1.75$ mmol). Crude methyl (4R)-2-(pyridin-2-yl)thiazolidine-4-carboxylate (7e) was used without further purification in the next step.

Step 2: Methyl (2R,4R)-3-(2'-Methoxybiphenyl-4-carbonyl)-2-(pyridin-2-yl)thiazolidine-4-carboxylate (14a). Using crude $7 \mathbf{e}(95 \mathrm{mg})$ and 2 '-methoxybiphenyl-4-carbonyl chloride (116 mg, $0.47 \mathrm{mmol}$ ), methyl ester 14a was prepared as described for $\mathbf{8 a}$ and obtained after flash chromatography (EtOAc/PE, 1:2 $\rightarrow 1: 1)$ as a clear viscous oil $\left(77 \mathrm{mg}, 42 \%\right.$ yield): $R_{f}=0.35$ (DCM with $\left.2 \% \mathrm{MeOH}\right) ;{ }^{1} \mathrm{H}$ NMR $\left(400 \mathrm{MHz}, \mathrm{CDCl}_{3}\right) \delta 8.53(\mathrm{~d}, J=4.7 \mathrm{~Hz}, 1 \mathrm{H}), 8.15-7.99(\mathrm{~m}, 1 \mathrm{H})$, 7.80-7.71 (m, 1H), 7.44-7.37 (m, 3H), 7.37-7.27 (m, 2H), 7.26$7.16(\mathrm{~m}, 2 \mathrm{H}), 7.05-6.91(\mathrm{~m}, 2 \mathrm{H}), 6.18(\mathrm{br} \mathrm{s}, 1 \mathrm{H}), 5.25($ app s, $1 \mathrm{H})$, 3.85 (br s, $3 \mathrm{H}), 3.77(\mathrm{~s}, 3 \mathrm{H}), 3.42-3.32(\mathrm{~m}, 2 \mathrm{H}) ;{ }^{13} \mathrm{C}$ NMR $(101$ $\mathrm{MHz}, \mathrm{CDCl}_{3}$ ) 171.1, 170.9, 156.5, 149.6, 141.4, 137.1, 133.4, 130.8, $129.6,129.3,126.9,122.7,121.0,120.6,111.4,69.6,65.2,55.6,52.8$, 32.0; HRMS (ESI) calcd for $\mathrm{C}_{24} \mathrm{H}_{23} \mathrm{~N}_{2} \mathrm{O}_{4} \mathrm{~S}\left(\mathrm{M}+\mathrm{H}^{+}\right)$435.1373, found 435.1395 .

Step 3: The title compound $\mathbf{1 4}$ was prepared as described for $\mathbf{9}$ using methyl ester 14a (75 mg, $0.17 \mathrm{mmol}$ ) and LiI (4 equiv) and obtained after flash chromatography (EtOAc/PE, 2:1 $\rightarrow$ EtOAc $[1 \%$ $\mathrm{AcOH}])$ as brown crystals $(53 \mathrm{mg}, 73 \%$ yield $): R_{f}=0.18(\mathrm{EtOAc} / \mathrm{PE}$, 2:1 $[1 \% \mathrm{AcOH}]) ; \operatorname{dec} 114-120{ }^{\circ} \mathrm{C} ;{ }^{1} \mathrm{H}$ NMR $\left(400 \mathrm{MHz}, \mathrm{CDCl}_{3}\right) \delta$ $8.58(\mathrm{~d}, J=4.8 \mathrm{~Hz}, 1 \mathrm{H}), 7.88$ (br s, $1 \mathrm{H}), 7.61-7.49(\mathrm{~m}, 4 \mathrm{H}), 7.45-$ $7.39(\mathrm{~m}, 1 \mathrm{H}), 7.37-7.30(\mathrm{~m}, 1 \mathrm{H}), 7.29-7.13(\mathrm{~m}, 2 \mathrm{H}), 7.07-6.95$ $(\mathrm{m}, 2 \mathrm{H}), 6.63(\mathrm{br} \mathrm{s}, 1 \mathrm{H}), 5.14($ app s, $1 \mathrm{H}), 3.79(\mathrm{~s}, 3 \mathrm{H}), 3.58-3.41$ $(\mathrm{m}, 2 \mathrm{H}) ;{ }^{13} \mathrm{C}$ NMR $\left(101 \mathrm{MHz}, \mathrm{CDCl}_{3}\right) \delta 173.4,170.1,157.4,156.5$, $147.4,141.7,139.6,133.2,130.8,129.9,129.5,129.3,126.7,124.3$ 123.3, 121.0, 111.4, 67.6, 65.9, 55.6, 37.5; HRMS (ESI) calcd for $\mathrm{C}_{23} \mathrm{H}_{20} \mathrm{~N}_{2} \mathrm{NaO}_{4} \mathrm{~S}\left(\mathrm{M}+\mathrm{Na}^{+}\right)$443.1036, found 443.1056. HPLC: $t_{\mathrm{R}}=$ $10.25 \min , 99.5 \%$. $[\alpha]^{20}{ }_{\mathrm{D}}+59^{\circ}$ (c 1.0, DCM).

(2R,4R)-2-(Furan-2-yl)-3-(2'-methoxybiphenyl-4-carbonyl)thiazolidine-4-carboxylic Acid (15). Step 1: Methyl (2R,4R)-2(Furan-2-yl)-3-thiazolidine-4-carboxylate (7j). The thiazolidine was 
prepared as described for $7 \mathbf{a}$ using L-cysteine methyl ester hydrochloride $(150 \mathrm{mg}, 0.87 \mathrm{mmol})$ and 2 -furancarboxaldehyde $(168 \mathrm{mg}$, $1.75 \mathrm{mmol}$ ). Crude methyl (4R)-2-(furan-2-yl)thiazolidine-4-carboxylate $(7 \mathbf{j})$ was used without further purification in the next step.

Step 2: Methyl (2R,4R)-2-(Furan-2-yl)-3-(2'-methoxybiphenyl-4carbonyl)thiazolidine-4-carboxylate (15a). Using crude $7 \mathbf{j}(91 \mathrm{mg})$ and $2^{\prime}$-methoxybiphenyl-4-carbonyl chloride $(116 \mathrm{mg}, 0.47 \mathrm{mmol})$, the title compound 15a was prepared as described for $\mathbf{8 a}$ and obtained after flash chromatography (EtOAc/PE, 1:3) as a brown viscous oil $(46 \mathrm{mg}, 25 \%$ yield $): R_{f}=0.21(\mathrm{EtOAc} / \mathrm{PE}, 1: 3) ;{ }^{1} \mathrm{H}$ NMR $\left(400 \mathrm{MHz}, \mathrm{CDCl}_{3}\right) \delta 7.59-7.48(\mathrm{~m}, 4 \mathrm{H}), 7.42-7.39(\mathrm{~m}, 1 \mathrm{H}), 7.36-$ $7.31(\mathrm{~m}, 1 \mathrm{H}), 7.29(\mathrm{dd}, J=7.5,1.7 \mathrm{~Hz}, 1 \mathrm{H}), 7.05-7.00(\mathrm{~m}, 2 \mathrm{H})$, $6.87-6.78(\mathrm{~m}, 1 \mathrm{H}), 6.37(\mathrm{dd}, J=3.1,1.8 \mathrm{~Hz}, 1 \mathrm{H}), 6.14($ br s, $1 \mathrm{H})$, 5.25-5.08 (m, 1H), $3.80(\mathrm{~s}, 6 \mathrm{H}), 3.48-3.34(\mathrm{~m}, 2 \mathrm{H}) ;{ }^{13} \mathrm{C}$ NMR $\left(101 \mathrm{MHz}, \mathrm{CDCl}_{3}\right) \delta 170.5,156.5,152.4,142.8,141.5,133.2,130.9$, 129.7, 129.4, 127.2, 121.1, 111.5, 110.7, 109.4, 63.6, 62.7, 55.7, 52.9, 32.4; HRMS (ESI) calcd for $\mathrm{C}_{23} \mathrm{H}_{22} \mathrm{NO}_{5} \mathrm{~S}\left(\mathrm{M}+\mathrm{H}^{+}\right) 424.1213$, found 424.1222.

Step 3: The title compound $\mathbf{1 5}$ was prepared as described for 9 using methyl ester $15 \mathrm{a}$ (43 $\mathrm{mg}, 0.10 \mathrm{mmol}$ ) and LiI (4 equiv) and obtained after flash chromatography (EtOAc/PE, 1:2 [2\% AcOH $]$ ) and subsequent freeze-drying as a whitish amorphous powder $(33 \mathrm{mg}$, $80 \%$ yield $): R_{f}=0.18(\mathrm{EtOAc} / \mathrm{PE}, 1: 2[2 \% \mathrm{AcOH}]) ;{ }^{1} \mathrm{H}$ NMR $(400$ $\left.\mathrm{MHz}, \mathrm{CDCl}_{3}\right) \delta 7.55-7.49(\mathrm{~m}, 4 \mathrm{H}), 7.38(\mathrm{~d}, J=1.3 \mathrm{~Hz}, 1 \mathrm{H}), 7.36-$ $7.30(\mathrm{~m}, 1 \mathrm{H}), 7.28-7.24(\mathrm{~m}, 1 \mathrm{H}), 7.06-6.93(\mathrm{~m}, 2 \mathrm{H}), 6.70(\mathrm{~d}, J=$ $2.8 \mathrm{~Hz}, 1 \mathrm{H}), 6.36-6.32(\mathrm{~m}, 1 \mathrm{H}), 6.15(\mathrm{br} \mathrm{s}, 1 \mathrm{H}), 5.22-5.12(\mathrm{~m}, 1 \mathrm{H})$, $3.78(\mathrm{~s}, 3 \mathrm{H}), 3.53-3.36(\mathrm{~m}, 2 \mathrm{H}) ;{ }^{13} \mathrm{C}$ NMR $\left(101 \mathrm{MHz}, \mathrm{CDCl}_{3}\right) \delta$ $172.8,171.7,156.5,151.8,143.0,141.9,132.7,130.9,129.8,129.47$, $129.45,127.2,121.1,111.5,110.9,109.3,63.9,63.0,55.7,31.9$; HRMS (ESI) calcd for $\mathrm{C}_{22} \mathrm{H}_{19} \mathrm{NNaO}_{5} \mathrm{~S}\left(\mathrm{M}+\mathrm{Na}^{+}\right)$432.0876, found 432.0877. HPLC: $t_{\mathrm{R}}=11.84 \mathrm{~min}, 98.8 \%$. $[\alpha]^{20}{ }_{\mathrm{D}}-1^{\circ}(c 1.0, \mathrm{DCM})$.

(2R,4R)-2-(tert-Butyl)-3-(2'-methoxybiphenyl-4-carbonyl)thiazolidine-4-carboxylic Acid (16). Step 1: The methyl ester of the title compound (16a) was prepared as described for $8 \mathrm{a}$ using $7 \mathrm{~d}$ (62 $\mathrm{mg}, 0.31 \mathrm{mmol}$ ) and 2'-methoxybiphenyl-4-carbonyl chloride (84 $\mathrm{mg}, 0.34 \mathrm{mmol}$ ) and obtained after flash chromatography (DCM/PE, $1: 1 \rightarrow \mathrm{DCM} \rightarrow \mathrm{DCM} /$ EtOAc $1: 1)$ as a clear oil $(63 \mathrm{mg}, 50 \%$ yield $):$ $R_{f}=0.34(\mathrm{EtOAc} / \mathrm{PE}, 1: 3) ;{ }^{1} \mathrm{H}$ NMR $\left(400 \mathrm{MHz}, \mathrm{CDCl}_{3}\right) \delta 7.58-$ $7.55(\mathrm{~m}, 4 \mathrm{H}), 7.38-7.28(\mathrm{~m}, 2 \mathrm{H}), 7.06-6.96(\mathrm{~m}, 2 \mathrm{H}), 5.75(\mathrm{br} \mathrm{s}$, $1 \mathrm{H}), 4.93($ app s, $1 \mathrm{H}), 3.80(\mathrm{~s}, 3 \mathrm{H}), 3.73(\mathrm{~s}, 3 \mathrm{H}), 3.36(\mathrm{dd}, J=11.6$, $5.9 \mathrm{~Hz}, 1 \mathrm{H}), 3.22-3.11(\mathrm{~m}, 1 \mathrm{H}), 1.04(\mathrm{~s}, 9 \mathrm{H}) ;{ }^{13} \mathrm{C}$ NMR $(101 \mathrm{MHz}$, $\left.\mathrm{CDCl}_{3}\right) \delta 173.1,171.1,156.5,140.6,135.0,130.8,129.7,129.3,126.8$, 121.1, 111.5, 73.5, 66.0, 55.7, 52.6, 38.8, 33.7, 27.2; HRMS (ESI) calcd for $\mathrm{C}_{23} \mathrm{H}_{27} \mathrm{NNaO}_{4} \mathrm{~S}\left(\mathrm{M}+\mathrm{Na}^{+}\right)$436.1530, found 436.1672.

Step 2: The title compound $\mathbf{1 6}$ was prepared as described for $\mathbf{9}$ using methyl ester 16a (48 mg, $0.12 \mathrm{mmol})$ and LiI (4 equiv) and obtained after flash chromatography (EtOAc/PE, 1:3 [1\% AcOH] $)$ to give a cloudy oil $(28 \mathrm{mg}, 60 \%$ yield $): R_{f}=0.23(\mathrm{EtOAc} / \mathrm{PE}, 1: 3[1 \%$ $\mathrm{AcOH}]) ;{ }^{1} \mathrm{H}$ NMR $\left(400 \mathrm{MHz}, \mathrm{CDCl}_{3}\right) \delta 7.67-7.53(\mathrm{~m}, 4 \mathrm{H}), 7.39-$ $7.30(\mathrm{~m}, 2 \mathrm{H}), 7.08-6.98(\mathrm{~m}, 2 \mathrm{H}), 5.47($ br s, $1 \mathrm{H}), 5.15-5.00(\mathrm{~m}$, $1 \mathrm{H}), 3.82(\mathrm{~s}, 3 \mathrm{H}), 4.00-3.12(\mathrm{~m}, 2 \mathrm{H}), 0.88(\mathrm{~s}, 9 \mathrm{H}) ;{ }^{13} \mathrm{C}$ NMR $(101$ $\left.\mathrm{MHz}, \mathrm{CDCl}_{3}\right) \delta 173.8,170.2,155.6,140.8,132.0,129.9,129.0,128.6$, $128.3,126.2,120.1,110.6,74.1,64.2,54.7,38.3,31.1,26.1$; HRMS (ESI) calcd for $\mathrm{C}_{22} \mathrm{H}_{25} \mathrm{NNaO}_{4} \mathrm{~S}\left(\mathrm{M}+\mathrm{Na}^{+}\right)$422.1397, found 422.1393. HPLC: $t_{\mathrm{R}}=12.64 \mathrm{~min}, 99.8 \%$. $[\alpha]^{20}{ }_{\mathrm{D}}-100^{\circ}(c 0.5, \mathrm{DCM})$.

(2R,4R)-3-Benzoyl-2-(2-chlorophenyl)thiazolidine-4-carboxylic Acid (18). Step 1: The methyl ester of the title compound (18a) was prepared as described for 8 a using $7 \mathrm{a}(156 \mathrm{mg}, 0.60 \mathrm{mmol})$ and benzoyl chloride $(79 \mu \mathrm{L}, 0.68 \mathrm{mmol})$ and obtained after flash chromatography (EtOAc/PE, 1:3) as a clear oil (125 mg, 57\% yield): $R_{f}=0.18(\mathrm{EtOAc} / \mathrm{PE}, 1: 3) ;{ }^{1} \mathrm{H} \mathrm{NMR}\left(400 \mathrm{MHz}, \mathrm{CDCl}_{3}\right) \delta 8.36$ (d, $J$ $=7.0 \mathrm{~Hz}, 1 \mathrm{H}), 7.45-7.13(\mathrm{~m}, 8 \mathrm{H}), 6.20(\mathrm{br} \mathrm{s}, 1 \mathrm{H}), 5.09($ app s, $1 \mathrm{H})$, $3.86(\mathrm{~s}, 3 \mathrm{H}), 3.42-3.30(\mathrm{~m}, 1 \mathrm{H}), 3.27-3.15(\mathrm{~m}, 1 \mathrm{H}) ;{ }^{13} \mathrm{C}$ NMR $\left(101 \mathrm{MHz}, \mathrm{CDCl}_{3}\right) \delta 171.0,170.6,139.4,134.9,131.6,130.8,129.8$, 129.1, 128.3, 127.7, 127.3, 126.9, 65.9, 65.7, 52.8, 31.3; HRMS (ESI) calcd for $\mathrm{C}_{18} \mathrm{H}_{16} \mathrm{ClNNaO}_{3} \mathrm{~S}\left(\mathrm{M}+\mathrm{Na}^{+}\right)$384.0432, found 384.0447.

Step 2: The title compound $\mathbf{1 8}$ was prepared as described for 9 using methyl ester 18a (114 mg, $0.32 \mathrm{mmol})$ and LiI (4 equiv) and obtained after flash chromatography (EtOAc $[1 \% \mathrm{AcOH}]$ ) and subsequent freeze-drying as white crystals $(59 \mathrm{mg}, 53 \%$ yield $): R_{f}=$
0.18 (EtOAc [1\% AcOH]); mp 166-172 ${ }^{\circ} \mathrm{C} ;{ }^{1} \mathrm{H}$ NMR $(400 \mathrm{MHz}$, $\left.\mathrm{CDCl}_{3}\right) \delta 11.39($ br s, $1 \mathrm{H}), 8.14(\mathrm{~d}, J=7.3 \mathrm{~Hz}, 1 \mathrm{H}), 7.43-7.30(\mathrm{~m}$, $4 \mathrm{H}), 7.30-7.18(\mathrm{~m}, 4 \mathrm{H}), 6.22(\mathrm{br} \mathrm{s}, 1 \mathrm{H}), 5.29-5.08(\mathrm{~m}, 1 \mathrm{H}), 3.48-$ $3.39(\mathrm{~m}, 1 \mathrm{H}), 3.38-3.28(\mathrm{~m}, 1 \mathrm{H}) ;{ }^{13} \mathrm{C} \mathrm{NMR}\left(101 \mathrm{MHz}, \mathrm{CDCl}_{3}\right) \delta$ 173.2, 172.2, 138.9, 134.5, 131.6, 131.2, 129.9, 129.3, 128.4, 127.6, 127.5, 127.1, 66.2, 66.0, 31.1; HRMS (ESI) calcd for $\mathrm{C}_{17} \mathrm{H}_{14} \mathrm{ClNNaO}_{3} \mathrm{~S}\left(\mathrm{M}+\mathrm{Na}^{+}\right)$370.0275, found 370.0285. HPLC: $t_{\mathrm{R}}$ $=11.73 \mathrm{~min}, 95.2 \%$. $[\alpha]_{\mathrm{D}}^{20}+30^{\circ}$ (c 1.0, DCM $)$.

(2R,4R)-3-([1,1'-Biphenyl]-4-carbonyl)-2-(2-chlorophenyl)thiazolidine-4-carboxylic Acid (19). Step 1: To a vial charged with 8 a $(99 \mathrm{mg}, 0.20 \mathrm{mmol})$ and phenylboronic acid $(25 \mathrm{mg}, 0.20 \mathrm{mmol})$ were added toluene $(1.3 \mathrm{~mL})$ and $\mathrm{MeOH}(0.7 \mathrm{~mL})$. The reaction mixture was purged with argon $(\times 5)$, and to it were added $\mathrm{Pd}\left(\mathrm{PPh}_{3}\right)_{4}$ $(12 \mathrm{mg}, 11 \mu \mathrm{mol})$ and aqueous $\mathrm{Na}_{2} \mathrm{CO}_{3}(170 \mu \mathrm{L}, 4.0 \mathrm{M})$. The reaction was capped and stirred at $80^{\circ} \mathrm{C}$ overnight under argon, then treated with water and extracted with EtOAc $(\times 3)$, washed with brine, dried over $\mathrm{Na}_{2} \mathrm{SO}_{4}$, and concentrated in vacuo, and the methyl ester of the title compound (19a) was obtained after flash chromatography $\left(\right.$ EtOAc/PE, 1:3) as a viscous oil $\left(58 \mathrm{mg}, 65 \%\right.$ yield): $R_{f}=0.24$ (EtOAc/PE, 1:3); ${ }^{1} \mathrm{H}$ NMR $\left(400 \mathrm{MHz}, \mathrm{CDCl}_{3}\right) \delta 8.40(\mathrm{~d}, J=7.0 \mathrm{~Hz}$, $1 \mathrm{H}), 7.56-7.51(\mathrm{~m}, 2 \mathrm{H}), 7.47-7.32(\mathrm{~m}, 9 \mathrm{H}), 7.31-7.25(\mathrm{~m}, 1 \mathrm{H})$, $6.30(\mathrm{br} \mathrm{s}, 1 \mathrm{H}), 5.21-5.09(\mathrm{~m}, 1 \mathrm{H}), 3.90(\mathrm{~s}, 3 \mathrm{H}), 3.43-3.36(\mathrm{~m}$, $1 \mathrm{H}), 3.28-3.18(\mathrm{~m}, 1 \mathrm{H}) ;{ }^{13} \mathrm{C}$ NMR $\left(101 \mathrm{MHz}, \mathrm{CDCl}_{3}\right) \delta 170.9$, $170.8,143.8,140.0,133.5,131.7,130.0,129.2,129.0,128.1,127.9$, 127.8, 127.4, 127.2, 127.0, 66.1, 65.9, 52.9, 31.3; HRMS (ESI) calcd for $\mathrm{C}_{24} \mathrm{H}_{20} \mathrm{ClNNaO}_{3} \mathrm{~S}\left(\mathrm{M}+\mathrm{Na}^{+}\right) 460.0745$, found 460.0725 .

Step 2: The title compound 19 was prepared as described for 9 using methyl ester 19a (57 mg, $0.13 \mathrm{mmol}$ ) and Lil (4 equiv) and obtained after flash chromatography (EtOAc/PE, 1:1 [2\% AcOH]) and subsequent freeze-drying as a white amorphous powder $(41 \mathrm{mg}$, $75 \%$ yield $): R_{f}=0.16(\mathrm{EtOAc} / \mathrm{PE}, 1: 1[2 \% \mathrm{AcOH}]) ;{ }^{1} \mathrm{H}$ NMR $(400$ $\left.\mathrm{MHz}, \mathrm{CDCl}_{3}\right) \delta 8.08(\mathrm{~d}, J=4.6 \mathrm{~Hz}, 1 \mathrm{H}), 7.74-7.63(\mathrm{~m}, 1 \mathrm{H}), 7.54-$ $7.50(\mathrm{~m}, 2 \mathrm{H}), 7.50-7.39(\mathrm{~m}, 4 \mathrm{H}), 7.39-7.32(\mathrm{~m}, 4 \mathrm{H}), 7.30-7.20$ $(\mathrm{m}, 1 \mathrm{H}), 6.33$ (br s, $1 \mathrm{H}), 5.24$ (app s, $1 \mathrm{H}), 3.49-3.35(\mathrm{~m}, 2 \mathrm{H}) ;{ }^{13} \mathrm{C}$ NMR $\left(101 \mathrm{MHz}, \mathrm{CDCl}_{3}\right) \delta 172.6,172.3,144.2,139.9,138.9,133.0$, $131.7,130.1,129.4,129.0,128.2,127.8,127.6,127.3,127.1,66.5$, 66.1, 31.0; HRMS (ESI) calcd for $\mathrm{C}_{23} \mathrm{H}_{19} \mathrm{ClNO}_{3} \mathrm{~S}\left(\mathrm{M}+\mathrm{H}^{+}\right)$ 424.0769, found 424.0783. HPLC: $t_{\mathrm{R}}=12.33 \mathrm{~min}, 97.8 \%$. $[\alpha]_{\mathrm{D}}^{20}$ $+39^{\circ}$ (c 1.0, DCM).

(2R,4R)-3-([1,1'-Biphenyl]-3-carbonyl)-2-(2-chlorophenyl)thiazolidine-4-carboxylic Acid (20). Step 1: The methyl ester of the title compound (20a) was prepared as described for 19a using $8 \mathbf{b}$ ( $84 \mathrm{mg}, 0.172 \mathrm{mmol}$ ) and phenylboronic acid $(21 \mathrm{mg}, 0.172 \mathrm{mmol})$ and obtained after flash chromatography (EtOAc/PE, 2:3) as a clear viscous oil (45 mg, 63\% yield): $R_{f}=0.24(\mathrm{EtOAc} / \mathrm{PE}, 2: 3) ;{ }^{1} \mathrm{H}$ NMR $\left(400 \mathrm{MHz}, \mathrm{CDCl}_{3}\right) \delta 8.43(\mathrm{~d}, J=6.6 \mathrm{~Hz}, 1 \mathrm{H}), 7.65-7.52(\mathrm{~m}, 1 \mathrm{H})$, 7.49-7.24 (m, 9H), 7.18-6.99 (m, 2H), $6.26($ br s, $1 \mathrm{H}), 5.21-5.07$ $(\mathrm{m}, 1 \mathrm{H}), 3.90(\mathrm{~s}, 3 \mathrm{H}), 3.47-3.33(\mathrm{~m}, 1 \mathrm{H}), 3.30-3.14(\mathrm{~m}, 1 \mathrm{H}) ;{ }^{13} \mathrm{C}$ NMR $\left(101 \mathrm{MHz}, \mathrm{CDCl}_{3}\right) \delta 171.3,170.7,141.0,139.8,135.3,131.8$, $130.0,129.5,129.2,129.1,128.8,128.0,127.7,127.6,126.9,126.2$, 125.7, 66.0, 52.9, 31.3; HRMS (ESI) calcd for $\mathrm{C}_{24} \mathrm{H}_{20} \mathrm{ClNNaO}_{3} \mathrm{~S}$ (M $+\mathrm{Na}^{+}$) 460.0745, found 460.0742 .

Step 2: The title compound $\mathbf{2 0}$ was prepared as described for 9 using methyl ester 20a $(41 \mathrm{mg}, 94 \mu \mathrm{mol})$ and LiI (4 equiv) and obtained after flash chromatography (EtOAc/PE, 1:1 [1\% AcOH] and subsequent freeze-drying as a white amorphous powder $(13 \mathrm{mg}$, $33 \%$ yield $): R_{f}=0.24(\mathrm{EtOAc} / \mathrm{PE}, 1: 1[1 \% \mathrm{AcOH}]) ;{ }^{1} \mathrm{H}$ NMR $(400$ $\left.\mathrm{MHz}, \mathrm{CDCl}_{3}\right) \delta 8.20-8.05(\mathrm{~m}, 1 \mathrm{H}), 7.60(\mathrm{~d}, J=5.6 \mathrm{~Hz}, 1 \mathrm{H}), 7.46-$ $7.23(\mathrm{~m}, 9 \mathrm{H}), 7.18-7.00(\mathrm{~m}, 2 \mathrm{H}), 6.26$ (br s, 1H), 5.20 (app s, $1 \mathrm{H})$, 3.49-3.26 (m, 2H); ${ }^{13} \mathrm{C}$ NMR (101 MHz, $\left.\mathrm{CDCl}_{3}\right) \delta 172.6(\mathrm{br})$, 141.2 , 139.7, 139.2, 134.9, 131.8, 130.1, 129.8, 129.3, 129.2, 128.9, $127.8,126.9,126.2,125.8,66.7,66.1,31.0$; HRMS (ESI) calcd for $\mathrm{C}_{23} \mathrm{H}_{18} \mathrm{ClNNaO}_{3} \mathrm{~S}\left(\mathrm{M}+\mathrm{Na}^{+}\right) 446.0588$, found 446.0578. HPLC: $t_{\mathrm{R}}=$ $12.94 \mathrm{~min}, 97.3 \%$. $[\alpha]_{\mathrm{D}}^{20}-2^{\circ}$ (c 0.1, DCM).

$(2 R, 4 R)-2-(2-C h l o r o p h e n y l)-3-\left(2^{\prime}\right.$-fluoro-3'-methoxybiphenyl-4-carbonyl)thiazolidine-4-carboxylic Acid (21). Step 1: The methyl ester of the title compound (21a) was prepared as described for 19a using 8a (101 $\mathrm{mg}, 0.21 \mathrm{mmol}$ ) and (2-fluoro-3methoxyphenyl)boronic acid (39 mg, $0.23 \mathrm{mmol}$ ) and obtained after flash chromatography (EtOAc/PE, 1:4) as a clear oil $(77 \mathrm{mg}$, 
$76 \%$ yield): $R_{\mathrm{f}}=0.25$ (EtOAc/PE, 1:4); ${ }^{1} \mathrm{H} \mathrm{NMR}\left(400 \mathrm{MHz}, \mathrm{CDCl}_{3}\right.$ ) $\delta 8.37(\mathrm{~d}, J=6.7 \mathrm{~Hz}, 1 \mathrm{H}), 7.45-7.23(\mathrm{~m}, 7 \mathrm{H}), 7.15-7.06(\mathrm{~m}, 1 \mathrm{H})$, 6.99-6.87 (m, 2H), 6.28 (br s, 1H), $5.13($ app s, $1 \mathrm{H}), 3.90(\mathrm{~s}, 6 \mathrm{H})$, 3.45-3.32 (m, $1 \mathrm{H}), 3.30-3.15(\mathrm{~m}, 1 \mathrm{H})$; ${ }^{13} \mathrm{C}$ NMR $(101 \mathrm{MHz}$, $\left.\mathrm{CDCl}_{3}\right) \delta 170.8,170.7,150.9,148.4(\mathrm{~d}, J=11.5 \mathrm{~Hz}), 139.4,138.3$, $134.0,131.7,129.9,129.2,129.0,128.9,128.8,127.9,127.4,127.2$, $124.1(\mathrm{~d}, J=4.3 \mathrm{~Hz}), 121.8,112.9,66.0,65.8,56.5,52.9,31.3$; HRMS (ESI) calcd for $\mathrm{C}_{25} \mathrm{H}_{21} \mathrm{ClFNNaO}_{4} \mathrm{~S}\left(\mathrm{M}+\mathrm{Na}^{+}\right)$508.0756, found 508.0767.

Step 2: The title compound $\mathbf{2 1}$ was prepared as described for 9 using methyl ester $21 \mathrm{a}(78 \mathrm{mg}, 0.16 \mathrm{mmol}$ ) and LiI (4 equiv) and obtained after flash chromatography (EtOAc/PE, 1:2 [1\% AcOH] and subsequent freeze-drying as a white amorphous powder $(28 \mathrm{mg}$, $37 \%$ yield $): R_{f}=0.14(\mathrm{EtOAc} / \mathrm{PE}, 1: 2[1 \% \mathrm{AcOH}]) ;{ }^{1} \mathrm{H}$ NMR $(400$ $\left.\mathrm{MHz}, \mathrm{CDCl}_{3}\right) \delta 8.04(\mathrm{~d}, J=5.9 \mathrm{~Hz}, 1 \mathrm{H}), 7.44-7.30(\mathrm{~m}, 6 \mathrm{H}), 7.27-$ $7.21(\mathrm{~m}, 1 \mathrm{H}), 7.10(\mathrm{td}, J=8.1,1.2 \mathrm{~Hz}, 1 \mathrm{H}), 6.96(\mathrm{td}, J=8.1,1.4 \mathrm{~Hz}$, $1 \mathrm{H}), 6.93-6.89(\mathrm{~m}, 1 \mathrm{H}), 6.32(\mathrm{br} \mathrm{s}, 1 \mathrm{H}), 5.28-5.15(\mathrm{~m}, 1 \mathrm{H}), 3.91$ (s, 3H), 3.50-3.32 (m, 2H); ${ }^{13} \mathrm{C}$ NMR $\left(101 \mathrm{MHz}, \mathrm{CDCl}_{3}\right) \delta 171.6$, $171.2,150.0,147.4$ (d, $J=11.8 \mathrm{~Hz}), 137.7,132.5,130.7,129.1,128.4$, $128.2,127.8,127.7,126.6,126.3,123.2(\mathrm{~d}, J=3.6 \mathrm{~Hz}), 120.9,112.1$, 65.4, 65.0, 55.6, 30.0; HRMS (ESI) calcd for $\mathrm{C}_{24} \mathrm{H}_{19} \mathrm{ClFNNaO}_{4} \mathrm{~S}$ (M $+\mathrm{Na}^{+}$) 494.0600, found 494.0596. HPLC: $t_{\mathrm{R}}=12.60 \mathrm{~min}, 99.4 \%$. $[\alpha]_{\mathrm{D}}^{20}+32^{\circ}(c 0.4, \mathrm{DCM})$.

$(2 R, 4 R)-2-(2-C h l o r o p h e n y l)-3-\left(4^{\prime}\right.$-methoxybiphenyl-4carbonyl)thiazolidine-4-carboxylic Acid (22). Step 1: The methyl ester of the title compound (22a) was prepared as described for 19a using 8a $(96,0.20 \mathrm{mmol})$ and (4-methoxyphenyl)boronic acid (31 $\mathrm{mg}, 0.21 \mathrm{mmol}$ ) and obtained after flash chromatography (EtOAc/ $\mathrm{PE}, 1: 3)$ as a clear viscous oil $\left(42 \mathrm{mg}, 46 \%\right.$ yield): $R_{f}=0.26$ (EtOAc/ PE, 1:3); ${ }^{1} \mathrm{H}$ NMR $\left(400 \mathrm{MHz}, \mathrm{CDCl}_{3}\right) \delta 8.38(\mathrm{~d}, J=7.2 \mathrm{~Hz}, 1 \mathrm{H})$, $7.48(\mathrm{~d}, J=8.6 \mathrm{~Hz}, 2 \mathrm{H}), 7.42-7.38(\mathrm{~m}, 3 \mathrm{H}), 7.38-7.27(\mathrm{~m}, 4 \mathrm{H})$, 6.98-6.92 (m, 2H), 6.29 (br s, $1 \mathrm{H}), 5.18-5.07(\mathrm{~m}, 1 \mathrm{H}), 3.89(\mathrm{~s}$, $3 \mathrm{H}), 3.83(\mathrm{~s}, 3 \mathrm{H}), 3.43-3.35(\mathrm{~m}, 1 \mathrm{H}), 3.28-3.18(\mathrm{~m}, 1 \mathrm{H}) ;{ }^{13} \mathrm{C}$ NMR $\left(101 \mathrm{MHz}, \mathrm{CDCl}_{3}\right) \delta 171.1,170.8,159.8,143.4,139.6,132.8$, $132.5,131.7,130.0,129.2,128.3,127.8,127.4,126.4,114.4,66.1$, 66.0, 55.5, 52.9, 31.3; HRMS (ESI) calcd for $\mathrm{C}_{25} \mathrm{H}_{22} \mathrm{ClNNaO}_{4} \mathrm{~S}(\mathrm{M}+$ $\left.\mathrm{Na}^{+}\right)$490.0850, found 490.0861 .

Step 2: The title compound 22 was prepared as described for 9 using methyl ester 22a (41 mg, $87 \mu \mathrm{mol}$ ) and LiI (4 equiv) and obtained after flash chromatography (EtOAc/PE, 1:2 [2\% AcOH $]$ ) and subsequent freeze-drying as a white amorphous powder $(29 \mathrm{mg}$, $73 \%$ yield $): R_{f}=0.32(\mathrm{EtOAc} / \mathrm{PE}, 1: 2[2 \% \mathrm{AcOH}]) ;{ }^{1} \mathrm{H}$ NMR $(400$ $\left.\mathrm{MHz}, \mathrm{CDCl}_{3}\right) \delta 8.09(\mathrm{~d}, J=5.8 \mathrm{~Hz}, 1 \mathrm{H}), 7.46-7.41(\mathrm{~m}, 2 \mathrm{H}), 7.39-$ $7.29(\mathrm{~m}, 6 \mathrm{H}), 7.26-7.21(\mathrm{~m}, 1 \mathrm{H}), 6.96-6.89(\mathrm{~m}, 2 \mathrm{H}), 6.30(\mathrm{br} \mathrm{s}$, $1 \mathrm{H}), 5.26-5.13(\mathrm{~m}, 1 \mathrm{H}), 3.83(\mathrm{~s}, 3 \mathrm{H}), 3.44-3.31(\mathrm{~m}, 2 \mathrm{H}) ;{ }^{13} \mathrm{C}$ NMR $\left(101 \mathrm{MHz}, \mathrm{CDCl}_{3}\right) \delta 172.8,172.4,159.9,143.7,139.0,132.3$, 131.6, 130.1, 129.4, 128.4, 127.9, 127.6, 126.5, 114.5, 66.6, 66.3, 55.5, 30.9; HRMS (ESI) calcd for $\mathrm{C}_{24} \mathrm{H}_{20} \mathrm{ClNNaO}_{4} \mathrm{~S}\left(\mathrm{M}+\mathrm{Na}^{+}\right) 476.0694$, found 476.0693. HPLC: $t_{\mathrm{R}}=12.79 \mathrm{~min}, 100 \%$. $[\alpha]_{\mathrm{D}}^{20}+47^{\circ}(c 0.4$, DCM).

$(2 R, 4 R)-3-\left(4^{\prime}\right.$ - A cetylbiphenyl-4-carbonyl)-2-(2chlorophenyl)thiazolidine-4-carboxylic Acid (23). Step 1: The methyl ester of the title compound (23a) was prepared as described for 19a using $8 \mathbf{a}(88 \mathrm{mg}, 0.18 \mathrm{mmol})$ and (4-acetylphenyl)boronic acid $(32 \mathrm{mg}, 0.19 \mathrm{mmol})$ and obtained after flash chromatography (EtOAc/PE, 1:2) as a white solid $\left(42 \mathrm{mg}, 48 \%\right.$ yield): $R_{f}=0.22$ (EtOAc/PE, 1:2); ${ }^{1} \mathrm{H}$ NMR $\left(400 \mathrm{MHz}, \mathrm{CDCl}_{3}\right) \delta 8.39(\mathrm{~d}, J=6.4 \mathrm{~Hz}$, $1 \mathrm{H}), 8.03-7.98(\mathrm{~m}, 2 \mathrm{H}), 7.62(\mathrm{~d}, J=8.2 \mathrm{~Hz}, 2 \mathrm{H}), 7.51-7.45(\mathrm{~m}$, $2 \mathrm{H}), 7.44-7.38(\mathrm{~m}, 2 \mathrm{H}), 7.35(\mathrm{dd}, J=7.9,1.2 \mathrm{~Hz}, 2 \mathrm{H}), 7.29(\mathrm{~d}, J=$ $7.2 \mathrm{~Hz}, 1 \mathrm{H}), 6.26(\mathrm{br} \mathrm{s}, 1 \mathrm{H}), 5.20-5.06(\mathrm{~m}, 1 \mathrm{H}), 3.90(\mathrm{~s}, 3 \mathrm{H}), 3.45-$ $3.36(\mathrm{~m}, 1 \mathrm{H}), 3.29-3.18(\mathrm{~m}, 1 \mathrm{H}), 2.62(\mathrm{~s}, 3 \mathrm{H}) ;{ }^{13} \mathrm{C} \mathrm{NMR}(101$ $\left.\mathrm{MHz}, \mathrm{CDCl}_{3}\right) \delta 197.7,170.7,144.5,142.4,139.4,136.5,134.4,131.7$, 130.0, 129.3, 129.1, 127.9, 127.5, 127.4, 127.2, 66.1, 65.9, 53.0, 31.3, 26.8; HRMS (ESI) calcd for $\mathrm{C}_{26} \mathrm{H}_{23} \mathrm{ClNO}_{4} \mathrm{~S}\left(\mathrm{M}+\mathrm{H}^{+}\right)$480.1031, found 480.1054 .

Step 2: The title compound 23 was prepared as described for 9 using methyl ester 23a (42 mg, $86 \mu \mathrm{mol}$ ) and LiI (4 equiv) and obtained after flash chromatography (EtOAc/PE, 1:1 [2\% AcOH]) and subsequent freeze-drying as a white solid ( $31 \mathrm{mg}, 78 \%$ yield $): R_{f}=$ 0.17 (EtOAc/PE, 1:1 [2\% AcOH]); mp 202-208 ${ }^{\circ} \mathrm{C} ;{ }^{1} \mathrm{H}$ NMR (400
$\left.\mathrm{MHz}, \mathrm{CDCl}_{3}\right) \delta 8.14(\mathrm{~d}, J=5.0 \mathrm{~Hz}, 1 \mathrm{H}), 7.97(\mathrm{~d}, J=8.3 \mathrm{~Hz}, 2 \mathrm{H})$ $7.55(\mathrm{~d}, J=7.9 \mathrm{~Hz}, 2 \mathrm{H}), 7.47-7.39(\mathrm{~m}, 2 \mathrm{H}), 7.39-7.29(\mathrm{~m}, 4 \mathrm{H})$, 7.29-7.21 (m, 1H), 6.26 (br s, $1 \mathrm{H}), 5.26-5.11(\mathrm{~m}, 1 \mathrm{H}), 3.48-3.31$ $(\mathrm{m}, 2 \mathrm{H}), 2.62(\mathrm{~s}, 3 \mathrm{H}) ;{ }^{13} \mathrm{C}$ NMR $\left(101 \mathrm{MHz}, \mathrm{CDCl}_{3}\right) \delta 197.8,172.7$, $172.0,144.3$, 142.7, 139.0, 136.6, 134.0, 131.6, 130.1, 129.4, 129.1, 128.0, 127.6, 127.4, 127.3, 66.5, 31.0, 26.8; HRMS (ESI) calcd for $\mathrm{C}_{25} \mathrm{H}_{20} \mathrm{ClNNaO}_{4} \mathrm{~S}\left(\mathrm{M}+\mathrm{Na}^{+}\right)$488.0694, found 488.0695. HPLC: $t_{\mathrm{R}}=$ $12.18 \mathrm{~min}, 95.7 \%$. $[\alpha]^{20}{ }_{\mathrm{D}}+64^{\circ}$ (c 0.4, DCM).

$(2 R, 4 R)-2-(2-C h l o r o p h e n y l)-3-\left(4^{\prime}\right.$-cyanobiphenyl-4carbonyl)thiazolidine-4-carboxylic Acid (24). Step 1: The methyl ester of the title compound (24a) was prepared as described for 19a using $8 \mathrm{a}(81 \mathrm{mg}, 0.17 \mathrm{mmol})$ and (4-cyanophenyl)boronic acid (26 $\mathrm{mg}, 0.18 \mathrm{mmol}$ ) and obtained after flash chromatography (EtOAc/ $\mathrm{PE}, 2: 7)$ as a white viscous oil ( $31 \mathrm{mg}, 41 \%$ yield): $R_{f}=0.27$ (EtOAc/ PE, 1:3); ${ }^{1} \mathrm{H}$ NMR (400 MHz, $\left.\mathrm{CDCl}_{3}\right) \delta 8.38(\mathrm{~d}, J=6.4 \mathrm{~Hz}, 1 \mathrm{H})$, 7.74-7.70 (m, 2H), 7.64-7.60 (m, 2H), 7.49-7.33 (m, 6H), 7.32$7.28(\mathrm{~m}, 1 \mathrm{H}), 6.24($ br s, $1 \mathrm{H}), 5.24-5.06(\mathrm{~m}, 1 \mathrm{H}), 3.91(\mathrm{~s}, 3 \mathrm{H})$, 3.47-3.37 (m, 1H), 3.29-3.16 (m, 1H); ${ }^{13} \mathrm{C}$ NMR (101 MHz, $\left.\mathrm{CDCl}_{3}\right) \delta 170.6,170.5,144.5,141.6,139.4,134.9,132.8,131.7,130.0$, 129.4, 128.0, 127.9, 127.5, 127.2, 118.8, 111.8, 66.0, 65.8, 53.0, 31.3; HRMS (ESI) calcd for $\mathrm{C}_{25} \mathrm{H}_{19} \mathrm{ClN}_{2} \mathrm{NaO}_{3} \mathrm{~S}\left(\mathrm{M}+\mathrm{Na}^{+}\right)$485.0697, found 485.0696 .

Step 2: The title compound $\mathbf{2 4}$ was prepared as described for 9 using methyl ester 24a (31 mg, $67 \mu \mathrm{mol}$ ) and LiI (4 equiv) and obtained after flash chromatography (EtOAc/PE, 1:2 [2\% AcOH]) and subsequent freeze-drying as a white amorphous powder $(21 \mathrm{mg}$, $69 \%$ yield): $R_{f}=0.15(\mathrm{EtOAc} / \mathrm{PE}, 1: 2[2 \% \mathrm{AcOH}]) ;{ }^{1} \mathrm{H}$ NMR $(400$ $\left.\mathrm{MHz}^{\mathrm{CDCl}}\right)_{3} \delta 8.13(\mathrm{~d}, J=6.0 \mathrm{~Hz}, 1 \mathrm{H}), 7.73-7.67(\mathrm{~m}, 2 \mathrm{H}), 7.61-$ $7.55(\mathrm{~m}, 2 \mathrm{H}), 7.46-7.31(\mathrm{~m}, 6 \mathrm{H}), 7.29-7.21(\mathrm{~m}, 1 \mathrm{H}), 6.25(\mathrm{br} \mathrm{s}$, $1 \mathrm{H})$, 5.24-5.14 (m, $1 \mathrm{H}), 3.47-3.39(\mathrm{~m}, 1 \mathrm{H}), 3.39-3.31(\mathrm{~m}, 1 \mathrm{H})$; ${ }^{13} \mathrm{C}$ NMR $\left(101 \mathrm{MHz}, \mathrm{CDCl}_{3}\right) \delta 172.7,171.7,144.3,141.9,138.9$, $134.5,132.8,131.6,130.1,129.5,128.1,127.9,127.6,127.3,118.7$, $111.9,66.4,66.3$, 31.0; HRMS (ESI) calcd for $\mathrm{C}_{24} \mathrm{H}_{17} \mathrm{ClN}_{2} \mathrm{NaO}_{3} \mathrm{~S}$ (M $+\mathrm{Na}^{+}$) 471.0541, found 471.0554. HPLC: $t_{\mathrm{R}}=12.30 \mathrm{~min}, 95.8 \%$. $[\alpha]^{20}{ }_{\mathrm{D}}+59^{\circ}(c \mathrm{c} 0.5, \mathrm{DCM})$.

$(2 R, 4 R)-3-\left(2^{\prime}-C h\right.$ lorobiphenyl-4-carbonyl)-2-(2chlorophenyl)thiazolidine-4-carboxylic Acid (25). Step 1: The methyl ester of the title compound (25a) was prepared as described for 19a using 8a (98 mg, $0.20 \mathrm{mmol}$ ) and (2-chlorophenyl)boronic acid $(34 \mathrm{mg}, 0.22 \mathrm{mmol}$ ) and obtained after flash chromatography (EtOAc/PE, 1:5) as a viscous oil $(80 \mathrm{mg}, 84 \%$ yield $): R_{f}=0.16$ (EtOAc/PE, 1:5); ${ }^{1} \mathrm{H}$ NMR $\left(400 \mathrm{MHz}, \mathrm{CDCl}_{3}\right) \delta 8.37(\mathrm{~d}, J=6.9 \mathrm{~Hz}$, $1 \mathrm{H}), 7.60-7.12(\mathrm{~m}, 11 \mathrm{H}), 6.30(\mathrm{br} \mathrm{s}, 1 \mathrm{H}), 5.21-5.07(\mathrm{~m}, 1 \mathrm{H}), 3.90$ (s, 3H), 3.44-3.33 (m, 1H), 3.29-3.19 (m, 1H); ${ }^{13} \mathrm{C}$ NMR $(101$ $\left.\mathrm{MHz}, \mathrm{CDCl}_{3}\right) \delta 170.8,170.7,141.9,139.5,139.3,133.9,132.4,131.7$, $131.2,130.1,129.9,129.4,129.2,129.1,127.9,127.4,127.0,126.8$, 65.9, 65.7, 52.9, 31.4; HRMS (ESI) calcd for $\mathrm{C}_{24} \mathrm{H}_{20} \mathrm{Cl}_{2} \mathrm{NO}_{3} \mathrm{~S}(\mathrm{M}+$ $\mathrm{H}^{+}$) 472.0535, found 472.0576 .

Step 2: The title compound 25 was prepared as described for 9 using methyl ester $25 \mathrm{a}(81 \mathrm{mg}, 0.17 \mathrm{mmol})$ and LiI (4 equiv) and obtained after flash chromatography (EtOAc/PE, 1:2 [1\% AcOH $]$ ) and subsequent freeze-drying as a white amorphous powder $(56 \mathrm{mg}$, $72 \%$ yield): $R_{f}=0.19($ EtOAc/PE, $1: 2[1 \% \mathrm{AcOH}]) ;{ }^{1} \mathrm{H}$ NMR $(400$ $\left.\mathrm{MHz}, \mathrm{CDCl}_{3}\right) \delta 8.29$ (br s, $\left.1 \mathrm{H}\right), 8.08(\mathrm{~d}, J=5.4 \mathrm{~Hz}, 1 \mathrm{H}), 7.46-7.42$ $(\mathrm{m}, 1 \mathrm{H}), 7.39-7.21(\mathrm{~m}, 10 \mathrm{H}), 6.34(\mathrm{br} \mathrm{s}, 1 \mathrm{H}), 5.31-5.16(\mathrm{~m}, 1 \mathrm{H})$, 3.66-3.29 (m, 2H); ${ }^{13} \mathrm{C}$ NMR (101 MHz, $\left.\mathrm{CDCl}_{3}\right) \delta 172.8,172.2$, $142.4,139.4,138.7,133.5,132.5,131.7,131.2,130.2$, 130.1, 129.6, 129.4, 129.2, 127.6, 127.3, 127.0, 126.9, 66.3, 66.0, 31.3; HRMS (ESI) calcd for $\mathrm{C}_{23} \mathrm{H}_{17} \mathrm{Cl}_{2} \mathrm{NNaO}_{3} \mathrm{~S}\left(\mathrm{M}+\mathrm{Na}^{+}\right) 480.0198$, found 480.0186 . HPLC: $t_{\mathrm{R}}=13.33 \mathrm{~min}, 96.8 \%$. $[\alpha]_{\mathrm{D}}^{20}+73^{\circ}(c 1.0, \mathrm{MeOH})$.

(2R,4R)-2-(2-Chlorophenyl)-3-(2'-methylbiphenyl-4carbonyl)thiazolidine-4-carboxylic Acid (26). Step 1: The methyl ester or the title compound (26a) was prepared as described for 19a using $8 \mathrm{a}(100 \mathrm{mg}, 0.21 \mathrm{mmol})$ and $o$-tolylboronic acid $(31 \mathrm{mg}, 0.23$ $\mathrm{mmol}$ ) and obtained after flash chromatography (EtOAc/PE, 1:5) as a clear viscous oil $(81 \mathrm{mg}, 86 \%$ yield $): R_{f}=0.25($ EtOAc $/ \mathrm{PE}, 1: 5) ;{ }^{1} \mathrm{H}$ NMR (400 MHz, $\left.\mathrm{CDCl}_{3}\right) \delta 8.38(\mathrm{~d}, J=7.3 \mathrm{~Hz}, 1 \mathrm{H}), 7.41-7.35(\mathrm{~m}$, $1 \mathrm{H}), 7.32-7.11(\mathrm{~m}, 10 \mathrm{H}), 6.30(\mathrm{br} \mathrm{s}, 1 \mathrm{H}), 5.14(\mathrm{app} \mathrm{s}, 1 \mathrm{H}), 3.90(\mathrm{~s}$, $3 \mathrm{H}), 3.45-3.33(\mathrm{~m}, 1 \mathrm{H}), 3.31-3.22(\mathrm{~m}, 1 \mathrm{H}), 2.17(\mathrm{~s}, 3 \mathrm{H}) ;{ }^{13} \mathrm{C}$ NMR $\left(101 \mathrm{MHz}, \mathrm{CDCl}_{3}\right) \delta 171.0,170.7,144.6,140.8,139.4,135.3$, 
$133.3,131.6,130.5,129.8,129.6,129.2,129.1,127.9,127.8,127.4$, 126.8, 125.9, 65.8, 65.7, 52.9, 31.5, 20.3; HRMS (ESI) calcd for $\mathrm{C}_{25} \mathrm{H}_{22} \mathrm{ClNNaO}_{3} \mathrm{~S}\left(\mathrm{M}+\mathrm{Na}^{+}\right)$474.0901, found 474.0922.

Step 2: The title compound 26 was prepared as described for 9 using methyl ester $26 \mathrm{a}(81 \mathrm{mg}, 0.18 \mathrm{mmol})$ and LiI (4 equiv) and obtained after flash chromatography (EtOAc/PE, 1:3 [1\% AcOH]) and subsequent freeze-drying as a white amorphous powder $(54 \mathrm{mg}$, $54 \%$ yield): $R_{f}=0.24(\mathrm{EtOAc} / \mathrm{PE}, 1: 3[1 \% \mathrm{AcOH}]) ;{ }^{1} \mathrm{H}$ NMR $(400$ $\left.\mathrm{MHz}, \mathrm{CDCl}_{3}\right) \delta 8.11(\mathrm{~d}, J=7.2 \mathrm{~Hz}, 1 \mathrm{H}), 8.04(\mathrm{br} \mathrm{s}, 1 \mathrm{H}), 7.56-6.99$ $(\mathrm{m}, 11 \mathrm{H}), 6.34(\mathrm{br} \mathrm{s}, 1 \mathrm{H}), 5.37-5.14(\mathrm{~m}, 1 \mathrm{H}), 3.51-3.34(\mathrm{~m}, 2 \mathrm{H})$, $2.17(\mathrm{~s}, 3 \mathrm{H}) ;{ }^{13} \mathrm{C}$ NMR $\left(101 \mathrm{MHz}, \mathrm{CDCl}_{3}\right) \delta 172.0,171.3,144.0$, $139.8,137.9,134.3,131.8,130.6,129.5,128.9,128.6,128.4,128.3$, $126.9,126.7,126.6,125.9,125.0,65.2,64.9,30.2,19.4$; HRMS (ESI) calcd for $\mathrm{C}_{24} \mathrm{H}_{20} \mathrm{ClNNaO}_{3} \mathrm{~S}\left(\mathrm{M}+\mathrm{Na}^{+}\right) 460.0745$, found 460.0738 . HPLC: $t_{\mathrm{R}}=13.53 \mathrm{~min}, 97.2 \%$. $[\alpha]^{20}{ }_{\mathrm{D}}+38^{\circ}(c 1.0, \mathrm{DCM})$.

(2R,4R)-2-(2-Chlorophenyl)-3-(4-(5-methylthiophen-2-yl)benzoyl)thiazolidine-4-carboxylic Acid (27). Step 1: The methyl ester of the title compound (27a) was prepared as described for 19a using $8 \mathbf{a}(106 \mathrm{mg}, 0.22 \mathrm{mmol})$ and 5-methylthiophene-2-boronic acid pinacol ester (51 mg, $0.23 \mathrm{mmol})$ and obtained after flash chromatography (EtOAc/PE, 1:5) as a red oil $(78 \mathrm{mg}, 78 \%$ yield): $R_{f}=0.20($ EtOAc/PE, $1: 5) ;{ }^{1} \mathrm{H}$ NMR $\left(400 \mathrm{MHz}, \mathrm{CDCl}_{3}\right) \delta 8.37$ (d, $J$ $=7.2 \mathrm{~Hz}, 1 \mathrm{H}), 7.43-7.35(\mathrm{~m}, 5 \mathrm{H}), 7.32-7.28(\mathrm{~m}, 2 \mathrm{H}), 7.11(\mathrm{~d}, J=$ $3.5 \mathrm{~Hz}, 1 \mathrm{H}), 6.72-6.70(\mathrm{~m}, 1 \mathrm{H}), 6.28(\mathrm{br} \mathrm{s}, 1 \mathrm{H}), 5.17-5.04(\mathrm{~m}, 1 \mathrm{H})$, $3.88(\mathrm{~s}, 3 \mathrm{H}), 3.41-3.33(\mathrm{~m}, 1 \mathrm{H}), 3.25-3.16(\mathrm{~m}, 1 \mathrm{H}), 2.48(\mathrm{~s}, 3 \mathrm{H})$; ${ }^{13} \mathrm{C}$ NMR $\left(101 \mathrm{MHz}, \mathrm{CDCl}_{3}\right) \delta 170.7,141.0,140.6,139.4,137.2$, 132.8, 131.7, 130.0, 129.2, 128.0, 127.8, 127.4, 126.6, 125.0, 124.2, 66.1, 65.9, 52.9, 31.2, 15.6; HRMS (ESI) calcd for $\mathrm{C}_{23} \mathrm{H}_{21} \mathrm{ClNO}_{3} \mathrm{~S}_{2}$ $\left(\mathrm{M}+\mathrm{H}^{+}\right)$458.0646, found 458.0640 .

Step 2: The title compound $\mathbf{2 7}$ was prepared as described for 9 using methyl ester $27 \mathrm{a}(65 \mathrm{mg}, 0.14 \mathrm{mmol})$ and LiI (4 equiv) and obtained after flash chromatography (EtOAc/PE, 1:2 [2\% AcOH]) and subsequent freeze-drying as a white amorphous powder $(48 \mathrm{mg}$, $75 \%$ yield $): R_{f}=0.27($ EtOAc/PE, $1: 2[2 \% \mathrm{AcOH}]) ;{ }^{1} \mathrm{H}$ NMR $(400$ $\left.\mathrm{MHz}^{\mathrm{CDCl}} \mathrm{CD}_{3}\right) \delta 8.06(\mathrm{~d}, J=5.9 \mathrm{~Hz}, 1 \mathrm{H}), 7.79(\mathrm{br} \mathrm{s}, 1 \mathrm{H}), 7.44-7.33$ $(\mathrm{m}, 4 \mathrm{H}), 7.30-7.22(\mathrm{~m}, 3 \mathrm{H}), 7.11(\mathrm{~d}, J=3.6 \mathrm{~Hz}, 1 \mathrm{H}), 6.74-6.68(\mathrm{~m}$, $1 \mathrm{H}), 6.31(\mathrm{br} \mathrm{s}, 1 \mathrm{H}), 5.24-5.11(\mathrm{~m}, 1 \mathrm{H}), 3.47-3.30(\mathrm{~m}, 2 \mathrm{H}), 2.49$ $(\mathrm{s}, 3 \mathrm{H}) ;{ }^{13} \mathrm{C}$ NMR $\left(101 \mathrm{MHz}, \mathrm{CDCl}_{3}\right) \delta 172.8,172.1,141.2,140.5$, $138.9,137.7,132.3,131.6,130.2,129.4,128.1,127.6,127.5,126.6$, $125.1,124.4,66.6,66.2,30.9,15.6$; HRMS (ESI) calcd for $\mathrm{C}_{22} \mathrm{H}_{18} \mathrm{ClNNaO}_{3} \mathrm{~S}_{2}\left(\mathrm{M}+\mathrm{Na}^{+}\right)$466.0309, found 466.0296. HPLC: $t_{\mathrm{R}}=13.43 \mathrm{~min}, 98.6 \%$. $[\alpha]_{\mathrm{D}}^{20}+38^{\circ}(\mathrm{c} 1.0, \mathrm{DCM})$.

(2R,4R)-2-(2-Chlorophenyl)-3-(4-(phenylethynyl)benzoyl)thiazolidine-4-carboxylic Acid (28). Step 1: The methyl ester of the title compound (28a) was prepared as described for $\mathbf{8 a}$ using $\mathbf{7 a}$ (111 mg, $0.43 \mathrm{mmol}$ ) and 4-(phenylethynyl)benzoyl chloride (113 $\mathrm{mg}, 0.47 \mathrm{mmol}$ ) and obtained after flash chromatography (EtOAc/ $\mathrm{PE}, 1: 3)$ as a clear viscous oil $(127 \mathrm{mg}, 65 \%$ yield $): R_{f}=0.31$ (EtOAc/ PE, 1:3); ${ }^{1} \mathrm{H}$ NMR (400 MHz, $\left.\mathrm{CDCl}_{3}\right) \delta 8.35(\mathrm{~d}, J=7.0 \mathrm{~Hz}, 1 \mathrm{H})$, 7.53-7.45 (m, 2H), 7.41-7.19 (m, 10H), 6.21 (br s, 1H), 5.10 (app $\mathrm{s}, 1 \mathrm{H}), 3.87(\mathrm{~s}, 3 \mathrm{H}), 3.46-3.30(\mathrm{~m}, 1 \mathrm{H}), 3.29-3.13(\mathrm{~m}, 1 \mathrm{H}) ;{ }^{13} \mathrm{C}$ NMR $\left(101 \mathrm{MHz}, \mathrm{CDCl}_{3}\right) \delta 170.5,170.4,139.2,134.2,133.1,131.7$, $131.4,129.9,129.2,128.7,128.4,127.7,127.4,127.1,126.0,122.7$, 91.6, 88.5, 65.9, 65.7, 52.8, 31.2; HRMS (ESI) calcd for $\mathrm{C}_{26} \mathrm{H}_{21} \mathrm{ClNO}_{3} \mathrm{~S}\left(\mathrm{M}+\mathrm{H}^{+}\right)$462.0925, found 462.0938 .

Step 2: The title compound 28 was prepared as described for 9 using methyl ester $28 \mathrm{a}(83 \mathrm{mg}, 0.18 \mathrm{mmol})$ and $\mathrm{LiI}$ (4 equiv) and obtained after flash chromatography (EtOAc/PE, 1:2 [2\% AcOH] and subsequent freeze-drying as a white amorphous powder $(67 \mathrm{mg}$, $83 \%$ yield): $R_{f}=0.25($ EtOAc/PE, 1:2 $[2 \% \mathrm{AcOH}]) ;{ }^{1} \mathrm{H}$ NMR $(400$ $\left.\mathrm{MHz}, \mathrm{CDCl}_{3}\right) \delta 8.13(\mathrm{~d}, J=7.3 \mathrm{~Hz}, 1 \mathrm{H}), 8.04-7.93(\mathrm{~m}, 1 \mathrm{H}), 7.52-$ $7.47(\mathrm{~m}, 2 \mathrm{H}), 7.42-7.32(\mathrm{~m}, 7 \mathrm{H}), 7.29-7.23(\mathrm{~m}, 2 \mathrm{H}), 6.24(\mathrm{br} \mathrm{s}$, $1 \mathrm{H}), 5.23-5.15(\mathrm{~m}, 1 \mathrm{H}), 3.50-3.42(\mathrm{~m}, 1 \mathrm{H}), 3.38-3.30(\mathrm{~m}, 1 \mathrm{H})$; ${ }^{13} \mathrm{C}$ NMR $\left(101 \mathrm{MHz}, \mathrm{CDCl}_{3}\right) \delta 173.0,171.6,138.8,133.7,131.8$, $131.6,130.1,129.4,128.8,128.5,127.6,127.5,127.3,126.5,122.8$, 91.9, 88.5, 66.3, 66.1, 31.0; HRMS (ESI) calcd for $\mathrm{C}_{25} \mathrm{H}_{18} \mathrm{ClNNaO}_{3} \mathrm{~S}$ $\left(\mathrm{M}+\mathrm{Na}^{+}\right) 470.0588$, found 470.0597 . HPLC: $t_{\mathrm{R}}=13.58 \mathrm{~min}, 98.7 \%$. $[\alpha]_{\mathrm{D}}^{20}+61^{\circ}(c 1.0, \mathrm{DCM})$.

$(2 R, 4 R)-2-(2-C h l o r o p h e n y l)-3-(4-((2-$ methoxyphenyl)ethynyl)benzoyl)thiazolidine-4-carboxylic Acid (29). Step 1: To a predried vial charged with $8 \mathrm{a}(72 \mathrm{mg}, 0.15 \mathrm{mmol})$ and 1-ethynyl-2methoxybenzene $(26 \mathrm{mg}, 0.19 \mathrm{mmol})$ was added THF $(1.2 \mathrm{~mL}$, anhydrous). The reaction mixture was purged with argon $(\times 3)$, and to it were added $\mathrm{Pd}\left(\mathrm{PPh}_{3}\right)_{2} \mathrm{Cl}_{2}(6 \mathrm{mg}, 9.0 \mu \mathrm{mol}), \mathrm{CuI}(4 \mathrm{mg}, 22 \mu \mathrm{mol})$, and $\mathrm{Et}_{3} \mathrm{~N}(81 \mu \mathrm{L}, 0.58 \mathrm{mmol})$. The reaction was capped and stirred at rt for $4 \mathrm{~h}$ under argon, whereafter the mixture was concentrated in vacuo. The methyl ester 29a was obtained after flash chromatography $(\mathrm{EtOAc} / \mathrm{PE}, 1: 3)$ as a white oil $(55 \mathrm{mg}, 76 \%$ yield $): R_{f}=0.17$ (EtOAc/PE, 1:3); $\left.{ }^{1} \mathrm{H} \mathrm{NMR} \mathrm{(400} \mathrm{MHz,} \mathrm{CDCl}_{3}\right) \delta 8.35$ (d, $J=7.1 \mathrm{~Hz}$, $1 \mathrm{H}), 7.46(\mathrm{dd}, J=7.6,1.5 \mathrm{~Hz}, 1 \mathrm{H}), 7.44-7.34(\mathrm{~m}, 4 \mathrm{H}), 7.34-7.23$ $(\mathrm{m}, 4 \mathrm{H}), 6.97-6.84(\mathrm{~m}, 2 \mathrm{H}), 6.21(\mathrm{br} \mathrm{s}, 1 \mathrm{H}), 5.10($ app s, $1 \mathrm{H}), 3.89$ (s, 6H), 3.43-3.34 (m, 1H), 3.27-3.18 (m, $1 \mathrm{H}) ;{ }^{13} \mathrm{C}$ NMR $(101$ $\left.\mathrm{MHz}, \mathrm{CDCl}_{3}\right) \delta 170.7,160.1,139.4,134.0,133.8,131.5,130.3,130.0$, 129.3, 127.7, 127.4, 127.1, 126.5, 120.6, 112.0, 110.8, 92.6, 88.2, 66.1, 65.9, 55.9, 53.0, 31.2; HRMS (ESI) calcd for $\mathrm{C}_{27} \mathrm{H}_{22} \mathrm{ClNNaO}_{4} \mathrm{~S}(\mathrm{M}+$ $\mathrm{Na}^{+}$) 514.0850, found 514.0766.

Step 2: The title compound 29 was prepared as described for 9 using methyl ester 29a (55 mg, $0.11 \mathrm{mmol}$ ) and LiI (4 equiv) and obtained after flash chromatography (EtOAc/PE, 1:1 [1\% AcOH]) and subsequent freeze-drying as a white amorphous powder $(39 \mathrm{mg}$, $72 \%$ yield): $R_{f}=0.23($ EtOAc/PE, $1: 1[1 \% \mathrm{AcOH}]) ;{ }^{1} \mathrm{H}$ NMR $(400$ $\left.\mathrm{MHz}^{\mathrm{CDCl}}{ }_{3}\right) \delta 8.06(\mathrm{~d}, J=6.6 \mathrm{~Hz}, 1 \mathrm{H}), 7.50-7.21(\mathrm{~m}, 9 \mathrm{H}), 6.98-$ $6.86(\mathrm{~m}, 2 \mathrm{H}), 6.25(\mathrm{br} \mathrm{s}, 1 \mathrm{H}), 5.25-5.08(\mathrm{~m}, 1 \mathrm{H}), 3.90(\mathrm{~s}, 3 \mathrm{H})$, $3.47-3.40(\mathrm{~m}, 1 \mathrm{H}), 3.40-3.33(\mathrm{~m}, 1 \mathrm{H}) ;{ }^{13} \mathrm{C}$ NMR $(101 \mathrm{MHz}$, $\left.\mathrm{CDCl}_{3}\right) \delta 172.8,171.9,160.2,138.8,133.8,133.5,131.6,130.4,130.2$, $129.5,128.0,127.6,127.5,127.2,126.9,120.7,112.0,110.9,92.5$, 88.5, 66.4, 66.1, 56.0, 30.9; HRMS (ESI) calcd for $\mathrm{C}_{26} \mathrm{H}_{20} \mathrm{ClNNaO}_{4} \mathrm{~S}$ $\left(\mathrm{M}+\mathrm{Na}^{+}\right)$500.0694, found 500.0714. HPLC: $t_{\mathrm{R}}=13.23 \mathrm{~min}, 96.2 \%$. $[\alpha]_{\mathrm{D}}^{20}+68^{\circ}$ (c 1.0, DCM).

(2R,4R)-2-(2-Chlorophenyl)-3-(4-(1-methyl-1H-pyrazol-5-yl)benzoyl)thiazolidine-4-carboxylic Acid (30). Step 1: The methyl ester of the title compound (30a) was prepared as described for 19a using $8 \mathrm{a}(93 \mathrm{mg}, 0.19 \mathrm{mmol})$ and 1-methyl-1H-pyrazole-5-boronic acid pinacol ester $(41 \mathrm{mg}, 0.19 \mathrm{mmol})$ and obtained after flash chromatography (EtOAc/PE, 1:1) as a clear viscous oil $(17 \mathrm{mg}, 20 \%$ yield): $R_{f}=0.17(\mathrm{EtOAc} / \mathrm{PE}, 1: 1) ;{ }^{1} \mathrm{H} \mathrm{NMR}\left(400 \mathrm{MHz}, \mathrm{CDCl}_{3}\right) \delta$ $8.36(\mathrm{~d}, J=6.7 \mathrm{~Hz}, 1 \mathrm{H}), 7.48(\mathrm{~d}, J=1.8 \mathrm{~Hz}, 1 \mathrm{H}), 7.43-7.21(\mathrm{~m}$, $7 \mathrm{H}), 6.28(\mathrm{~d}, J=1.5 \mathrm{~Hz}, 1 \mathrm{H}), 6.24(\mathrm{br} \mathrm{s}, 1 \mathrm{H}), 5.18-5.06(\mathrm{~m}, 1 \mathrm{H})$, $3.90(\mathrm{~s}, 3 \mathrm{H}), 3.82(\mathrm{~s}, 3 \mathrm{H}), 3.46-3.37(\mathrm{~m}, 1 \mathrm{H}), 3.30-3.20(\mathrm{~m}, 1 \mathrm{H})$; ${ }^{13} \mathrm{C}$ NMR (101 MHz, $\left.\mathrm{CDCl}_{3}\right) \delta 170.6,170.4,142.5,139.2,138.7$, $134.8,133.1,131.6,130.0,129.4,128.6,128.0,127.54,127.45,106.5$, 65.9, 65.6, 53.0, 37.6, 31.4; HRMS (ESI) calcd for $\mathrm{C}_{22} \mathrm{H}_{21} \mathrm{ClN}_{3} \mathrm{O}_{3} \mathrm{~S}$ $\left(\mathrm{M}+\mathrm{H}^{+}\right)$442.0987, found 442.1007.

Step 2: The title compound $\mathbf{3 0}$ was prepared as described for 9 using methyl ester 30a (17 mg, $39 \mu \mathrm{mol}$ ) and LiI (4 equiv) and obtained after flash chromatography (EtOAc $[1 \% \mathrm{AcOH}]$ ) and subsequent freeze-drying as a white amorphous powder $(12 \mathrm{mg}, 71 \%$ yield): $R_{f}=0.14($ EtOAc $[1 \% \mathrm{AcOH}]) ;{ }^{1} \mathrm{H}$ NMR $\left(400 \mathrm{MHz}, \mathrm{CDCl}_{3}\right)$ $\delta 8.28(\mathrm{~d}, J=7.2 \mathrm{~Hz}, 1 \mathrm{H}), 7.55(\mathrm{~d}, J=1.9 \mathrm{~Hz}, 1 \mathrm{H}), 7.40-7.21(\mathrm{~m}$, $7 \mathrm{H}), 6.29(\mathrm{~d}, J=1.2 \mathrm{~Hz}, 1 \mathrm{H}), 6.25(\mathrm{br} \mathrm{s}, 1 \mathrm{H}), 5.26-5.15(\mathrm{~m}, 1 \mathrm{H})$, $3.84(\mathrm{~s}, 3 \mathrm{H}), 3.52-3.43(\mathrm{~m}, 1 \mathrm{H}), 3.42-3.32(\mathrm{~m}, 1 \mathrm{H}) ;{ }^{13} \mathrm{C} \mathrm{NMR}$ $\left(101 \mathrm{MHz}, \mathrm{CDCl}_{3}\right) \delta 172.4,171.1,142.8,139.1,138.5,134.9,132.9$, $131.5,129.9,129.4,128.7,128.0,127.6,125.4,106.6,66.2,66.1,37.4$, 31.4; HRMS (ESI) calcd for $\mathrm{C}_{21} \mathrm{H}_{19} \mathrm{ClN}_{3} \mathrm{O}_{3} \mathrm{~S}\left(\mathrm{M}+\mathrm{H}^{+}\right)$428.0830, found 428.0836. HPLC: $t_{\mathrm{R}}=10.84 \mathrm{~min}, 98.1 \%$. $[\alpha]^{20}{ }_{\mathrm{D}}+31^{\circ}(c 0.2$, DCM).

(2R,4R)-2-(2-Chlorophenyl)-3-(4-(3,5-dimethylisoxazol-4yl)benzoyl)thiazolidine-4-carboxylic Acid (31). Step 2: The methyl ester of the title compound (31a) was prepared as described for 19a using 8a (106 mg, $0.22 \mathrm{mmol}$ ) and 3,5-dimethylisoxazole-4boronic acid pinacol ester $(51 \mathrm{mg}, 0.23 \mathrm{mmol})$ and obtained after flash chromatography (EtOAc/PE, 1:3) as white needles (63 mg, 63\% yield): $R_{f}=0.14($ EtOAc/PE, $1: 3) ; \mathrm{mp} 146-148{ }^{\circ} \mathrm{C} ;{ }^{1} \mathrm{H}$ NMR $(400$ $\left.\mathrm{MHz}_{\mathrm{CDCl}}\right) \delta 8.36(\mathrm{~d}, J=6.9 \mathrm{~Hz}, 1 \mathrm{H}), 7.44-7.36(\mathrm{~m}, 1 \mathrm{H}), 7.36-$ $7.22(\mathrm{~m}, 4 \mathrm{H}), 7.19-7.01(\mathrm{~m}, 2 \mathrm{H}), 6.25(\mathrm{br} \mathrm{s}, 1 \mathrm{H}), 5.20-5.08(\mathrm{~m}$, $1 \mathrm{H}), 3.91(\mathrm{~s}, 3 \mathrm{H}), 3.48-3.38(\mathrm{~m}, 1 \mathrm{H}), 3.33-3.22(\mathrm{~m}, 1 \mathrm{H}), 2.35(\mathrm{~s}$, $3 \mathrm{H}), 2.21(\mathrm{~s}, 3 \mathrm{H}) ;{ }^{13} \mathrm{C} \mathrm{NMR}\left(101 \mathrm{MHz}, \mathrm{CDCl}_{3}\right) \delta 170.6,165.7$, $158.4,139.2,134.0,133.1,131.5,129.8,129.3,128.9,128.0,127.5$, 115.9, 65.8, 65.5, 52.9, 31.5, 11.6, 10.7; HRMS (ESI) calcd for $\mathrm{C}_{23} \mathrm{H}_{21} \mathrm{ClN}_{2} \mathrm{NaO}_{4} \mathrm{~S}\left(\mathrm{M}+\mathrm{Na}^{+}\right) 479.0803$, found 479.0812 . 
Step 2: The title compound 31 was prepared as described for 9 using methyl ester 31a (61 mg, $0.13 \mathrm{mmol})$ and LiI (4 equiv) and obtained after flash chromatography (EtOAc/PE, 1:2 $\rightarrow$ EtOAc $[2 \%$ $\mathrm{AcOH}])$ and subsequent freeze-drying gave 31 as a powder $(25 \mathrm{mg}$, $42 \%$ yield $): R_{f}=0.21(\mathrm{EtOAc} / \mathrm{PE}, 1: 2[2 \% \mathrm{AcOH}]) ;{ }^{1} \mathrm{H}$ NMR $(600$ $\left.\mathrm{MHz}, \mathrm{DMSO}-d_{6}, 100{ }^{\circ} \mathrm{C}\right) \delta 8.35(\mathrm{dd}, J=7.8,1.0 \mathrm{~Hz}, 1 \mathrm{H}), 7.42-7.34$ (m, 3H), 7.33-7.29 (m, 1H), 7.29-7.26 (m, 3H), $6.41(\mathrm{~s}, 1 \mathrm{H}), 5.02$ $(\mathrm{t}, J=6.5 \mathrm{~Hz}, 1 \mathrm{H}), 3.62(\mathrm{dd}, J=12.0,6.6 \mathrm{~Hz}, 1 \mathrm{H}), 3.30(\mathrm{dd}, J=12.1$, $6.4 \mathrm{~Hz}, 1 \mathrm{H}), 2.35(\mathrm{~s}, 3 \mathrm{H}), 2.17(\mathrm{~s}, 3 \mathrm{H}) ;{ }^{13} \mathrm{C}$ NMR $(151 \mathrm{MHz}$, DMSO- $\left.d_{6}, 100{ }^{\circ} \mathrm{C}\right) \delta 170.5,168.9,164.8,157.3,138.2,134.6,131.3$, 130.6, 128.62, 128.55, 128.1, 127.7, 126.7, 126.3, 114.9, 64.9, 63.9, 32.1, 10.5, 9.5; HRMS (ESI) calcd for $\mathrm{C}_{22} \mathrm{H}_{19} \mathrm{ClN}_{2} \mathrm{NaO}_{4} \mathrm{~S}\left(\mathrm{M}+\mathrm{Na}^{+}\right)$ 465.0646, found 465.0627. HPLC: $t_{\mathrm{R}}=11.65 \mathrm{~min}, 98.3 \%$. $[\alpha]^{20}{ }_{\mathrm{D}}$ $+72^{\circ}(c 0.5, \mathrm{MeOH})$

(2R,4R)-2-(2-Chlorophenyl)-3-(4-(5-cyclopropyl-3-phenylisoxazol-4-yl)benzoyl)thiazolidine-4-carboxylic Acid (32). Step 1: Methyl (2R,4R)-2-(2-Chlorophenyl)-3-(4-(4,4,5,5-tetramethyl-1,3,2dioxaborolan-2-yl)benzoyl)thiazolidine-4-carboxylate. In a vial, a mixture of $8 \mathrm{a}$ (120 mg, $0.25 \mathrm{mmol})$, bis(pinacolato)diboron (69 $\mathrm{mg}, 0.27 \mathrm{mmol})$, and potassium acetate $(61 \mathrm{mg}, 0.62 \mathrm{mmol})$ in DMF $(0.35 \mathrm{~mL})$ was purged with argon $(\times 5)$, followed by the addition of $1,1^{\prime}$-bis(phenylphosphino)ferrocene palladium dichloride $(9.0 \mathrm{mg}$, $12.30 \mu \mathrm{mol})$, and the mixture was again purged with argon $(\times 5)$. The reaction was capped and stirred at $50{ }^{\circ} \mathrm{C}$ under argon until consumption of starting material $(20 \mathrm{~h})$. The reaction was treated with water and extracted with EtOAc ( $\times 5)$, washed with brine, dried over $\mathrm{Na}_{2} \mathrm{SO}_{4}$, and concentrated in vacuo.

Step 2: 5-Cyclopropyl-4-iodo-3-phenylisoxazole. To (Z)-3-cyclopropyl-1-phenylprop-2-yn-1-one O-methyl oxime $(69 \mathrm{mg}, 0.35$ $\mathrm{mmol})$ dissolved in dry DCM $(3.5 \mathrm{~mL})$ was added $\mathrm{IBr}(143 \mathrm{mg}$, $0.69 \mathrm{mmol}$ ), and the reaction was stirred at $\mathrm{rt}$ until consumption of starting material. The reaction mixture was washed with saturated $\mathrm{Na}_{2} \mathrm{~S}_{2} \mathrm{O}_{3}$, extracted with DCM $(\times 5)$, dried over $\mathrm{Na}_{2} \mathrm{SO}_{4}$, and concentrated in vacuo. The crude 5-cyclopropyl-4-iodo-3-phenylisoxazole was filtered through a plug of silica using PE (1\% EtOAc) and used without further purification in the next step.

Step 3: Methyl (2R,4R)-2-(2-Chlorophenyl)-3-(4-(5-cyclopropyl-3phenylisoxazol-4-yl)benzoyl)thiazolidine-4-carboxylate (32a). In a vial, to crude boronate from step $1(100 \mathrm{mg})$ were added crude 5cyclopropyl-4-iodo-3-phenylisoxazole $(55 \mathrm{mg}, 0.18 \mathrm{mmol})$ and XPhos Pd G4 precatalyst $(3.8 \mathrm{mg}, 4.4 \mu \mathrm{mol})$. The vial was capped and purged with argon $(\times 5)$. Reactants were dissolved in THF $(0.41 \mathrm{~mL}$, degassed), after which $\mathrm{K}_{3} \mathrm{PO}_{4}(0.82 \mathrm{~mL}, 0.5 \mathrm{M}$, degassed) was added and the reaction was stirred at $80{ }^{\circ} \mathrm{C}$ for $5 \mathrm{~h}$ under argon. The reaction was treated with water and extracted with EtOAc $(\times 5)$, washed with brine, dried over $\mathrm{Na}_{2} \mathrm{SO}_{4}$, and concentrated in vacuo. The title compound was obtained after flash chromatography $(\mathrm{EtOAc} / \mathrm{PE}, 1: 3)$ as a cloudy viscous oil $(25 \mathrm{mg}, 26 \%$ yield $): R_{f}=$ $0.20\left(\right.$ EtOAc/PE, 1:3); ${ }^{1} \mathrm{H}$ NMR $\left(400 \mathrm{MHz}, \mathrm{CDCl}_{3}\right) \delta 8.34(\mathrm{~d}, J=$ $7.3 \mathrm{~Hz}, 1 \mathrm{H}), 7.41-7.28(\mathrm{~m}, 8 \mathrm{H}), 7.27-7.22(\mathrm{~m}, 2 \mathrm{H}), 7.17-7.06(\mathrm{~m}$, $2 \mathrm{H}), 6.23(\mathrm{~s}, 1 \mathrm{H}), 5.17-5.03(\mathrm{~m}, 1 \mathrm{H}), 3.90(\mathrm{~s}, 3 \mathrm{H}), 3.41(\mathrm{dd}, J=6.4$, $12.1 \mathrm{~Hz}, 1 \mathrm{H}), 3.29-3.19(\mathrm{~m}, 1 \mathrm{H}), 1.98-1.89(\mathrm{~m}, 1 \mathrm{H}), 1.20-1.12$ $(\mathrm{m}, 2 \mathrm{H}), 1.06-0.97(\mathrm{~m}, 2 \mathrm{H}) ;{ }^{13} \mathrm{C}$ NMR $\left(101 \mathrm{MHz}, \mathrm{CDCl}_{3}\right) \delta 170.9$, $170.6,161.2,139.4,134.1,133.3,131.5,129.9,129.9,129.6,129.3$, $128.8,128.7,128.5,127.9,127.5,127.4,114.4,65.9,65.8,53.0,31.4$, 8.4, 7.8; HRMS (ESI) calcd for $\mathrm{C}_{30} \mathrm{H}_{25} \mathrm{ClN}_{2} \mathrm{O}_{4} \mathrm{~S}\left(\mathrm{M}+\mathrm{H}^{+}\right)$545.1296, found 545.1309 .

Step 4: The title compound 32 was prepared as described for 9 using methyl ester 32a (27 mg, $49 \mu \mathrm{mol}$ ) and LiI (4 equiv) and obtained after flash chromatography (EtOAc/PE, 1:1 [1\% AcOH $]$ ) and subsequent freeze-drying as a white amorphous powder $(19 \mathrm{mg}$, $75 \%$ yield $): R_{f}=0.17(\mathrm{EtOAc} / \mathrm{PE}, 1: 1[1 \% \mathrm{AcOH}]) ;{ }^{1} \mathrm{H}$ NMR $(400$ $\left.\mathrm{MHz} \mathrm{CDCl}_{3}\right) \delta 8.08(\mathrm{~d}, J=6.8 \mathrm{~Hz}, 1 \mathrm{H}), 7.40-7.27(\mathrm{~m}, 8 \mathrm{H}), 7.25-$ $7.19(\mathrm{~m}, 2 \mathrm{H}), 7.18-7.09(\mathrm{~m}, 2 \mathrm{H}), 6.27(\mathrm{~s}, 1 \mathrm{H}), 5.25-5.12(\mathrm{~m}, 1 \mathrm{H})$, $3.52-3.32(\mathrm{~m}, 2 \mathrm{H}), 1.99-1.87(\mathrm{~m}, 1 \mathrm{H}), 1.20-1.14(\mathrm{~m}, 2 \mathrm{H}), 1.05-$ $0.99(\mathrm{~m}, 2 \mathrm{H}) ;{ }^{13} \mathrm{C}$ NMR (101 MHz, $\left.\mathrm{CDCl}_{3}\right) \delta 172.7,172.0,171.0$, $161.2,138.9,133.6,131.5,130.01,129.95,129.7,129.5,128.7,128.5$, 127.6, 127.4, 114.3, 66.3, 66.0, 31.2, 8.5, 7.8; HRMS (ESI) calcd for $\mathrm{C}_{29} \mathrm{H}_{23} \mathrm{ClN}_{2} \mathrm{O}_{4} \mathrm{~S}\left(\mathrm{M}+\mathrm{Na}^{+}\right)$553.0959, found 553.0965. HPLC: $t_{\mathrm{R}}=$ $13.58 \mathrm{~min}, 98.8 \%$.
(2R,4R)-3-(4-(3,5-Dimethylisoxazol-4-yl)benzoyl)-2-phenylthiazolidine-4-carboxylic Acid (33). Step 1: The methyl ester of the title compound (33a) was prepared as described for $8 \mathbf{a}$ using $\mathbf{7 g}$ (55 mg, $0.25 \mathrm{mmol})$ and 4-(3,5-dimethylisoxazol-4-yl)benzoyl chloride (64 mg, $0.27 \mathrm{mmol}$ ) and obtained after flash chromatography $(\mathrm{EtOAc} / \mathrm{PE}, 2: 5)$ as a clear viscous oil $\left(30 \mathrm{mg}, 29 \%\right.$ yield): $R_{f}=0.22$ (EtOAc/PE, 1:1); ${ }^{1} \mathrm{H}$ NMR $\left(400 \mathrm{MHz}, \mathrm{CDCl}_{3}\right) \delta 7.65-7.54(\mathrm{~m}$, $2 \mathrm{H}), 7.45-7.36(\mathrm{~m}, 2 \mathrm{H}), 7.36-7.30(\mathrm{~m}, 2 \mathrm{H}), 7.30-7.24(\mathrm{~m}, 1 \mathrm{H})$, 7.19-7.05 (m, 2H), 6.09 (br s, 1H), 5.19 (app s, $1 \mathrm{H}), 3.86(\mathrm{~s}, 3 \mathrm{H})$, $3.50-3.23(\mathrm{~m}, 2 \mathrm{H}), 2.36(\mathrm{~s}, 3 \mathrm{H}), 2.22(\mathrm{~s}, 3 \mathrm{H}) ;{ }^{13} \mathrm{C}$ NMR $(101 \mathrm{MHz}$, $\left.\mathrm{CDCl}_{3}\right) \delta 170.5,170.4,165.7,158.5,141.2,134.7,133.1,128.9,128.6$, $128.1,127.8,126.9,116.0,68.3,65.2,52.9,32.4,11.7,10.9$; HRMS (ESI) calcd for $\mathrm{C}_{23} \mathrm{H}_{23} \mathrm{~N}_{2} \mathrm{O}_{4} \mathrm{~S}\left(\mathrm{M}+\mathrm{H}^{+}\right)$423.1373, found 423.1381 .

Step 2: The title compound $\mathbf{3 3}$ was prepared as described for 9 using methyl ester 33a (30 mg, $71 \mu \mathrm{mol}$ ) and LiI (4 equiv) and obtained after flash chromatography $(\mathrm{EtOAc} / \mathrm{PE}, 1: 1[2 \% \mathrm{AcOH}])$ and subsequent freeze-drying as a white amorphous powder $(18 \mathrm{mg}$, $61 \%$ yield $): R_{f}=0.14(\mathrm{EtOAc} / \mathrm{PE}, 1: 1[2 \% \mathrm{AcOH}]) ;{ }^{1} \mathrm{H}$ NMR $(400$ $\left.\mathrm{MHz} \mathrm{CDCl}_{3}\right) \delta 7.56-7.34(\mathrm{~m}, 4 \mathrm{H}), 7.33-7.20(\mathrm{~m}, 3 \mathrm{H}), 7.19-7.08$ (m, 2H), 6.12 (br s, $1 \mathrm{H}), 5.24$ (app s, $1 \mathrm{H}), 3.50-3.37(\mathrm{~m}, 2 \mathrm{H}), 2.36$ $(\mathrm{s}, 3 \mathrm{H}), 2.22(\mathrm{~s}, 3 \mathrm{H}) ;{ }^{13} \mathrm{C} \mathrm{NMR}\left(101 \mathrm{MHz}, \mathrm{CDCl}_{3}\right) \delta 172.7,171.9$, $165.8,158.5,140.5,134.1,133.5,129.0,128.8,128.3,127.8,126.7$, 116.0, 68.9, 65.3, 31.7, 11.7, 10.9; HRMS (ESI) calcd for $\mathrm{C}_{22} \mathrm{H}_{21} \mathrm{~N}_{2} \mathrm{O}_{4} \mathrm{~S}\left(\mathrm{M}+\mathrm{H}^{+}\right)$409.1217, found 409.1228. HPLC: $t_{\mathrm{R}}=$ $10.98 \mathrm{~min}, 99.9 \%$. $[\alpha]_{\mathrm{D}}^{20}+44^{\circ}$ (c 0.3 , DCM).

(2R,4R)-3-(4-(3,5-Dimethylisoxazol-4-yl)benzoyl)-2-(2ethynylphenyl)thiazolidine-4-carboxylic Acid (34). Step 1: Methyl (4R)-2-(2-Ethynylphenyl)thiazolidine-4-carboxylate (7h). The thiazolidine was prepared as described for 7a using L-cysteine methyl ester hydrochloride $(352 \mathrm{mg}, 2.05 \mathrm{mmol})$ and 2-ethynylbenzaldehyde (315 mg, $2.42 \mathrm{mmol}$ ). The crude was filtered through silica (EtOAc/ PE, 1:3) and concentrated in vacuo to give the crude $7 \mathbf{h}$, which was used in the next step without further purification.

Step 2: Methyl (2R,4R)-3-(4-(3,5-Dimethylisoxazol-4-yl)benzoyl)-2(2-ethynylphenyl)thiazolidine-4-carboxylate (34a). Using crude $7 \mathbf{h}$ (69 $\mathrm{mg}$ ) and 4-(3,5-dimethylisoxazol-4-yl)benzoyl chloride (72 mg, 0.31 $\mathrm{mmol})$, the title compound was prepared as described for $\mathbf{8 a}$ and obtained after flash chromatography (EtOAc/PE, 1:2) as a clear oil (26 mg, 21\% yield): $R_{f}=0.26$ (EtOAc/PE, 1:1); ${ }^{1} \mathrm{H}$ NMR $(400 \mathrm{MHz}$, $\left.\mathrm{CDCl}_{3}\right) \delta 8.29(\mathrm{~d}, J=7.8 \mathrm{~Hz}, 1 \mathrm{H}), 7.48-7.43(\mathrm{~m}, 1 \mathrm{H}), 7.40(\mathrm{~d}, J=$ $7.3 \mathrm{~Hz}, 1 \mathrm{H}), 7.36-7.20(\mathrm{~m}, 3 \mathrm{H}), 7.17-6.98(\mathrm{~m}, 2 \mathrm{H}), 6.38(\mathrm{br} \mathrm{s}, 1 \mathrm{H})$, 5.21-5.04 (m, 1H), $3.90(\mathrm{~s}, 3 \mathrm{H}), 3.46-3.39(\mathrm{~m}, 1 \mathrm{H}), 3.31(\mathrm{~s}, 1 \mathrm{H})$, $3.36-3.22(\mathrm{~m}, 1 \mathrm{H}), 2.34(\mathrm{~s}, 3 \mathrm{H}), 2.20(\mathrm{~s}, 3 \mathrm{H}) ;{ }^{13} \mathrm{C}$ NMR $(101 \mathrm{MHz}$, $\left.\mathrm{CDCl}_{3}\right) \delta 170.7,170.5,165.7,158.5,144.4,134.3,133.1,132.9,129.6$, $128.9,127.9,127.6,126.4,119.5,116.1,84.9,80.6,66.4,65.7,52.9$, 31.8, 11.6, 10.8; HRMS (ESI) calcd for $\mathrm{C}_{25} \mathrm{H}_{23} \mathrm{~N}_{2} \mathrm{O}_{4} \mathrm{~S}\left(\mathrm{M}+\mathrm{H}^{+}\right)$ 447.1373, found 447.1391 .

Step 3: The title compound $\mathbf{3 4}$ was prepared as described for 9 using methyl ester 34a (27 mg, $60 \mu \mathrm{mol}$ ) and LiI (4 equiv) and obtained after flash chromatography (EtOAc/PE, 2:1 [1\% AcOH $]$ ) and subsequent freeze-drying as a brownish amorphous powder (18 $\mathrm{mg}, 70 \%$ yield $): R_{f}=0.16(\mathrm{EtOAc} / \mathrm{PE}, 3: 1[1 \% \mathrm{AcOH}]) ;{ }^{1} \mathrm{H}$ NMR $\left(400 \mathrm{MHz} \mathrm{CDCl}_{3}\right) \delta 9.59($ br s, $1 \mathrm{H}), 8.03(\mathrm{~d}, J=6.6 \mathrm{~Hz}, 1 \mathrm{H}), 7.48-$ $7.36(\mathrm{~m}, 2 \mathrm{H}), 7.36-7.20(\mathrm{~m}, 3 \mathrm{H}), 7.17-7.03(\mathrm{~m}, 2 \mathrm{H}), 6.43$ (br s, $1 \mathrm{H}), 5.27-5.19(\mathrm{~m}, 1 \mathrm{H}), 3.53-3.41(\mathrm{~m}, 2 \mathrm{H}), 3.30(\mathrm{~s}, 1 \mathrm{H}), 2.35(\mathrm{~s}$, $3 \mathrm{H}), 2.21(\mathrm{~s}, 3 \mathrm{H}) ;{ }^{13} \mathrm{C} \mathrm{NMR}\left(101 \mathrm{MHz}, \mathrm{CDCl}_{3}\right) \delta 172.5,171.8$, $165.8,158.5,143.7,133.8,133.3,133.2,129.8,129.1,128.0,127.6$, 126.1, 119.5, 116.1, 85.0, 80.5, 66.9, 65.9, 31.5, 11.6, 10.8; HRMS (ESI) calcd for $\mathrm{C}_{24} \mathrm{H}_{20} \mathrm{~N}_{2} \mathrm{NaO}_{4} \mathrm{~S}\left(\mathrm{M}+\mathrm{Na}^{+}\right)$455.1036, found 455.1058. HPLC: $t_{\mathrm{R}}=11.25 \mathrm{~min}, 99.0 \%$. $[\alpha]^{20}{ }_{\mathrm{D}}+84^{\circ}(c 0.2, \mathrm{DCM})$.

(2R,4R)-3-(4-(3,5-Dimethylisoxazol-4-yl)benzoyl)-2-(2methoxyphenyl)thiazolidine-4-carboxylic Acid (35). Step 1: The methyl ester of the title compound (35a) was prepared as described for 8a using 7 f $(69 \mathrm{mg}, 0.27 \mathrm{mmol})$ and 4-(3,5dimethylisoxazol-4-yl)benzoyl chloride $(71 \mathrm{mg}, 0.30 \mathrm{mmol})$ and obtained after flash chromatography (EtOAc/PE, 1:2) as a clear oil (91 mg, 74\% yield): $R_{f}=0.26$ (EtOAc/PE, 1:1); ${ }^{1} \mathrm{H} \mathrm{NMR}(400 \mathrm{MHz}$, $\left.\mathrm{CDCl}_{3}\right) \delta 8.18(\mathrm{~d}, J=6.0 \mathrm{~Hz}, 1 \mathrm{H}), 7.47-7.33(\mathrm{~m}, 2 \mathrm{H}), 7.34-7.26$ (m, 1H), 7.18-7.02 (m, 3H), $6.84(\mathrm{~d}, J=8.1 \mathrm{~Hz}, 1 \mathrm{H}), 6.26(\mathrm{br} \mathrm{s}$, $1 \mathrm{H}), 5.17-5.07$ (m, $1 \mathrm{H}), 3.89$ (br s, $3 \mathrm{H}), 3.73$ (br s, $3 \mathrm{H}), 3.44-3.32$ 
(m, 1H), 3.29-3.18 (m, 1H), $2.35(\mathrm{~s}, 3 \mathrm{H}), 2.21(\mathrm{~s}, 3 \mathrm{H}) ;{ }^{13} \mathrm{C} \mathrm{NMR}$ $\left(101 \mathrm{MHz}, \mathrm{CDCl}_{3}\right) \delta 170.6,170.5,165.5,158.3,155.2,134.3,132.9$, $130.5,129.2,128.6,127.8,126.9,120.9,115.9,110.6,65.6,63.1,55.5$, 52.7, 31.5, 11.6, 10.7; HRMS (ESI) calcd for $\mathrm{C}_{24} \mathrm{H}_{25} \mathrm{~N}_{2} \mathrm{O}_{5} \mathrm{~S}\left(\mathrm{M}+\mathrm{H}^{+}\right)$ 453.1479, found 453.1459 .

Step 2: The title compound 35 was prepared as described for 9 using methyl ester $35 \mathrm{a}(91 \mathrm{mg}, 0.20 \mathrm{mmol}$ ) and LiI (4 equiv) and obtained after flash chromatography (EtOAc/PE, 3:1 [1\% AcOH]) and subsequent freeze-drying as a white amorphous powder $(41 \mathrm{mg}$, $46 \%$ yield): $R_{f}=0.12(\mathrm{EtOAc} / \mathrm{PE}, 3: 1[1 \% \mathrm{AcOH}]) ;{ }^{1} \mathrm{H}$ NMR $(400$ MHz, DMSO- $\left.d_{6}\right) \delta 13.28$ (br s, $\left.1 \mathrm{H}\right), 8.11(\mathrm{~d}, J=4.8 \mathrm{~Hz}, 1 \mathrm{H}), 7.69-$ $7.39(\mathrm{~m}, 1 \mathrm{H}), 7.36-7.16(\mathrm{~m}, 4 \mathrm{H}), 7.08-6.87(\mathrm{~m}, 2 \mathrm{H}), 6.18(\mathrm{br} \mathrm{s}$, $1 \mathrm{H}), 4.98-4.88(\mathrm{~m}, 1 \mathrm{H}), 3.91-3.73(\mathrm{~m}, 1 \mathrm{H}), 3.62(\mathrm{~s}, 3 \mathrm{H}), 3.33-$ $3.05(\mathrm{~m}, 1 \mathrm{H}), 2.36(\mathrm{~s}, 3 \mathrm{H}), 2.18(\mathrm{~s}, 3 \mathrm{H}) ;{ }^{13} \mathrm{C} \mathrm{NMR}(101 \mathrm{MHz}$, DMSO- $\left.d_{6}\right) \delta 170.9,169.3,165.5,157.9,155.0,134.5,131.7,129.8$, 128.9, 128.3, 126.9, 126.6, 120.3, 115.2, 110.8, 64.9, 61.7, 55.5, 31.3, 11.2, 10.3; HRMS (ESI) calcd for $\mathrm{C}_{23} \mathrm{H}_{23} \mathrm{~N}_{2} \mathrm{O}_{5} \mathrm{~S}\left(\mathrm{M}+\mathrm{H}^{+}\right) 439.1322$, found 439.1318. HPLC: $t_{\mathrm{R}}=11.11 \mathrm{~min}, 96.4 \%$. $[\alpha]^{20}{ }_{\mathrm{D}}+89^{\circ}(c$ 1.0, $\mathrm{MeOH})$.

(2R,4R)-3-(4-(3,5-Dimethylisoxazol-4-yl)benzoyl)-2-(pyridin2-yl)thiazolidine-4-carboxylic Acid (36). Step 1: The methyl ester of the title compound (36a) was prepared as described for 8a using 7 e $(70.0 \mathrm{mg}, 0.31 \mathrm{mmol})$ and 4-(3,5-dimethylisoxazol-4-yl)benzoyl chloride $(77 \mathrm{mg}, 0.33 \mathrm{mmol})$ and obtained after flash chromatography (EtOAc/PE, 2:1) as a brownish viscous oil (95 $\mathrm{mg}, 73 \%$ yield): $R_{f}=$ 0.21 (DCM [4\% $\mathrm{MeOH}]) ;{ }^{1} \mathrm{H}$ NMR (400 $\left.\mathrm{MHz}, \mathrm{CDCl}_{3}\right) \delta 8.55-$ $8.37(\mathrm{~m}, 1 \mathrm{H}), 8.16-8.00(\mathrm{~m}, 1 \mathrm{H}), 7.83-7.64(\mathrm{~m}, 1 \mathrm{H}), 7.57-6.74$ $(\mathrm{m}, 5 \mathrm{H}), 6.41^{*}\left(\right.$ br s $\left.1 \mathrm{H}^{1}\right), 6.07\left(\right.$ app m, $\left.1 \mathrm{H}^{1}\right), 5.63-5.52^{*}\left(\mathrm{~m}, 1 \mathrm{H}^{2}\right)$, 5.35-4.94 (m, $\left.1 \mathrm{H}^{2}\right), 3.82\left(\mathrm{br} \mathrm{s}, 3 \mathrm{H}^{3}\right), 3.64 *\left(\mathrm{~s}, 3 \mathrm{H}^{3}\right), 3.52-3.16(\mathrm{~m}$, $2 \mathrm{H}), 2.31$ (s, 3H), 2.17 (s, 3H); ${ }^{13} \mathrm{C}$ NMR (101 MHz, $\left.\mathrm{CDCl}_{3}\right) \delta$ $170.6,170.4,165.6,158.3,149.6,149.4,137.1,134.3,133.1,128.9$, 127.6, 122.7, 120.6, 115.8, 69.4, 65.0, 52.9, 52.8, 31.8, 11.6, 10.7; HRMS (ESI) calcd for $\mathrm{C}_{22} \mathrm{H}_{22} \mathrm{~N}_{3} \mathrm{O}_{4} \mathrm{~S}\left(\mathrm{M}+\mathrm{H}^{+}\right)$424.1326, found 424.1317.

Step 2: The title compound 36 was prepared as described for 9 using methyl ester $36 \mathrm{a}(51 \mathrm{mg}, 0.12 \mathrm{mmol}$ ) and LiI (4 equiv) and obtained after flash chromatography (EtOAc $[5 \% \mathrm{AcOH}]$ ) and subsequent freeze-drying as a brownish amorphous powder $(32 \mathrm{mg}$, $65 \%$ yield): $R_{f}=0.15$ (EtOAc $\left.[5 \% \mathrm{AcOH}]\right) ;{ }^{1} \mathrm{H}$ NMR $(400 \mathrm{MHz}$, $\left.\mathrm{MeOH}-d_{4}\right) \delta 8.61-8.30(\mathrm{~m}, 2 \mathrm{H}), 7.99-7.68(\mathrm{~m}, 2 \mathrm{H}), 7.46-7.11(\mathrm{~m}$, $4 \mathrm{H}), 6.54^{*}(\mathrm{~s}, 1 \mathrm{H}), 6.11($ br s, $1 \mathrm{H}), 5.08($ app s, $1 \mathrm{H}), 4.86^{*}$ (app s, $1 \mathrm{H}), 3.66-3.35(\mathrm{~m}, 2 \mathrm{H}), 2.46-2.33(\mathrm{~m}, 3 \mathrm{H}), 2.29-2.14(\mathrm{~m}, 3 \mathrm{H})$; ${ }^{13} \mathrm{C}$ NMR $\left(101 \mathrm{MHz}, \mathrm{MeOH}-d_{4}\right) \delta 176.0,172.4,167.4,161.7,160.8$, $159.8,149.2,148.4,139.7,137.0,136.5,133.8,130.2,128.9,128.4$, 124.4, 123.6, 117.2, 70.3, 69.1, 36.5, 33.5, 11.4, 10.6; HRMS (ESI) calcd for $\mathrm{C}_{21} \mathrm{H}_{20} \mathrm{~N}_{3} \mathrm{O}_{4} \mathrm{~S}\left(\mathrm{M}+\mathrm{H}^{+}\right)$410.1169, found 410.1153. HPLC: $t_{\mathrm{R}}=8.86 \min , 97.9 \%$. $[\alpha]^{20}{ }_{\mathrm{D}}+116^{\circ}(\mathrm{c} 0.5, \mathrm{DCM})$.

Synthesis of (2S,5R)-5-(2-Chlorophenyl)-1-(4-(3,5-dimethylisoxazol-4-yl)benzoyl)pyrrolidine-2-carboxylic Acid (37). Step 1: Methyl (2S,5R)-5-(2-Chlorophenyl)-1-(4-(3,5-dimethylisoxazol-4-yl)benzoyl)pyrrolidine-2-carboxylate (37a). In a predried vial, to a suspension of 4-(3,5-dimethylisoxazol-4-yl)benzoic acid (24 mg, $0.11 \mathrm{mmol}$; see the Supporting Information) and BTFFH $(40 \mathrm{mg}$, $0.13 \mathrm{mmol})$ in dry DCM $(110 \mu \mathrm{L})$ under argon was added DIPEA $(65 \mu \mathrm{L}, 0.38 \mathrm{mmol})$, and the reaction was stirred for $2 \mathrm{~h}$ at $\mathrm{rt}$. To the in situ generated acid fluoride was added $6(20 \mathrm{mg}, 83 \mu \mathrm{mol})$ dissolved in dry DCM $(100 \mu \mathrm{L})$. The vial was sealed, and the reaction was heated to $80{ }^{\circ} \mathrm{C}$ and stirred overnight. The reaction mixture was cooled to rt, water was added, the aqueous phase was extracted with $\mathrm{EtOAc}(\times 5)$, and the combined organic phases were washed with brine, dried over $\mathrm{Na}_{2} \mathrm{SO}_{4}$, and concentrated in vacuo to obtain 37 after flash chromatography (EtOAc/PE, 1:2) as a clear viscous oil (32 $\mathrm{mg}, 86 \%): R_{f}=0.14$ (EtOAc/PE, 1:2); $\left.{ }^{1} \mathrm{H} \mathrm{NMR} \mathrm{(400} \mathrm{MHz,} \mathrm{CDCl}_{3}\right)$ $\delta 8.32(\mathrm{~d}, J=7.7 \mathrm{~Hz}, 1 \mathrm{H}), 8.16-8.08(\mathrm{~m}, 1 \mathrm{H}) *, 7.65-7.54(\mathrm{~m}$, $2 \mathrm{H})^{*}, 7.34-7.24(\mathrm{~m}, 3 \mathrm{H}), 7.19-7.09(\mathrm{~m}, 2 \mathrm{H}), 7.02(\mathrm{~d}, J=7.9 \mathrm{~Hz}$, $2 \mathrm{H}), 5.69-5.57(\mathrm{~m}, 1 \mathrm{H}) *, 5.41-5.31(\mathrm{~m}, 1 \mathrm{H}), 4.81(\mathrm{t}, J=7.2 \mathrm{~Hz}$, $1 \mathrm{H}), 4.58-4.50(\mathrm{~m}, 1 \mathrm{H}) *, 3.89(\mathrm{~s}, 3 \mathrm{H}), 3.71(\mathrm{~s}, 3 \mathrm{H}) *, 2.47-2.35$ $(\mathrm{m}, 2 \mathrm{H}), 2.32(\mathrm{~s}, 3 \mathrm{H}), 2.18(\mathrm{~s}, 3 \mathrm{H}), 2.17-2.09(\mathrm{~m}, 1 \mathrm{H}), 2.03-1.95$ $(\mathrm{m}, 1 \mathrm{H}) ;{ }^{13} \mathrm{C}$ NMR $\left(101 \mathrm{MHz}, \mathrm{CDCl}_{3}\right) \delta 172.9,170.7,165.6,158.6$, 140.4 , 135.0, 132.2, 131.7, 129.2, 128.7, 128.6, 127.6, 127.3, 116.2,
61.6, 61.2, 52.5, 34.4, 27.6, 11.5, 10.7; HRMS (ESI) calcd for $\mathrm{C}_{24} \mathrm{H}_{24} \mathrm{ClN}_{2} \mathrm{O}_{4}\left(\mathrm{M}+\mathrm{H}^{+}\right)$, 439.1419; found, 439.1420 .

Step 2: (2S,5R)-5-(2-Chlorophenyl)-1-(4-(3,5-dimethylisoxazol-4-yl)benzoyl)pyrrolidine-2-carboxylic Acid (37). Ester 37a (16 mg, $37 \mu \mathrm{mol})$ was dissolved in freshly distilled THF $(0.4 \mathrm{~mL}), \mathrm{LiOH}_{\mathrm{aq}}(0.12 \mathrm{~mL}, 0.6$ $\mathrm{M}$ ) was added, and the reaction was run at rt until full conversion of starting material as indicated by HPLC. The reaction mixture was quenched with $\mathrm{HCl}(1 \mathrm{M})$ until $\mathrm{pH} 2$, diluted with water, extracted with EtOAc $(\times 5)$, and the organic phases were washed with brine, dried over $\mathrm{Na}_{2} \mathrm{SO}_{4}$, and concentrated in vacuo to give the title compound 37 as a cloudy viscous oil $(15 \mathrm{mg}, 93 \%$ yield $): R_{f}=0.23$ (EtOAc/PE, 1:2 [2\% AcOH] ); ${ }^{1} \mathrm{H}$ NMR $\left(400 \mathrm{MHz}, \mathrm{CDCl}_{3}\right) \delta 7.73-$ $7.59(\mathrm{~m}, 1 \mathrm{H}), 7.33-7.21(\mathrm{~m}, 3 \mathrm{H}), 7.17-7.03(\mathrm{~m}, 4 \mathrm{H}), 5.43(\mathrm{t}, J=$ $6.2 \mathrm{~Hz}, 1 \mathrm{H}), 4.97(\mathrm{t}, J=6.5 \mathrm{~Hz}, 1 \mathrm{H}), 2.53-2.25(\mathrm{~m}, 3 \mathrm{H}), 2.32(\mathrm{~s}$, $3 \mathrm{H}), 2.19(\mathrm{~s}, 3 \mathrm{H}), 2.04-1.97(\mathrm{~m}, 1 \mathrm{H}) ;{ }^{13} \mathrm{C} \mathrm{NMR}\left(101 \mathrm{MHz}, \mathrm{CDCl}_{3}\right)$ $\delta 172.9,172.8,165.7,158.6,139.5,134.0,132.9,131.8,129.4,128.9$, 128.1, 127.9, 127.3, 116.1, 62.6, 62.3, 34.2, 26.6, 11.6, 10.7; HRMS (ESI) calcd for $\mathrm{C}_{23} \mathrm{H}_{21} \mathrm{ClN}_{2} \mathrm{NaO}_{4}\left(\mathrm{M}+\mathrm{Na}^{+}\right)$447.1082, found 447.1066. HPLC: $t_{\mathrm{R}}=11.32 \mathrm{~min}, 99.8 \%$. $[\alpha]_{\mathrm{D}}^{20}-33^{\circ}(c 0.4, \mathrm{DCM})$.

Crystallography. Data for $\mathbf{1 4}$ were collected at $100(1) \mathrm{K}$ on a Synergy, Dualflex, AtlasS2 diffractometer using $\mathrm{Cu} \mathrm{K} \alpha$ radiation $(\lambda=$ $1.54184 \AA)$ and the CrysAlis PRO 1.171.39.12b suite. ${ }^{50}$ Using SHELXLE, ${ }^{51}$ the structure was solved by dual space methods $\left(\right.$ SHELXT $^{52}$ ) and refined on $F^{2}$ using all the reflections (SHELXL$2016^{53}$ ). All the non-hydrogen atoms were refined using anisotropic atomic displacement parameters. Hydrogen atoms were inserted at calculated positions using a riding model except for the $\mathrm{H} 1$ of the carboxylate group, which was located in the difference map and its coordinates were refined. The absolute configuration was unambiguously established from the crystallographic data. Parameters for data collection and refinement are summarized in Table S1.

Molecular Modeling. A homology model of hFFA2 in complex with 1 was obtained as described previously. ${ }^{32}$ The model was based on a crystal structure of hFFA1 (PDB code 4PHU) ${ }^{54}$ As 31 fully displaces $\left[{ }^{3} \mathrm{H}\right]-1$ at increasing concentrations in a radioligand binding assay (Table 4), the compound was docked into the binding site defined by 1 . Prior to docking, 31 was prepared (LigPrep, version 2.7, Schrödinger, LLC) using the OPLS-2005 force field. ${ }^{55}$ Ionization states were generated using Epik at $\mathrm{pH} 7.0 \pm 2.0$ (Epik, version 2.5, Schrödinger, LLC). Induced-fit docking was performed using the IFD 2006 protocol (Glide version 5.9, Schrödinger, LLC; Prime version 3.2, Schrödinger, LLC). Ligand conformational sampling was executed using default settings; initial Glide docking was performed using standard settings; the maximum number of poses of 31 was restricted to 20. Redocking was executed for 31-hFFA2 complexes within $30 \mathrm{kcal} / \mathrm{mol}$ of the lowest energy ligand-protein complex. Residues were refined within $5 \AA$ of bound 31 .

In Vitro Assays. $\beta$-Arrestin-2 Interaction Assay. HEK293T cells were maintained in Dulbecco's modification of Eagle's medium (DMEM) supplemented with $10 \%$ fetal bovine serum, $2 \mathrm{mM} \mathrm{L}$ glutamine, and $1 \times$ penicillin/streptomycin mixture (Sigma) at $37{ }^{\circ} \mathrm{C}$ and $5 \% \mathrm{CO}_{2}$. Cells were grown to $60 \%$ density and co-transfected at a 4:1 ratio with plasmids encoding an eYFP-tagged form of the receptor construct of interest and a $\beta$-arrestin- 2 fused to Renilla luciferase using a polyethyleneimine-based transfection protocol. ${ }^{56,57}$ Cells were transferred into white 96 -well plates at $24 \mathrm{~h}$ post-transfection and incubated for $24 \mathrm{~h}$ at $37^{\circ} \mathrm{C}$. Immediately prior to conducting the assay, cells were washed, and the culture medium was replaced with Hanks' balanced salt solution. To quantify $\beta$-arrestin- 2 recruitment to the receptor induced by FFA2 agonists, the Renilla luciferase substrate coelenterazine $\mathrm{h}$ (Nanolight Tech, Pinetop, CA) was added to a final concentration of $2.5 \mu \mathrm{M}$, and cells were incubated for $5 \mathrm{~min}$ at $37^{\circ} \mathrm{C}$. Next, varying concentrations of agonist were added, and cells were incubated for an additional $10 \mathrm{~min}$ at $37^{\circ} \mathrm{C}$. BRET resulting from receptor- $\beta$-arrestin- 2 interaction was assessed by measuring the ratio of luminescence at 535 and $475 \mathrm{~nm}$ using a PHERAstar FS plate reader fitted with the BRET1 optic module (BMG Labtech, Aylesbury, U.K.). $\mathrm{pEC}_{50}$ values were determined with at least three independent replicates. 
CAMP Assay. All cAMP experiments were performed using Flp-In T-REx 293 cells modified to express receptors of interest in an inducible manner, which were maintained in DMEM without sodium pyruvate supplemented with $10 \%$ fetal bovine serum, $1 \times$ penicillin/ streptomycin mixture, $5 \mu \mathrm{g} / \mathrm{mL}$ blasticidin, and $200 \mu \mathrm{g} / \mathrm{mL}$ hygromycin B. ${ }^{58}$ Experiments were carried out using a homogeneous time-resolved FRET-based detection kit (Cis-Bio Bioassays, Codolet, France) in accordance with the manufacturer's protocol. Cells were plated at 2000 cells/well in low-volume white 384 -well plates. The ability of compounds to inhibit $1 \mu \mathrm{M}$ forskolin-induced cAMP production was quantified following a $30 \mathrm{~min}$ incubation of agonist compounds with cells, which were induced to express receptors of interest by a $16 \mathrm{~h}$ treatment with $100 \mathrm{ng} / \mathrm{mL}$ doxycycline. $\mathrm{pEC}_{50}$ values were determined with at least three independent replicates.

Radioligand Binding Assay. Radioligand competition binding experiments were performed as established previously. ${ }^{41}$ The radioligand $\left[{ }^{3} \mathrm{H}\right]-\mathbf{1}$ at approximately $K_{\mathrm{d}}$ concentration was incubated with varying concentrations of unlabeled compounds and $5 \mu \mathrm{g}$ of purified membranes isolated from Flp-In T-REx cells induced to express the receptor construct of interest. Nonspecific binding of the radioligand was determined in the presence of $10 \mu \mathrm{M}$ CATPB. ${ }^{30}$ After a $2 \mathrm{~h}$ incubation at $25{ }^{\circ} \mathrm{C}$, bound $\left[{ }^{3} \mathrm{H}\right]-1$ and free $\left[{ }^{3} \mathrm{H}\right]-1$ were separated by rapid vacuum filtration and radioactivity was quantified by liquid scintillation spectrometry. To determine the affinity of unlabeled ligands in terms of $K_{\mathrm{i}}$ values, competition binding curves were fit to an inverse three-parameter sigmoidal one-site $K_{\mathrm{i}}$ value fit with radioligand affinity and concentration as constraints. $K_{\mathrm{i}}$ values were determined with $n=6$ independent experiments for 31 and with $n=3$ for all other compounds.

Isolation of Human Neutrophils and Migration Assay. Neutrophils were isolated from human whole blood as described previously. ${ }^{59}$ After isolation, neutrophils were immediately resuspended in RPMI 1640 containing $0.5 \%$ fatty acid-free bovine serum albumin. Test compounds were prepared at the indicated concentrations in the same buffer and added at the bottom of a 96well plate (Sigma-Aldrich). Inserts were then mounted to the plate, and neutrophils were added $(3000$ cells $/ \mu \mathrm{L})$. Cells were incubated at $37{ }^{\circ} \mathrm{C}$ for $1.5 \mathrm{~h}$, and migrated cells were then collected and ATP content was assessed using ATPlite luminescence assay system (PerkinElmer) according to the manufacturer's instructions. Each experiment was performed with $n=4-6$ independent replicates.

Derivation of Primary Mouse Adipocytes and Lipolysis Assay. Epididymal fat was collected from male mice, and isolation of preadipocytes was obtained as described previously. ${ }^{59}$ Animals were cared for in accordance with national guidelines on animal experimentation. Preadipocytes were subsequently differentiated in DMEM medium (DMEM, 10\% fetal bovine serum, $4 \mathrm{mM}$ glutamine, $10 \mathrm{mM}$ HEPES, $10 \mu \mathrm{g} / \mathrm{mL}$ insulin, $25 \mu \mathrm{g} / \mathrm{mL}$ sodium ascorbate, 10 $\mu \mathrm{M}$ rosiglitazone) for 8 days. After this, mature adipocytes were challenged with test compounds and glycerol production was quantified as previously reported. ${ }^{59}$ Each experiment was performed with $n=3-4$ independent replicates.

Chemical Stability. A $10 \mathrm{mM}$ stock solution of $\mathbf{3 1}$ in DMSO was diluted in phosphate buffer $(10 \mathrm{mM}, \mathrm{pH}=7.4)$ obtaining $1.2 \mathrm{~mL}$ of $50 \mu \mathrm{M}$ compound solution in phosphate buffer. The sample was shaken $(650 \mathrm{rpm})$ at $37{ }^{\circ} \mathrm{C}$, and samples were taken out at different time intervals during the 3 -week experiment. The study was performed in duplicate, each parallel and with double injection. The stability was calculated based on peak area of the 0 point sample.

Stability in Simulated Gastric and Intestinal Fluids. FaSSIF and FaSSGF were prepared in accordance with the manufacturer's procedure. A $50 \mu \mathrm{M}$ solution of $\mathbf{3 1}$ was prepared from FaSSIF/ FaSSGF and a $10 \mathrm{mM}$ stock solution of 31 in DMSO, and the samples were incubated in a thermomixer $\left(37^{\circ} \mathrm{C}, 650 \mathrm{rpm}\right)$ for 0 and $120 \mathrm{~min}$. Afterward, the samples were quenched with acetonitrile $(+0.5 \% \mathrm{HCOOH})$, centrifuged for $10 \mathrm{~min}$ at $10000 \mathrm{rpm}$ and the supernatant was analyzed by HPLC. The stability was calculated based on peak area of the 0 point sample. The study was performed in duplicate. Average values are reported.
Microsomal Stability. Microsomal stability was studied in mouse liver microsomes $(0.5 \mathrm{mg} / \mathrm{mL})$ at a final test compound concentration of $1 \mu \mathrm{M}$, essentially as previously described. ${ }^{60}$ In brief, prewarmed $\left(37^{\circ} \mathrm{C}\right) 0.1 \mathrm{M} \mathrm{PBS}_{7.4}$ was added to $10 \mathrm{mM} \mathrm{NADPH}$ in PBS and test compound 31 ( $1 \mathrm{mM}$ in DMSO). The samples were incubated for $5 \mathrm{~min}$ at $37{ }^{\circ} \mathrm{C}$ before addition of newly thawn microsomes. The samples were mixed by gentle vortexing and incubated for $1 \mathrm{~h}$ at $37^{\circ} \mathrm{C}, 300 \mathrm{rpm}$ in a thermomixer. Samples were quenched by addition of ice-cold $\mathrm{MeOH} / \mathrm{MeCN}$ (1:1) and centrifuged for $5 \mathrm{~min}$ at $10000 \mathrm{~g}$. The supernantant was transferred to HPLC vials and stored in the freezer until analysis by HPLC. The metabolic stability was calculated based on the 0 min sample. The experiment was performed in triplicate.

\section{ASSOCIATED CONTENT}

\section{Supporting Information}

The Supporting Information is available free of charge on the ACS Publications website at DOI: 10.1021/acs.jmedchem. 8 b00855.

Synthetic procedures, collection and crystallographic data for 14, and high- and low-temperature ${ }^{1} \mathrm{H}$ and ${ }^{13} \mathrm{C}$ NMR spectra of 31 (PDF)

Coordinates for crystal structure of 14 (PDB)

Molecular strings formula and some data (CSV)

\section{AUTHOR INFORMATION}

\section{Corresponding Author}

*E-mail: tu@sund.ku.dk.

ORCID

Richard R. Sprenger: 0000-0002-3947-1606

Christine J. McKenzie: 0000-0001-5587-0626

Elisabeth Rexen Ulven: 0000-0003-1243-7587

Trond Ulven: 0000-0002-8135-1755

\section{Author Contributions}

The manuscript was written through contributions of all authors. All authors have given approval to the final version of the manuscript.

\section{Notes}

The authors declare no competing financial interest. CCDC 1844850 contains the supplementary crystallographic data for this paper. These data can be obtained free of charge from the Cambridge Crystallographic Data Centre via www. ccdc.cam.ac.uk/data_request/cif

\section{ACKNOWLEDGMENTS}

We thank Paul C. Stein for recording of high temperature ${ }^{1} \mathrm{H}$ and ${ }^{13} \mathrm{C}$ NMR spectra of 31 , Britt Grathwohl for assistance with in vitro stability studies, Rikke L. Jørgensen for help with synthesis, and Thue W. Schwartz for helpful discussions. This research was funded by the Danish Strategic Research Foundation (Grant 11-116196), the Biotechnology and Biological Sciences Research Council (Grant BB/L027887/ 1), and the University of Southern Denmark. E.R.U. is supported by a fellowship from the Lundbeck Foundation (Grant R181-2014-3247). We are grateful for funding from the Carlsberg Foundation Grant CF15-0675 for the X-ray diffractometer.

\section{ABBREVIATIONS USED}

BRET, bioluminescence resonance energy transfer; BTFFH, $N, N, N^{\prime}, N^{\prime}$-bis(tetramethylene)fluoroformamidinium hexafluorophosphate; DIPEA, $N, N$-diisopropylethylamine; 
FaSSGF, fasted state simulated gastric fluid; FFA1, free fatty acid receptor 1 (GPR40); FFA2, free fatty acid receptor 2 (GPR43); FFA3, free fatty acid receptor 3 (GPR41); LLE, lipophilic ligand efficiency; nr, no response; PE, petroleum ether; PYY, peptide tyrosine tyrosine; SCFA, short-chain fatty acid.

\section{REFERENCES}

(1) Nilsson, N. E.; Kotarsky, K.; Owman, C.; Olde, B. Identification of a free fatty acid receptor, $\mathrm{FFA}_{2} \mathrm{R}$, expressed on leukocytes and activated by short-chain fatty acids. Biochem. Biophys. Res. Commun. 2003, 303, 1047-1052.

(2) Brown, A. J.; Goldsworthy, S. M.; Barnes, A. A.; Eilert, M. M.; Tcheang, L.; Daniels, D.; Muir, A. I.; Wigglesworth, M. J.; Kinghorn, I.; Fraser, N. J.; Pike, N. B.; Strum, J. C.; Steplewski, K. M.; Murdock, P. R.; Holder, J. C.; Marshall, F. H.; Szekeres, P. G.; Wilson, S.; Ignar, D. M.; Foord, S. M.; Wise, A.; Dowell, S. J. The orphan G proteincoupled receptors GPR41 and GPR43 are activated by propionate and other short chain carboxylic acids. J. Biol. Chem. 2003, 278, 11312-11319.

(3) Le Poul, E.; Loison, C.; Struyf, S.; Springael, J. Y.; Lannoy, V.; Decobecq, M. E.; Brezillon, S.; Dupriez, V.; Vassart, G.; Van Damme, J.; Parmentier, M.; Detheux, M. Functional characterization of human receptors for short chain fatty acids and their role in polymorphonuclear cell activation. J. Biol. Chem. 2003, 278, 25481-25489.

(4) Offermanns, S. Free fatty acid (FFA) and hydroxy carboxylic acid (HCA) receptors. Annu. Rev. Pharmacol. Toxicol. 2014, 54, 407434.

(5) Milligan, G.; Shimpukade, B.; Ulven, T.; Hudson, B. D. Complex pharmacology of free fatty acid receptors. Chem. Rev. 2017, 117, 67110.

(6) Hong, Y. H.; Nishimura, Y.; Hishikawa, D.; Tsuzuki, H.; Miyahara, H.; Gotoh, C.; Choi, K. C.; Feng, D. D.; Chen, C.; Lee, H. G.; Katoh, K.; Roh, S. G.; Sasaki, S. Acetate and propionate short chain fatty acids stimulate adipogenesis via GPCR43. Endocrinology 2005, 146, 5092-5099.

(7) Karaki, S.; Mitsui, R.; Hayashi, H.; Kato, I.; Sugiya, H.; Iwanaga, T.; Furness, J. B.; Kuwahara, A. Short-chain fatty acid receptor, GPR43, is expressed by enteroendocrine cells and mucosal mast cells in rat intestine. Cell Tissue Res. 2006, 324, 353-360.

(8) Sivaprakasam, S.; Gurav, A.; Paschall, A. V.; Coe, G. L.; Chaudhary, K.; Cai, Y.; Kolhe, R.; Martin, P.; Browning, D.; Huang, L.; Shi, H.; Sifuentes, H.; Vijay-Kumar, M.; Thompson, S. A.; Munn, D. H.; Mellor, A.; McGaha, T. L.; Shiao, P.; Cutler, C. W.; Liu, K.; Ganapathy, V.; Li, H.; Singh, N. An essential role of Ffar2 (Gpr43) in dietary fibre-mediated promotion of healthy composition of gut microbiota and suppression of intestinal carcinogenesis. Oncogenesis 2016, 5, e238.

(9) Harig, J. M.; Soergel, K. H.; Komorowski, R. A.; Wood, C. M. Treatment of diversion colitis with short-chain-fatty acid irrigation. $N$. Engl. J. Med. 1989, 320, 23-28.

(10) Vernia, P.; Marcheggiano, A.; Caprilli, R.; Frieri, G.; Corrao, G.; Valpiani, D.; Di Paolo, M. C.; Paoluzi, P.; Torsoli, A. Short-chain fatty acid topical treatment in distal ulcerative colitis. Aliment. Pharmacol. Ther. 1995, 9, 309-313.

(11) Maslowski, K. M.; Vieira, A. T.; Ng, A.; Kranich, J.; Sierro, F.; Yu, D.; Schilter, H. C.; Rolph, M. S.; Mackay, F.; Artis, D.; Xavier, R. J.; Teixeira, M. M.; Mackay, C. R. Regulation of inflammatory responses by gut microbiota and chemoattractant receptor GPR43. Nature 2009, 461, 1282-1286.

(12) Sina, C.; Gavrilova, O.; Forster, M.; Till, A.; Derer, S.; Hildebrand, F.; Raabe, B.; Chalaris, A.; Scheller, J.; Rehmann, A.; Franke, A.; Ott, S.; Hasler, R.; Nikolaus, S.; Folsch, U. R.; Rose-John, S.; Jiang, H. P.; Li, J.; Schreiber, S.; Rosenstiel, P. G protein-coupled receptor 43 Is essential for neutrophil recruitment during intestinal inflammation. J. Immunol. 2009, 183, 7514-7522.

(13) Namour, F.; Galien, R.; Van Kaem, T.; Van der Aa, A.; Vanhoutte, F.; Beetens, J.; Van't Klooster, G. Safety, pharmacokinetics and pharmacodynamics of GLPG0974, a potent and selective FFA2 antagonist, in healthy male subjects. Br. J. Clin. Pharmacol. 2016, 82, 139-148.

(14) Kaline, K.; Bornstein, S. R.; Bergmann, A.; Hauner, H.; Schwarz, P. E. The importance and effect of dietary fiber in diabetes prevention with particular consideration of whole grain products. Horm. Metab. Res. 2007, 39, 687-693.

(15) Priyadarshini, M.; Villa, S. R.; Fuller, M.; Wicksteed, B.; Mackay, C. R.; Alquier, T.; Poitout, V.; Mancebo, H.; Mirmira, R. G.; Gilchrist, A.; Layden, B. T. An acetate-specific GPCR, FFAR2, regulates insulin secretion. Mol. Endocrinol. 2015, 29, 1055-1066.

(16) Tolhurst, G.; Heffron, H.; Lam, Y. S.; Parker, H. E.; Habib, A. M.; Diakogiannaki, E.; Cameron, J.; Grosse, J.; Reimann, F.; Gribble, F. M. Short-chain fatty acids stimulate glucagon-like peptide-1 secretion via the G-protein-coupled receptor FFAR2. Diabetes 2012, 61, 364-371.

(17) Psichas, A.; Sleeth, M. L.; Murphy, K. G.; Brooks, L.; Bewick, G. A.; Hanyaloglu, A. C.; Ghatei, M. A.; Bloom, S. R.; Frost, G. The short chain fatty acid propionate stimulates GLP-1 and PYY secretion via free fatty acid receptor 2 in rodents. Int. J. Obes. 2015, 39, 424429.

(18) Tang, C.; Ahmed, K.; Gille, A.; Lu, S.; Grone, H. J.; Tunaru, S.; Offermanns, S. Loss of FFA 2 and FFA 3 increases insulin secretion and improves glucose tolerance in type 2 diabetes. Nat. Med. 2015, 21, 173-177.

(19) Kimura, I.; Ozawa, K.; Inoue, D.; Imamura, T.; Kimura, K.; Maeda, T.; Terasawa, K.; Kashihara, D.; Hirano, K.; Tani, T.; Takahashi, T.; Miyauchi, S.; Shioi, G.; Inoue, H.; Tsujimoto, G. The gut microbiota suppresses insulin-mediated fat accumulation via the short-chain fatty acid receptor GPR43. Nat. Commun. 2013, 4, 1829.

(20) Ulven, T. Short-chain free fatty acid receptors FFA2/GPR43 and FFA3/GPR41 as new potential therapeutic targets. Front. Endocrinol. 2012, 3, 111.

(21) Forbes, S.; Stafford, S.; Coope, G.; Heffron, H.; Real, K.; Newman, R.; Davenport, R.; Barnes, M.; Grosse, J.; Cox, H. Selective FFA2 agonism appears to act via intestinal PYY to reduce transit and food intake but does not improve glucose tolerance in mouse models. Diabetes 2015, 64, 3763-3771.

(22) Tang, C.; Offermanns, S. FFA2 and FFA3 in metabolic regulation. Handb. Exp. Pharmacol. 2016, 236, 205-220.

(23) Priyadarshini, M.; Wicksteed, B.; Schiltz, G. E.; Gilchrist, A.; Layden, B. T. SCFA receptors in pancreatic beta cells: novel diabetes targets? Trends Endocrinol. Metab. 2016, 27, 653-664.

(24) Milligan, G.; Bolognini, D.; Sergeev, E. Ligands at the free fatty acid receptors 2/3 (GPR43/GPR41). Handb. Exp. Pharmacol. 2016, $236,17-32$.

(25) Suckow, A. T.; Briscoe, C. P. Key questions for translation of FFA receptors: From pharmacology to medicines. Handb. Exp. Pharmacol. 2016, 236, 101-131.

(26) Lee, T.; Schwandner, R.; Swaminath, G.; Weiszmann, J.; Cardozo, M.; Greenberg, J.; Jaeckel, P.; Ge, H. F.; Wang, Y. C.; Jiao, X. Y.; Liu, J.; Kayser, F.; Tian, H.; Li, Y. Identification and functional characterization of allosteric agonists for the $G$ protein-coupled receptor FFA2. Mol. Pharmacol. 2008, 74, 1599-1609.

(27) Wang, Y. C.; Jiao, X. Y.; Kayser, F.; Liu, J. W.; Wang, Z. Y.; Wanska, M.; Greenberg, J.; Weiszmann, J.; Ge, H. F.; Tian, H.; Wong, S.; Schwandner, R.; Lee, T.; Li, Y. The first synthetic agonists of FFA2: Discovery and SAR of phenylacetamides as allosteric modulators. Bioorg. Med. Chem. Lett. 2010, 20, 493-498.

(28) Smith, N. J.; Ward, R. J.; Stoddart, L. A.; Hudson, B. D.; Kostenis, E.; Ulven, T.; Morris, J. C.; Trankle, C.; Tikhonova, I. G.; Adams, D. R.; Milligan, G. Extracellular loop 2 of the Free Fatty Acid receptor 2 mediates allosterism of a phenylacetamide ago-allosteric modulator. Mol. Pharmacol. 2011, 80, 163-173.

(29) Hoveyda, H.; Brantis, C. E.; Dutheuil, G.; Zoute, L.; Schils, D.; Bernard, J. Compounds, Pharmaceutical Composition and Methods for Use in Treating Metabolic Disorders. WO2010066682A1, 2010.

(30) Hudson, B. D.; Due-Hansen, M. E.; Christiansen, E.; Hansen, A. M.; Mackenzie, A. E.; Murdoch, H.; Pandey, S. K.; Ward, R. J.; 
Marquez, R.; Tikhonova, I. G.; Ulven, T.; Milligan, G. Defining the molecular basis for the first potent and selective orthosteric agonists of the FFA2 free fatty acid receptor. J. Biol. Chem. 2013, 288, 1729617312 .

(31) Hoveyda, H.; Schils, D.; Zoute, L.; Parcq, J.; Bernard, J.; Fraser, G. Compounds, Pharmaceutical Composition and Methods for Use in Treating Inflammatory Diseases. WO2015078949A1, 2015.

(32) Sergeev, E.; Hansen, A. H.; Bolognini, D.; Kawakami, K.; Kishi, T.; Aoki, J.; Ulven, T.; Inoue, A.; Hudson, B. D.; Milligan, G. A single extracellular amino acid in Free Fatty Acid Receptor 2 defines antagonist species selectivity and G protein selection bias. Sci. Rep. 2017, 7, 13741.

(33) Leeson, P. D.; Springthorpe, B. The influence of drug-like concepts on decision-making in medicinal chemistry. Nat. Rev. Drug Discovery 2007, 6, 881-890.

(34) Waring, M. J. Lipophilicity in drug discovery. Expert Opin. Drug Discovery 2010, 5, 235-248.

(35) Waring, M. J.; Arrowsmith, J.; Leach, A. R.; Leeson, P. D.; Mandrell, S.; Owen, R. M.; Pairaudeau, G.; Pennie, W. D.; Pickett, S. D.; Wang, J.; Wallace, O.; Weir, A. An analysis of the attrition of drug candidates from four major pharmaceutical companies. Nat. Rev. Drug Discovery 2015, 14, 475-486.

(36) Due-Hansen, M. E.; Pandey, S. K.; Christiansen, E.; Andersen, R.; Hansen, S. V.; Ulven, T. A protocol for amide bond formation with electron deficient amines and sterically hindered substrates. Org. Biomol. Chem. 2016, 14, 430-433.

(37) Ghosh, A. K.; Anderson, D. D. Tetrahydrofuran, tetrahydropyran, triazoles and related heterocyclic derivatives as HIV protease inhibitors. Future Med. Chem. 2011, 3, 1181-1197.

(38) Pinho e Melo, T. M. V. D.; Santos, C. I. A.; Rocha Gonsalves, A. M. d. A.; Paixão, J. A.; Beja, A. M. Synthesis of tricyclic isoindoles and thiazolo[3,2-c][1,3] benzoxazines. Tetrahedron 2004, 60, 39493955.

(39) Pinho e Melo, T. M. V. D.; Gomes, C. S. B.; Rocha Gonsalves, A. M. d. A.; Paixão, J. A.; Beja, A. M.; Ramos Silva, M.; Alte da Veiga, L. Cycloaddition reactions of 3-aryl-5-phenyl-5H,7H-thiazolo[3,4c] oxazol-4-ium-1-olates. Tetrahedron 2002, 58, 5093-5102.

(40) Hudson, B. D.; Christiansen, E.; Tikhonova, I. G.; Grundmann, M.; Kostenis, E.; Adams, D. R.; Ulven, T.; Milligan, G. Chemically engineering ligand selectivity at the free fatty acid receptor 2 based on pharmacological variation between species orthologs. FASEB J. 2012, 26, 4951-4965.

(41) Sergeev, E.; Hansen, A. H.; Pandey, S. K.; MacKenzie, A. E.; Hudson, B. D.; Ulven, T.; Milligan, G. Non-equivalence of key positively charged residues of the free fatty acid 2 receptor in the recognition and function of agonist versus antagonist ligands. J. Biol. Chem. 2016, 291, 303-317.

(42) Bjorkman, L.; Martensson, J.; Winther, M.; Gabl, M.; Holdfeldt, A.; Uhrbom, M.; Bylund, J.; Hojgaard Hansen, A.; Pandey, S. K.; Ulven, T.; Forsman, H.; Dahlgren, C. The neutrophil response induced by an agonist for free fatty acid receptor 2 (GPR43) Is primed by tumor necrosis factor alpha and by receptor uncoupling from the cytoskeleton but attenuated by tissue recruitment. Mol. Cell. Biol. 2016, 36, 2583-2595.

(43) Vermeire, S.; Kojecký, V.; Knoflícek, V.; Reinisch, W.; Van Kaem, T.; Namour, F.; Beetens, J.; Vanhoutte, F. GLPG0974, an FFA2 antagonist, in ulcerative colitis: efficacy and safety in a multicenter proof-of-concept study. J. Crohn's Colitis 2015, 9 (Suppl. 1), S39.

(44) Kolaczkowska, E.; Kubes, P. Neutrophil recruitment and function in health and inflammation. Nat. Rev. Immunol. 2013, 13, $159-175$.

(45) Pizzonero, M.; Dupont, S.; Babel, M.; Beaumont, S.; Bienvenu, N.; Blanque, R.; Cherel, L.; Christophe, T.; Crescenzi, B.; De Lemos, E.; Delerive, P.; Deprez, P.; De Vos, S.; Djata, F.; Fletcher, S.; Kopiejewski, S.; L’Ebraly, C.; Lefrancois, J. M.; Lavazais, S.; Manioc, M.; Nelles, L.; Oste, L.; Polancec, D.; Quenehen, V.; Soulas, F.; Triballeau, N.; van der Aar, E. M.; Vandeghinste, N.; Wakselman, E.; Brys, R.; Saniere, L. Discovery and optimization of an azetidine chemical series as a free fatty acid receptor 2 (FFA2) antagonist: From hit to clinic. J. Med. Chem. 2014, 57, 10044-10057.

(46) Vinolo, M. A. R.; Ferguson, G. J.; Kulkarni, S.; Damoulakis, G.; Anderson, K.; Bohlooly-Y, M.; Stephens, L.; Hawkins, P. T.; Curi, R. SCFAs induce mouse neutrophil chemotaxis through the GPR43 receptor. PLoS One 2011, 6, e21205.

(47) Mortensen, P. B.; Clausen, M. R. Short-chain fatty acids in the human colon: relation to gastrointestinal health and disease. Scand. J. Gastroenterol. 1996, 31 (sup216), 132-148.

(48) Ge, H.; Li, X.; Weiszmann, J.; Wang, P.; Baribault, H.; Chen, J. L.; Tian, H.; Li, Y. Activation of $\mathrm{G}$ protein-coupled receptor 43 in adipocytes leads to inhibition of lipolysis and suppression of plasma free fatty acids. Endocrinology 2008, 149, 4519-4526.

(49) Baell, J. B.; Holloway, G. A. New substructure filters for removal of pan assay interference compounds (PAINS) from screening libraries and for their exclusion in bioassays. J. Med. Chem. 2010, 53, 2719-2740.

(50) CrysAlis PRO 1.171.39.12b; Rigaku Oxford Diffraction, 2015.

(51) Hubschle, C. B.; Sheldrick, G. M.; Dittrich, B. ShelXle: a Qt graphical user interface for SHELXL. J. Appl. Crystallogr. 2011, 44, $1281-1284$

(52) Sheldrick, G. SHELXT - Integrated space-group and crystalstructure determination. Acta Crystallogr., Sect. A: Found. Adv. 2015, $71,3-8$.

(53) Sheldrick, G. M. Crystal structure refinement with SHELXL. Acta Crystallogr., Sect. C: Struct. Chem. 2015, 71, 3-8.

(54) Srivastava, A.; Yano, J.; Hirozane, Y.; Kefala, G.; Gruswitz, F.; Snell, G.; Lane, W.; Ivetac, A.; Aertgeerts, K.; Nguyen, J.; Jennings, A.; Okada, K. High-resolution structure of the human GPR40 receptor bound to allosteric agonist TAK-875. Nature 2014, 513, 124-127.

(55) Banks, J. L.; Beard, H. S.; Cao, Y.; Cho, A. E.; Damm, W.; Farid, R.; Felts, A. K.; Halgren, T. A.; Mainz, D. T.; Maple, J. R.; Murphy, R.; Philipp, D. M.; Repasky, M. P.; Zhang, L. Y.; Berne, B. J.; Friesner, R. A.; Gallicchio, E.; Levy, R. M. Integrated modeling program, applied chemical theory (IMPACT). J. Comput. Chem. 2005, 26, 1752-1780.

(56) Hudson, B. D.; Shimpukade, B.; Milligan, G.; Ulven, T. The molecular basis of ligand interaction at free fatty acid receptor 4 (FFA4/GPR120). J. Biol. Chem. 2014, 289, 20345-20358.

(57) MacKenzie, A. E.; Caltabiano, G.; Kent, T. C.; Jenkins, L.; McCallum, J. E.; Hudson, B. D.; Nicklin, S. A.; Fawcett, L.; Markwick, R.; Charlton, S. J.; Milligan, G. The antiallergic mast cell stabilizers lodoxamide and bufrolin as the first high and equipotent agonists of human and rat GPR35. Mol. Pharmacol. 2014, 85, 91-104.

(58) Ward, R. J.; Alvarez-Curto, E.; Milligan, G. Using the Flp-In TRex system to regulate GPCR expression. Methods Mol. Biol. 2011, 746, 21-37.

(59) Bolognini, D.; Moss, C. E.; Nilsson, K.; Petersson, A. U.; Donnelly, I.; Sergeev, E.; Konig, G. M.; Kostenis, E.; KurowskaStolarska, M.; Miller, A.; Dekker, N.; Tobin, A. B.; Milligan, G. A novel allosteric activator of free fatty acid 2 receptor displays unique Gi-functional bias. J. Biol. Chem. 2016, 291, 18915-18931.

(60) Hill, J. R. In vitro drug metabolism using liver microsomes. Curr. Protoc. Pharmacol. 2003, 23, 7.8.1-7.8.11. 